\title{
Changes in terrestrial near-surface wind speed and their possible causes: an overview
}

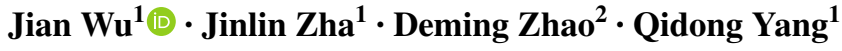

Received: 26 January 2017 / Accepted: 29 October 2017 / Published online: 9 November 2017

(C) The Author(s) 2017. This article is an open access publication

\begin{abstract}
Changes in terrestrial near-surface wind speed (SWS) are induced by a combination of anthropogenic activities and natural climate changes. Thus, the study of the long-term changes of SWS and their causes is very important for recognizing the effects of these processes. Although the slowdown in SWS has been analyzed in previous studies, to the best of knowledge, no overall comparison or detailed examination of this research has been performed. Similarly, the causes of the decreases in SWS and the best directions of future research have not been discussed in depth. Therefore, we analyzed a series of studies reporting SWS trends spanning the last 30 years from around the world. The changes in SWS differ among different regions. The most significant decreases have occurred in Central Asia and North America, with mean linear trends of $-0.11 \mathrm{~m} \mathrm{~s}^{-1}$ decade $^{-1}$; the second most significant decreases have occurred in Europe, East Asia, and South Asia, with mean linear trends of $-0.08 \mathrm{~m} \mathrm{~s}^{-1}$ decade $^{-1}$; and the weakest decrease has occurred in Australia. Although the SWS in Africa has decreased, this region lacks long-term observational data. Therefore, the uncertainties in the long-term SWS trend are higher in this region than in other regions. The changes in SWS, caused by a mixture of global-, regional-, and localscale factors, are mainly due to changes in driving forces and drag forces. The changes in the driving forces are caused by changes in atmospheric circulation, and the changes in the
\end{abstract}

Jian Wu

wujian@ynu.edu.cn

1 Department of Atmospheric Science, Yunnan University, Kunming 650091, China

2 CAS Key Laboratory of Regional Climate-Environment for Temperate East Asia, Institute of Atmospheric Physics, Chinese Academy of Sciences, Beijing 100029, China drag forces are caused by changes in the external and internal friction in the atmosphere. Changes in surface friction are mainly caused by changes in the surface roughness due to land use and cover change (LUCC), including urbanization, and changes in internal friction are mainly induced by changes in the boundary layer characteristics. Future studies should compare the spatio-temporal differences in SWS between high and low altitudes and quantify the effects of different factors on the SWS. Additionally, in-depth analysis of extreme SWS events and prediction of future mean and extreme SWS values at global and regional scales are also necessary.

Keywords Terrestrial near-surface wind speed · Land use and cover change $\cdot$ Driving force $\cdot$ Drag force

$\begin{array}{ll}\text { Abbreviations } & \\ \text { AAs } & \text { Anthropogenic aerosols } \\ \text { AHR } & \text { Anthropogenic heat release } \\ \text { AMWS } & \text { Annual maximum wind speeds } \\ \text { AO } & \text { Arctic Oscillation } \\ \text { AOGCM } & \text { Atmosphere-ocean general circulation } \\ & \text { model } \\ \text { BTTR } & \text { Beijing-Tianjin-Tangshan region } \\ \text { CMIP5 } & \text { Coupled Model Intercomparison Project } \\ & \text { phase 5 } \\ \text { CRU } & \text { A comparison of rural and urban SWS } \\ \text { DMWS } & \text { Daily maximum wind speed } \\ \text { DMGS } & \text { Daily maximum gust speed } \\ \text { DPWG } & \text { daily peak wind gusts } \\ \text { EAM } & \text { East Asian Monsoon } \\ \text { EASM } & \text { East Asian Summer Monsoon } \\ \text { EAWM } & \text { East Asian Winter Monsoon } \\ \text { ECP } & \text { Eastern China Plain }\end{array}$




\begin{tabular}{|c|c|}
\hline ECHAM5 & $\begin{array}{l}\text { 5th generation European Centre for } \\
\text { Medium-Weather forecast Hamburg } \\
\text { Atmospheric circulation model }\end{array}$ \\
\hline EFEs & External friction effects \\
\hline ENSO & El Niño-Southern Oscillation \\
\hline ERA-40 & $\begin{array}{l}\text { 45-year European Centre for Medium- } \\
\text { Range Weather Forecasts reanalysis } \\
\text { from September } 1957 \text { to August } 2002\end{array}$ \\
\hline ERA-Interim & $\begin{array}{l}\text { European Centre for Medium-Range } \\
\text { Weather Forecasts reanalysis from Janu- } \\
\text { ary } 1989 \text { onward (to be extended back } \\
\text { to January 1979) }\end{array}$ \\
\hline FWM & Frictional wind model \\
\hline GCM & Global climate model \\
\hline GHGs & Greenhouse gases \\
\hline HAM & Hamburg aerosol module \\
\hline IFEs & Internal friction effects \\
\hline LUCC & land use and cover change \\
\hline MME & multi-model ensemble \\
\hline MM5 & 5th Mesoscale Model \\
\hline MODIS & $\begin{array}{l}\text { Moderate-resolution imaging } \\
\text { spectroradiometer }\end{array}$ \\
\hline NAO & North Atlantic Oscillation \\
\hline NCEP-DOM & $\begin{array}{l}\text { National Center for Environmental } \\
\text { Prediction-Department of Energy }\end{array}$ \\
\hline NCEP-NCAR & $\begin{array}{l}\text { National Center for Environmental } \\
\text { Prediction-National Center for Atmos- } \\
\text { pheric Research }\end{array}$ \\
\hline $\mathrm{NCDC}$ & National Climate Data Center \\
\hline NCDC-DS3505 & $\begin{array}{l}\text { Land-based sites across the contigu- } \\
\text { ous United States, which was extracted } \\
\text { from the online data archive held by the } \\
\text { NCDC }\end{array}$ \\
\hline OMR & Observation minus reanalysis \\
\hline PBL & Planetary boundary layer \\
\hline PDO & Pacific decadal oscillation \\
\hline PGF & Pressure-gradient force \\
\hline PRDR & Pearl River Delta region \\
\hline $\mathrm{RCM}$ & Regional Climate Model \\
\hline SDM & Statistical downscaling method \\
\hline SNP & Subtropical North Pacific \\
\hline SSTs & Sea-surface temperatures \\
\hline SWS & Near-Surface Wind Speed \\
\hline SWSD & SWS difference \\
\hline TKE & Turbulent kinetic energy \\
\hline $\mathrm{TP}$ & Tibetan Plateau \\
\hline $\mathrm{Vg}$ & Geostrophic wind \\
\hline WNP & western North Pacific \\
\hline WRF & Weather Research and Forecasting \\
\hline YRDR & Yangtze River delta region \\
\hline
\end{tabular}

\section{Introduction}

The near-surface wind speed (SWS) is a regularly observed meteorological variable that can be affected by the pressuregradient force (PGF), the Coriolis force, the surface friction force, and the vertical exchange of horizontal momentum in the boundary layer (He et al. 2010). Long-term changes in the SWS can affect water vapor evaporation and hydrological cycles in some regions (Rayner 2007; McVicar et al. 2007; Donohue et al. 2010; Niyogi et al. 2011; Mclnnes et al. 2011; McMahon et al. 2013). Previous studies have attributed decreases in pan-evaporation to long-term decreases in SWS in some regions over the past 50 years (Roderick et al. 2007; McVicar and Roderick 2010; McVicar et al. 2012a). McVicar et al. (2012a) carried out a sensitivity analysis in an irrigated area in southeastern Australia and showed that decreasing SWSs have resulted in a decrease in pan-evaporation, with a change of $2 \mathrm{~m} \mathrm{~s}^{-1}$, resulting in a $20 \%$ change in the pan-evaporation rates. Studies have found that decreasing SWSs have significantly affected surface pan-evaporation over the Tibetan Plateau (TP), the Yellow River of China, and central and northern China over the last 30 years (Chen et al. 2006; Zhang et al. 2007; Liu et al. 2010; Liu and McVicar 2012). Furthermore, Liu et al. (2011a, 2014a) concluded that the $29 \%$ decrease in SWS that has occurred in China in recent years has led to a $1-3 \%$ decrease in annual pan-evaporation and a 1-6\% increase in runoff. Furthermore, this decrease in SWS accounted for $65 \%$ of the observed decrease in pan-evaporation during the period 1960-1991. Moreover, the decrease in SWS has slowed the expansion of drought areas, resulting in an $8.8 \%$ decrease in the drought area in China over the past 40 years (Liu et al. 2014a). The SWS decrease has also been identified as a key factor in reducing the atmospheric evaporative demand in China's Yangtze River Basin, Northwest China and North China Plain (Xu et al. 2006a; Shen et al. 2010; Song et al. 2010). Similar decreases in pan-evaporation, mainly attributed to SWS decreases, have also been reported in the United States (Hobbins 2004) and India (Verma et al. 2008; Bandyopadhyay et al. 2009). Further discussion of the importance of SWS in the evaporative process can be found in the studies of McVicar et al. (2012a, b), which review the influence of SWS changes on evaporation.

The SWS can influence visibility, aerosol distribution, and air quality (Munir et al. 2013; Onat and Stakeeva 2013; Zhu and Liang 2013; Wu et al. 2013; Zhang et al. 2016a), and decreases in the SWS can intensify the accumulation of aerosols, thereby reducing the solar radiation received at the surface. Lin et al. (2015) found that surface dimming was associated with decreases in SWS in some regions with severe air pollution in China. This dimming effect intensifies under low-SWS conditions because aerosol pollution is only blown away when the SWS is larger 
than $3.5 \mathrm{~m} \mathrm{~s}^{-1}$. Zhang et al. (2016a) simulated a feedback mechanism between stability in the boundary layer and the accumulation of aerosols in the Yangtze River delta region (YRDR) in eastern China. In this model, low SWSs in the stable boundary layer prevent the dispersion of aerosols, leading to the accumulation of aerosols, which further stabilize the boundary layer and further decrease the SWS (McVicar and Roderick 2010; Sterk et al. 2015). In addition, Jacobson and Kaufman (2006) revealed that changes in the frequency and severity of haze events are correlated with changes in SWS because decreases in the SWS weaken the horizontal momentum of the atmosphere, limiting the dispersion of air pollutants.

Wind energy is a clean and reproducible energy, and the global wind energy resource greatly exceeds the current total global energy demand (Pryor and Barthelmie 2011). Therefore, a rapid increase in wind power has been predicted in many countries and regions ( $\mathrm{Li}$ et al. 2008; Lu et al. 2009; Pryor and Barthelmie 2010; Greene et al. 2012; Tobin et al. 2015, 2016). Changes in the SWS can influence the distribution of wind energy. Some research has reported that a 1-5\% decrease in the SWS could induce a $1.7-8.6 \%$ loss in wind energy (Jacobson and Kaufman 2006; He et al. 2010). Hence, research on SWS changes and their causes should focus on the development and evaluation of wind power.

In recent decades, global warming, precipitation, and aerosols have become the focuses of climate change in the context of the intensification of anthropogenic activities, and less attention has been paid to long-term changes in terrestrial SWS in a changing climate. However, changes in terrestrial SWS result from a combination of natural changes and anthropogenic influences (Vautard et al. 2010). Pryor and Barthelmie (2010) reviewed the effects of climate change on wind energy but did not discuss the characteristics or potential causes of the observed changes in the terrestrial SWS in different regions. Globally, McVicar et al. (2012a) synthesized some studies on the changes in SWS and highlighted the importance of wind speed in the evaporative process; however, the causes that induced these decreases in the SWS were not analyzed in detail. Some studies on SWS changes have been published in recent years and have documented some regional characteristics and causes of SWS changes in different areas. Thus, summarizing these results from different regional and seasonal scales, analyzing the main causes of the observed changes in SWS, and discussing the direction of future research in terms of driving forces and drag forces are necessary. The general progress of research on terrestrial SWS changes in different regions is summarized in Sect. 2, followed by an in-depth analysis of the potential causes in Sects. 3 and 4. Further in-depth discussion of future research directions for this issue based on current achievements is presented in Sect. 5 .

\section{Variability in terrestrial SWS}

\subsection{Significant decreases in mean SWS in many regions across the globe}

The global and regional mean SWSs and their linear trends in recent decades are listed in Table 1, which shows numerous regional decreasing trends in SWS on different continents. Over the last 30 years, the global mean terrestrial SWS has been $3.5 \mathrm{~m} \mathrm{~s}^{-1}$ and has decreased linearly at a rate of $0.08 \mathrm{~m} \mathrm{~s}^{-1}$ decade $^{-1}$. Regional differences in SWSs were significant, with the maximum SWSs in Europe and North America and the lowest SWS in Australia. Vautard et al. (2010) analyzed changes in SWS at 822 stations across the globe and found a 5-15\% decrease in SWS in the mid-latitude belt regions in the Northern Hemisphere over the past 30 years. This overall decrease was associated with a more distinct decreasing trend for strong winds than for weak winds. Simultaneously, $73 \%$ of the total stations presented a decrease in the annual mean SWS, with linear trends of $-0.09,-0.16,-0.12$, and $-0.07 \mathrm{~m} \mathrm{~s}^{-1}$ decade $^{-1}$ in Europe, Central Asia, East Asia, and North America, respectively. Furthermore, a 5\% decrease in SWS has been found in South Asia (Fig. 1a). Subsequently, the frequencies of SWSs that were larger than 3 and $10 \mathrm{~m} \mathrm{~s}^{-1}$ reached their lowest percentages of $51.9 \%$ and $25 \%$ in all SWS records from the period 1981-2011 (Vautard et al. 2012). The results of numerical simulations also reflect these decreases in the terrestrial SWS. Bichet et al. (2012) found that the SWS over land was lower than that over oceans from 1870 to 2005 (Fig. 1b). These results were consistent with those of Vautard et al. (2010).

\subsubsection{Europe}

Some studies on SWS changes in Europe have been published in recent few decades. Pirazzoli and Tomasin (2003) found that wind activity in the central Mediterranean and Adriatic seas mostly decreased from 1951 to approximately the mid-1970s. Based on regional simulations with global models and forcing scenarios, Räisänen et al. (2004) revealed that wind events have increased by $8 \%$ in northern Europe and have decreased in the Mediterranean region. Similar results have also been obtained by Pryor et al. (2005a) using the Rossby Centre coupled Regional Climate Model (RCM). General circulation models and RCMs are designed to simulate the present climate and project future climate. Hence, they can effectively predict the principal features of wind speeds at the global-scale 
Table 1 Global and regional mean terrestrial SWSs and decadal linear trends in published papers

\begin{tabular}{|c|c|c|c|c|}
\hline Region & Mean wind speed (unit: $\mathrm{m} \mathrm{s}^{-1}$ ) & $\begin{array}{l}\text { Decadal linear trend (unit: } \\
\mathrm{m} \mathrm{s}^{-1} \text { decade }^{-1} \text { ) }\end{array}$ & $\begin{array}{l}\text { Number of sta- } \\
\text { tions }\end{array}$ & Original paper \\
\hline \multirow{4}{*}{$\begin{array}{l}\text { Global average (except } \\
\text { Australia) }\end{array}$} & $3.5(1981-2011)$ & $-0.078(1981-2011)$ & 1100 & Vautard et al. (2012) \\
\hline & $3.5(1981-2010)$ & $-0.077(1981-2013)$ & 1379 & Tobin et al. (2014) \\
\hline & $3.5(1981-2010)$ & $-0.082(1981-2014)$ & 1423 & Berrisford et al. (2015) \\
\hline & 3.309 (1981-2010) & $-0.087(1979-2015)$ & 2264 & Dunn et al. (2016) \\
\hline \multirow[t]{5}{*}{ Europe } & - & $-0.09(1979-2010)$ & 276 & Vautard et al. (2010) \\
\hline & $3.9(1981-2011)$ & $-0.086(1981-2011)$ & 410 & Vautard et al. (2012) \\
\hline & $3.8(1981-2013)$ & $-0.072(1981-2013)$ & 488 & Tobin et al. (2014) \\
\hline & 3.845 (1981-2014) & $-0.086(1981-2014)$ & 522 & Berrisford et al. (2015) \\
\hline & 3.747 (1981-2010) & $-0.087(1979-2015)$ & 589 & Dunn et al. (2016) \\
\hline \multirow[t]{5}{*}{ North America } & - & $-0.08(1979-2010)$ & 170 & Vautard et al. (2010) \\
\hline & $4.1(1981-2011)$ & $-0.105(1981-2011)$ & 250 & Vautard et al. (2012) \\
\hline & $3.8(1981-2010)$ & $-0.122(1981-2013)$ & 364 & Tobin et al. (2014) \\
\hline & $3.810(1981-2010)$ & $-0.120(1981-2014)$ & 378 & Berrisford et al. (2015) \\
\hline & 3.685 (1981-2010) & $-0.100(1979-2015)$ & 587 & Dunn et al. (2016) \\
\hline \multirow[t]{5}{*}{ East Asia } & - & $-0.12(1979-2010)$ & 190 & Vautard et al. (2010) \\
\hline & $2.7(1981-2011)$ & $-0.077(1981-2011)$ & 230 & Vautard et 1. (2012) \\
\hline & 2.8 (1981-2010) & $-0.065(1981-2013)$ & 247 & Tobin et al. (2014) \\
\hline & 2.829 (1981-2010) & $-0.078(1981-2014)$ & 251 & Berrisford et al. (2015) \\
\hline & 2.623 (1981-2010) & $-0.070(1979-2015)$ & 399 & Dunn et al. (2016) \\
\hline South Asia & - & $-0.08(1979-2008)$ & 40 & Vautard et al. (2010) \\
\hline \multirow[t]{5}{*}{ Central Asia } & - & $-0.16(1979-2010)$ & 96 & Vautard et al. (2010) \\
\hline & $2.5(1981-2011)$ & $-0.085(1981-2011)$ & 50 & Vautard et al. (2012) \\
\hline & $2.4(1981-2010)$ & $-0.067(1981-2013)$ & 53 & Tobin et al. (2014) \\
\hline & 2.479 (1981-2010) & $-0.096(1981-2014)$ & 57 & Berrisford et al. (2015) \\
\hline & 2.887 (1981-2010) & $-0.151(1979-2015)$ & 263 & Dunn et al. (2016) \\
\hline \multirow[t]{2}{*}{ Australia } & $2.1(1981-2011)$ & $-0.069(1981-2011)$ & 44 & Vautard et al. (2012) \\
\hline & 2.066 (1981-2010) & $-0.062(1979-2015)$ & 41 & Dunn et al. (2016) \\
\hline
\end{tabular}

but are unable to present the historically observed magnitude and spatial variability of wind speeds at the regionaland local-scale, because of their coarse spatial resolution (Fan et al. 2011, 2013; Wu et al. 2017). Therefore, the downscaling technique is needed to further study longterm changes in SWS. Garcia-Bustamante et al. (2012) studied the variability in the SWS over a complex terrain region in the northeastern Iberian Peninsula via a downscaling technique based on Canonical Correlation Analysis. The results showed that the zonal wind components had a weak downward trend from 1992 to 2006. Najac et al. (2009) proposed a statistical downscaling of 14 coupled atmosphere-ocean general circulation models (AOGCMs) and assessed the potential changes in the SWS. These authors also found a decrease in the Mediterranean area and southern France and that the most pronounced reduction in SWS occurred in central France (Najac et al. 2011). Pryor et al. (2006) applied a downscaling technique to generate a probability distribution of wind speed and found that the predicted maximum percentage decrease in downscaled mean wind speeds was lower than $-15 \%$ in northern Europe. In addition, Pryor et al. (2005b) also investigated potential changes in wind speed in the future and concluded that the projected mean wind speeds in 2081-2100 will be slightly lower than those observed during 1961-1990.

Decreases in SWS have been observed in Europe, while differences have been observed among the decreasing SWS trends in different regions (Fig. 2a). An SWS decrease at a rate of $-0.1 \mathrm{~m} \mathrm{~s}^{-1}$ decade $^{-1}$ from 1961 to 2005 was recorded in the Czech Republic, and the most distinct decrease in the monthly mean SWS was found in November, with a decreasing rate of $-0.2 \mathrm{~m} \mathrm{~s}^{-1}$ decade $^{-1}$ (Brazdil et al. 2009). A decreasing rate of $-0.09 \mathrm{~m} \mathrm{~s}^{-1}$ decade $^{-1}$ was observed in the Netherlands from 1970 to 2010 (Cusack 2013), in Switzerland from 1983 to 2006, and the northeastern region of Spain from 1992 to 2005 (McVicar et al. 2010; Jiménez et al. 2010). In Turkey, $72 \%$ of the stations had downward trends in annual mean SWS values from 1975 to 2006 at the rate of $-0.14 \mathrm{~m} \mathrm{~s}^{-1}$ decade $^{-1}$. In addition, 


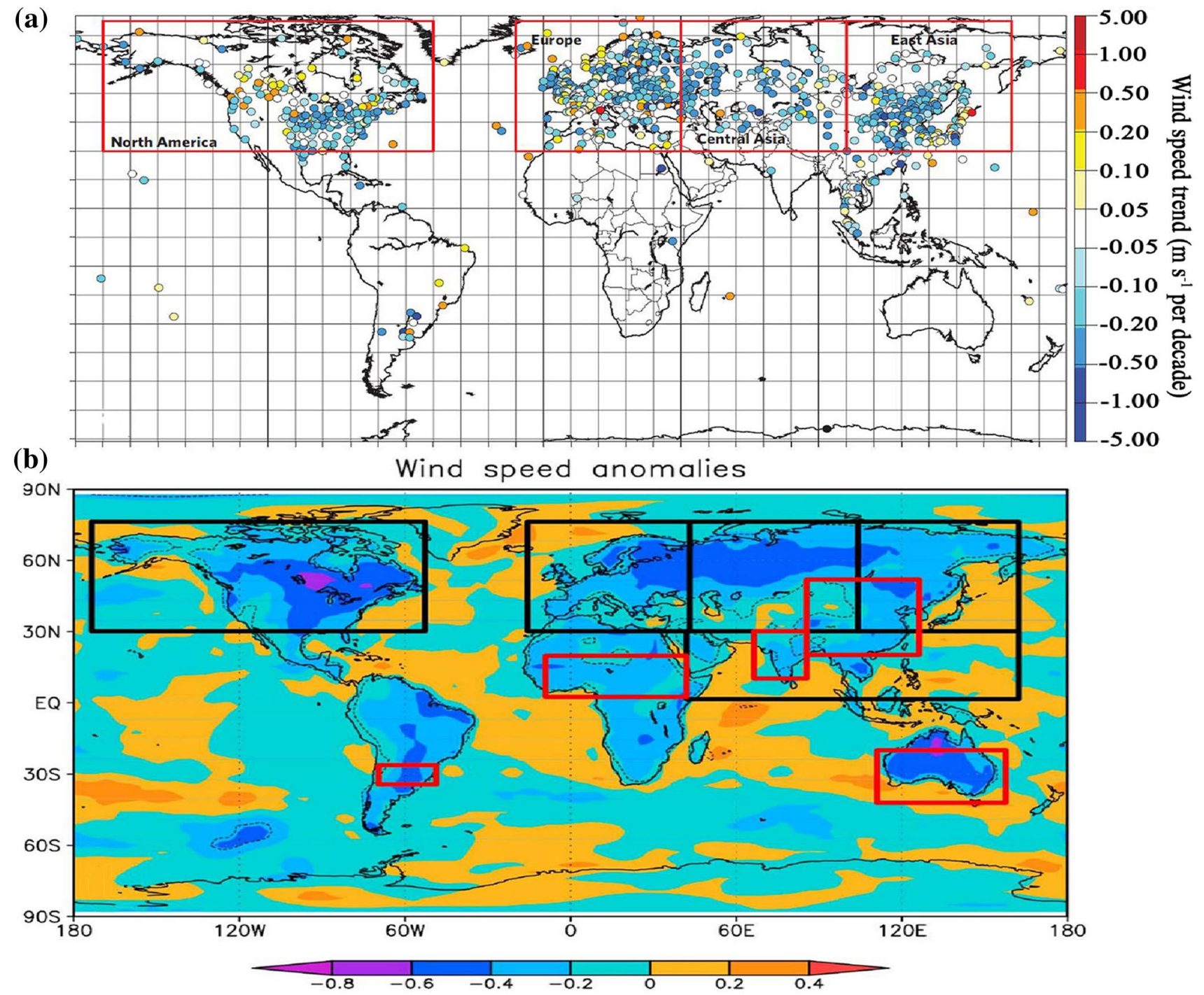

Fig. 1 a Observed surface wind speed trends. The 30-year (19792008) surface wind speed linear trend was calculated over all the available observations and each of the selected stations (unit: $\mathrm{m} \mathrm{s}^{-1}$ decade $\left.^{-1}\right)$. The area boundaries for the regions of interest can be found in Vautard et al. (2010). b Wind speed anomalies (unit: $\mathrm{m} \mathrm{s}^{-1}$ ) over 30 years as simulated by ECHAM5-HAM, which are associated with a doubling of the roughness length. The dashed contour lines delimit the areas where anomalies were significant at a $99.9 \%$ confidence level. The area boundaries for the regions of interest can be found in Bichet et al. (2012). (a and b copied from Vautard et al. (2010) and Bichet et al. (2012), respectively)

(Fig. 2b) (Azorin-Molina et al. 2014). Slight downward trends in different time periods have also been reported in Germany, where the SWS declined $-0.01,-0.02$ and $-0.03 \mathrm{~m} \mathrm{~s}^{-1}$ decade $^{-1}$ for the periods of 1951-2001, 1988-2006, and 1951-2000, respectively (Walter et al. 2006; Bormann 2011; Gerstengarbe et al. 2004). However, Böwer (2006) noted that the decline in SWS reached $-0.25 \mathrm{~m} \mathrm{~s}^{-1}$ decade $^{-1}$ in 1982-2005, which is a much larger value than those in other studies. In Italy, decreasing rates of -0.31 and $-0.13 \mathrm{~m} \mathrm{~s}^{-1}$ decade $^{-1}$ were found for the periods of 1951-1996 and 1955-1996, respectively (Pirazzoli and Tomasin 1999, 2003); hence, the decrease in Italy was (Portugal) for 1961-2011 and 1979-2008, respectively 

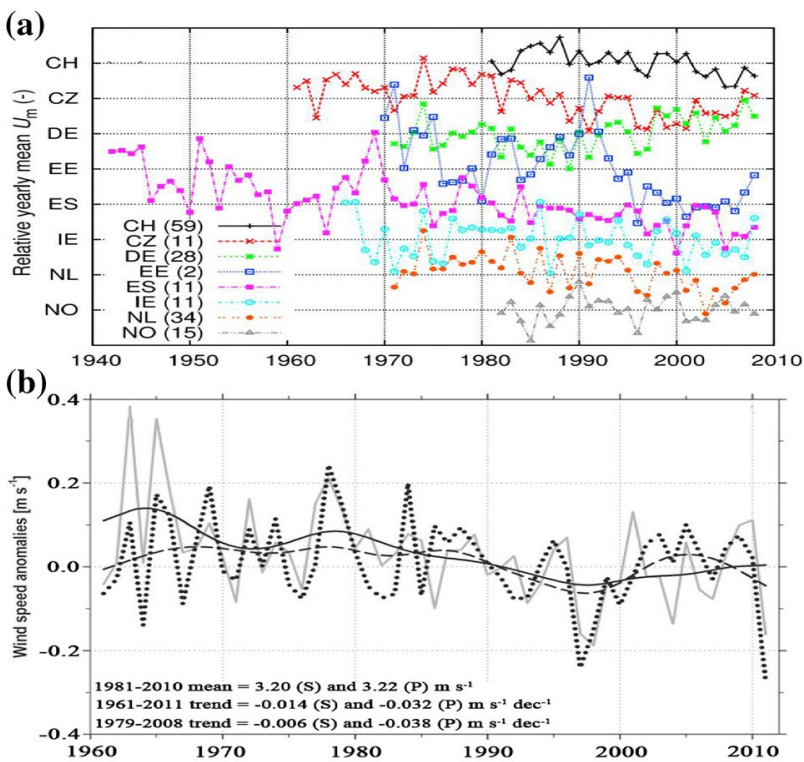

Fig. 2 a Series of standardized yearly mean wind speed, averaged per European country (CH (Switzerland), CZ (Czech Republic), DE (Germany), EE (Estonia), ES (Spain), IE (Ireland), NL (Netherlands), NO (Norway)); b mean annual wind speed anomalies (unit: $\mathrm{m} \mathrm{s}^{-1}$ ) series for Spain (S; black dotted line) and Portugal (P; dark gray solid line) from 1961 to 2011 . The 15-yr Gaussian low-pass filter is also shown with a black dashed line for Spain and with a black solid line for Portugal. The series are expressed as anomalies from the 19812010 mean (a copied from Wever (2012), and b copied from AzorinMolina et al. (2014))

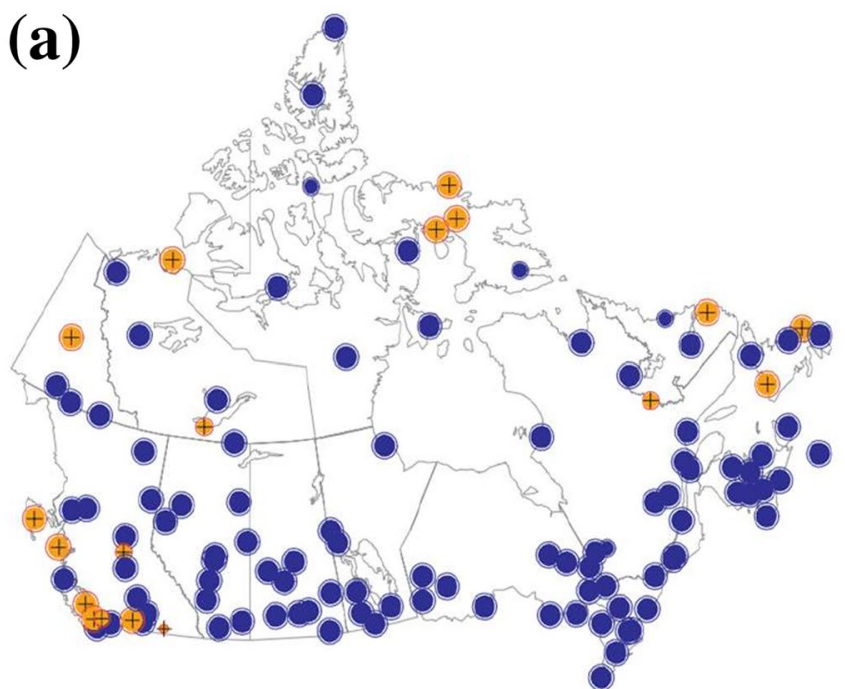

Fig. 3 Linear trend estimated for monthly mean series of a raw wind speed and $\mathbf{b}$ homogenized wind speeds in Canada. Orange symbols superimposed by a plus sign indicate upward trends, and the blue greater than that in other European regions. Inconsistent SWS trends in the same region in different time periods have also been reported in Greece and Belgium (Palaiologou et al. 2011; Brouyaux et al. 2009).

\subsubsection{North America}

The terrestrial SWS in North America also presented a declining trend over the last few decades. The most significant slowdown occurred in Mexico and reached $-0.31 \mathrm{~m} \mathrm{~s}^{-1}$ decade $^{-1}$ (Soler-Bientz et al. 2010). The SWS in Canada and the United States also experienced a clear slowdown. For example, the annual mean SWS showed a decreasing trend along the west coast of Canada from 1940 to 1990 , with a decreasing rate of $-0.17 \mathrm{~m} \mathrm{~s}^{-1} \mathrm{decade}^{-1}$, and the declines in annual mean SWS were matched by increases in the percentage of calm conditions and by decreases in high wind speeds (Tuller 2004). Based on the credibility of the raw wind dataset from Canada, Wan et al. (2010) homogenized monthly mean SWS series by adjusting all significant mean shifts and identified significant reductions in SWS throughout western Canada and most parts of southern Canada from 1953 to 2006 (Fig. 3b). In addition to Canada, some studies in the United States have also reported a decreasing trend in SWS and an accompanying decrease in decadal changes in SWS (Pryor et al. 2009; Pryor and Ledolter 2010). A significant decrease in SWS has been observed in the Western Plains region, where the SWS during the spring has decreased by $20 \%$ over the past 30 years (Green et al. 2012). Furthermore, the most significant decrease in SWS from 1989 to 1998 occurred in Wisconsin

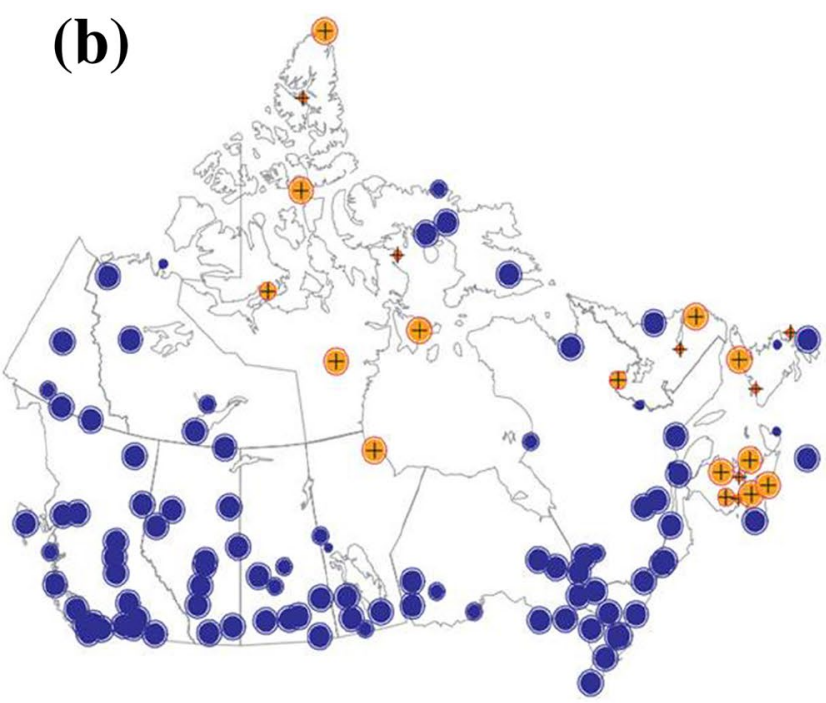

symbols indicate downward trends. Indicated are trends of $\mathrm{p} \geq 0.95$ (small dots), $0.80 \leq \mathrm{p}<0.95$ (medium dots), and $\mathrm{p}<0.80$ (large dots) (Copied from Wan et al. (2010)) 
and reached $-0.51 \mathrm{~m} \mathrm{~s}^{-1}$ decade $^{-1}$, whereas weak declines (smaller than $-0.09 \mathrm{~m} \mathrm{~s}^{-1}$ decade $^{-1}$ ) occurred in the southwestern region of Idaho (Reba et al. 2011), the American Midwest (Abhishek et al. 2010), the southern region of California (Rasmussen et al. 2011). Malloy et al. (2015) reported a clear slowdown in SWS in the southeastern United States, whereas Mahowald et al. (2007) reported an SWS reduction of only $-0.08 \mathrm{~m} \mathrm{~s}^{-1}$ decade $^{-1}$ in the southern United States. To estimate the wind trends over the contiguous United States, a comprehensive comparison of historical wind trends has been presented by Pryor et al. (2009), who found that the observational datasets exhibited significant decreases in annual mean SWSs. Similarly, decreasing SWS trends have also been observed in the reanalysis data of the National Center for Environmental Prediction-National Center for Atmospheric Research (NCEP-NCAR) and the 45-year European Centre for Medium-Range Weather Forecasts reanalysis from September 1957 to August 2002 (ERA40) and the results of the 5th Mesoscale Model (MM5) (run for 1979-2004 using boundary conditions from National Center for Environmental Prediction-Department of Energy (NCEP-DOM) reanalysis data), but these trends are weaker than those in the observational datasets. Similar differences in magnitude between SWS trends based on observational data and reanalysis data have also been reported by other previous studies (Vautard et al. 2010, 2012; Tobin et al. 2014; Berrisford et al. 2015; Dunn et al. 2016). Therefore, the regional differences in the changes in SWS over the United States are pronounced, and the decreasing SWS trends differ among the various datasets.

\subsubsection{Asia}

Research on terrestrial SWS changes in Asia has mainly focused on East Asia and Central Asia, and the studies in East Asia have mainly focused on China. A distinct decrease in SWS has been observed over China, and clear spatial differences in SWS have been reported (Xu et al. 2006b; Jiang et al. 2010; Guo et al. 2011). Average SWSs exceeding $2.2 \mathrm{~m} \mathrm{~s}^{-1}$ occur in the northern region of the Yellow River and in northwestern and southeastern China, and regions with average SWSs below $1.8 \mathrm{~m} \mathrm{~s}^{-1}$ include southwestern, central and some parts of southeastern China (Fig. 4a, b). At the same time, decreasing trends in SWS are more evident in regions with higher SWSs than those with lower SWSs (Fig. 4c, d) (Jiang et al. 2010; Zha et al. 2017a, b). Xu et al.
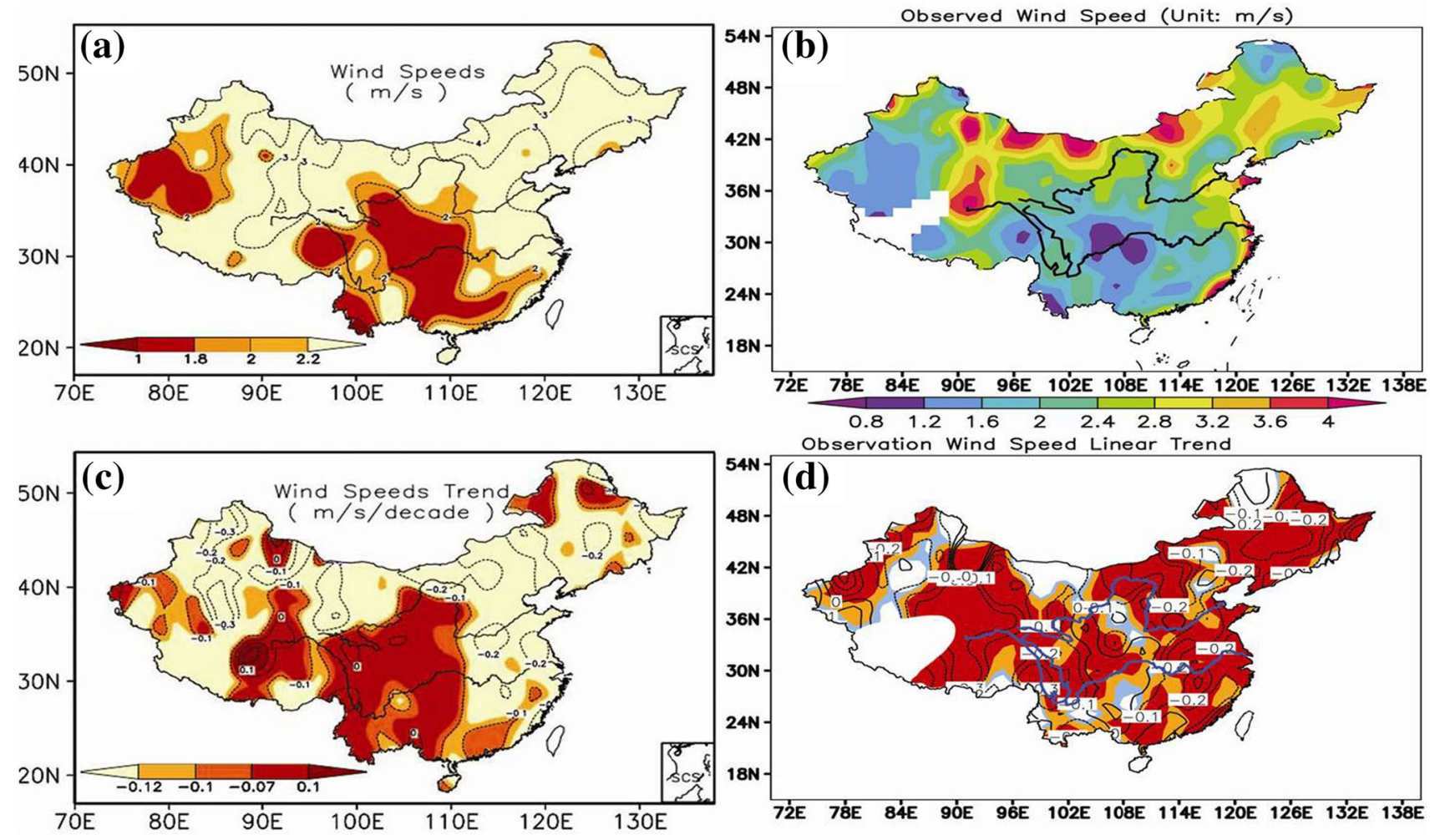

Fig. 4 Distributions of the averaged annual mean wind speed (a, b) (unit: $\mathrm{m} \mathrm{s}^{-1}$ ) and the linear trend of annual mean wind speed (c, d) (unit: $\mathrm{m} \mathrm{s}^{-1}$ decade $^{-1}$ ) in China. (light blue, yellow, and red in $\mathbf{d}$

denotes the linear trends passed the significant $t$-test at the 90, 95, 99\% level, respectively. a and c copied from Jiang et al. (2010); b and d copied from from Zha et al. (2017a)) 


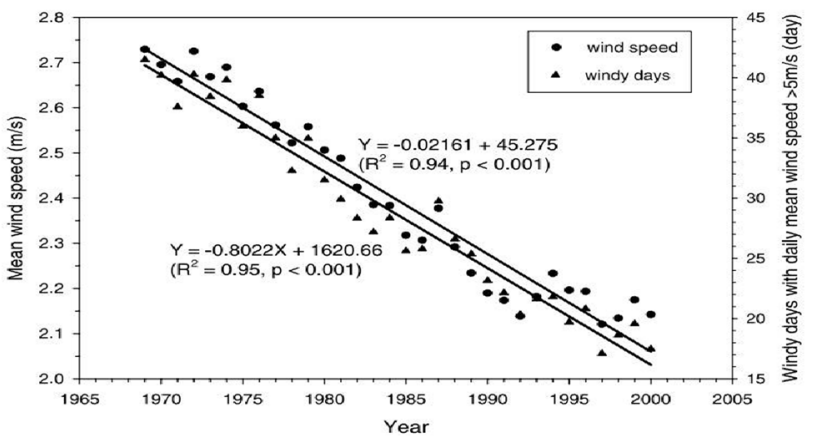

Fig. 5 Declining trend in the annual mean near-surface wind speed (unit: $\mathrm{m} \mathrm{s}^{-1}$ ) and the prevalence of windy days (daily mean wind speed $>5 \mathrm{~m} \mathrm{~s}^{-1}$ ) over China for the period 1969-2000. The top regression line and formula are for the wind speed, and the bottom regression line and formula are for windy days (Copied from Xu et al. (2006b)) (2006b) reported that the annual mean SWS decreased by $28 \%$ and that the frequency of daily SWSs that were higher than $5 \mathrm{~m} \mathrm{~s}^{-1}$ decreased by $58 \%$ during the period 1969-2000 (Fig. 5). Liu et al. (2014a) noted that the annual mean SWS decreased by more than $20 \%$ in most areas of China during the period 1966-2011. Guo et al. (2011) found that the decreasing trend in the annual mean SWS in China reached $-0.18 \mathrm{~m} \mathrm{~s}^{-1}$ decade $^{-1}$ and that the main contribution to this decrease in SWS came from the reduction of strong wind events. However, a decreasing rate of $-0.07 \mathrm{~m} \mathrm{~s}^{-1}$ dec$\mathrm{ade}^{-1}$ was reported by another study (Liu et al. 2011b), and this value is significantly lower than the previous results (Table 2). Fu et al. (2011) further found that the changes in SWS in China included four temporal stages: two relatively steady periods from 1961 to 1968 and from 1969 to 1974 with a sharp step in 1969 , a statistically significant decrease from 1974 to the 1990s, and another relatively steady period from the 1990s to 2007. These data on SWS changes in China are summarized in detail in Table 2, which

Table 2 Spatially averaged trends of wind speed (unit: $\mathrm{m} \mathrm{s}^{-1}$ decade $^{-1}$ ) over China from published studies

\begin{tabular}{|c|c|c|c|c|c|}
\hline Study number & Original paper & Study period & Region & $\begin{array}{l}\text { Number of } \\
\text { stations }\end{array}$ & $\begin{array}{l}\text { Trend } \\
\left(\mathrm{m} \mathrm{s}^{-1} \text { dec- }\right. \\
\left.\mathrm{ade}^{-1}\right)\end{array}$ \\
\hline 1 & Xu et al. (2006b) & 1969-2000 & China $\left(15-54^{\circ} \mathrm{N} ; 70^{\circ}-135^{\circ} \mathrm{E}\right)$ & 305 & -0.20 \\
\hline 2 & Li et al. (2008) & 1960-1999 & China $\left(15-54^{\circ} \mathrm{N} ; 70^{\circ}-135^{\circ} \mathrm{E}\right)$ & 604 & -0.12 \\
\hline 3 & Cong et al. (2009) & $1956-2005$ & China $\left(15-54^{\circ} \mathrm{N} ; 70^{\circ}-135^{\circ} \mathrm{E}\right)$ & 317 & -0.11 \\
\hline 4 & Jiang et al. (2010) & 1956-2004 & China $\left(15-54^{\circ} \mathrm{N} ; 70^{\circ}-135^{\circ} \mathrm{E}\right)$ & 535 & -0.12 \\
\hline 5 & Fu et al. (2011) & $1961-2007$ & China $\left(15-54^{\circ} \mathrm{N} ; 70^{\circ}-135^{\circ} \mathrm{E}\right)$ & 597 & -0.13 \\
\hline 6 & Guo et al. (2011) & 1969-2005 & China $\left(15-54^{\circ} \mathrm{N} ; 70^{\circ}-135^{\circ} \mathrm{E}\right)$ & 652 & -0.18 \\
\hline 7 & Yin et al. (2010a) & $1961-2008$ & China $\left(15-54^{\circ} \mathrm{N} ; 70^{\circ}-135^{\circ} \mathrm{E}\right)$ & 595 & -0.09 \\
\hline 8 & Yin et al. (2010b) & $1971-2008$ & China $\left(15-54^{\circ} \mathrm{N} ; 70^{\circ}-135^{\circ} \mathrm{E}\right)$ & 603 & -0.12 \\
\hline 9 & Liu et al. (2011a) & 1960-1991 & China $\left(15-54^{\circ} \mathrm{N} ; 70^{\circ}-135^{\circ} \mathrm{E}\right)$ & 518 & -0.12 \\
\hline 10 & Liu et al. (2011b) & $1992-2007$ & China $\left(15-54^{\circ} \mathrm{N} ; 70^{\circ}-135^{\circ} \mathrm{E}\right)$ & 518 & -0.07 \\
\hline 11 & Chen et al. (2013) & $1971-2007$ & China $\left(15-54^{\circ} \mathrm{N} ; 70^{\circ}-135^{\circ} \mathrm{E}\right)$ & 540 & -0.17 \\
\hline 12 & Lin et al. (2013) & 1960-2009 & China $\left(15-54^{\circ} \mathrm{N} ; 70^{\circ}-135^{\circ} \mathrm{E}\right)$ & 472 & -0.10 \\
\hline 13 & Liu et al. (2014) & $1966-2011$ & China $\left(15-54^{\circ} \mathrm{N} ; 70^{\circ}-135^{\circ} \mathrm{E}\right)$ & 741 & -0.16 \\
\hline 14 & Zha et al. (2017a) & 1979-2010 & China $\left(15-54^{\circ} \mathrm{N} ; 70^{\circ}-135^{\circ} \mathrm{E}\right)$ & 492 & -0.11 \\
\hline 15 & Zhang et al. (2007) & $1966-2003$ & Tibetan Plateau $\left(26-39^{\circ} \mathrm{N} ; 80^{\circ}-104^{\circ} \mathrm{E}\right)$ & 75 & -0.17 \\
\hline 16 & Mahowald et al. (2009) & $1973-2003$ & Western Deserts $\left(36-44^{\circ} \mathrm{N} ; 80^{\circ}-110^{\circ} \mathrm{E}\right)$ & 23 & -0.29 \\
\hline 17 & Zheng et al. (2009) & $1957-2001$ & Haihe River Basin $\left(35-42^{\circ} \mathrm{N} ; 111^{\circ}-120^{\circ} \mathrm{E}\right)$ & 45 & -0.14 \\
\hline 18 & You et al. (2010) & $1980-2005$ & Tibetan Plateau $\left(25-45^{\circ} \mathrm{N} ; 70^{\circ}-100^{\circ} \mathrm{E}\right)$ & 71 & -0.24 \\
\hline 19 & McVicar et al. (2010) & 1960-2006 & Loess Plateau $\left(33-42^{\circ} \mathrm{N} ; 100^{\circ}-115^{\circ} \mathrm{E}\right)$ & 82 & -0.14 \\
\hline 20 & Tang et al. (2011) & $1950-2007$ & Haihe River Basin $\left(34.9-42.8^{\circ} \mathrm{N} ; 112-119.8^{\circ} \mathrm{E}\right)$ & 34 & -0.10 \\
\hline 21 & Yang et al. (2011) & 1984-2006 & Tibetan Plateau $\left(25-40^{\circ} \mathrm{N} ; 70^{\circ}-105^{\circ} \mathrm{E}\right)$ & 78 & -0.30 \\
\hline 22 & Yang et al. (2012) & 1969-2009 & Southwestern China $\left(15-35^{\circ} \mathrm{N} ; 75^{\circ}-110^{\circ} \mathrm{E}\right)$ & 110 & -0.24 \\
\hline 23 & Yang et al. (2012) & 1969-2000 & Southwestern China $\left(15-35^{\circ} \mathrm{N} ; 75^{\circ}-110^{\circ} \mathrm{E}\right)$ & 110 & -0.37 \\
\hline 24 & Lin et al. (2013) & 1960-2009 & Tibetan Plateau $\left(15^{\circ}-54^{\circ} \mathrm{N} ; 70^{\circ}-135^{\circ} \mathrm{N}\right)$ & 64 & -0.06 \\
\hline 25 & Wu et al. (2016) & 1980-2011 & East China Plain $\left(21^{\circ}-34.5^{\circ} \mathrm{N} ; 112^{\circ}-135^{\circ} \mathrm{E}\right)$ & 93 & -0.13 \\
\hline 26 & Wu et al. (2017) & 1980-2011 & East China Plain $\left(21^{\circ}-34.5^{\circ} \mathrm{N} ; 112^{\circ}-135^{\circ} \mathrm{E}\right)$ & 93 & -0.13 \\
\hline 27 & Zha et al. (2016) & 1980-2011 & East China Plain $\left(21^{\circ}-34.5^{\circ} \mathrm{N} ; 112^{\circ}-135^{\circ} \mathrm{E}\right)$ & 93 & -0.13 \\
\hline
\end{tabular}


also shows significant differences among the linear trends of SWS series.

The regional differences in SWS changes are also pronounced. A slowdown in SWS has been found in both the NCEP-NCAR reanalysis data and the observational data over the TP (You et al. 2010), and the reductions in SWS are more evident in arid areas than in wet areas (Yang et al. 2011). Furthermore, an SWS decreasing rate of $-0.06 \mathrm{~m} \mathrm{~s}^{-1}$ decade $^{-1}$ over TP is presented by Lin et al. (2013), and this value is the lowest decreasing trend in the results listed in Table 2. A decreasing rate of $-0.14 \mathrm{~m} \mathrm{~s}^{-1}$ decade $^{-1}$ is present in the middle reaches of the Yellow River and Loess Plateau, as reported by McVicar et al. (2010) and Lin et al. (2013), but different results suggest that no decrease in SWS occurred in the reaches of Yellow River and southwestern TP during the period 1954-2004 (Jiang et al. 2010). The most significant decrease in SWS occurred in the inshore regions in southeastern China, as reported by Li et al. (2008) based on a comparison between reanalysis data and observations. The observed decrease in SWS in the Eastern China Plain (ECP) is best explained by an estimation that used a frictional wind model with an increase in the drag coefficient related to LUCC (Wu et al. 2016). A quantitative evaluation that used a downscaling method showed an SWS decreasing rate between -0.17 and $-0.23 \mathrm{~m} \mathrm{~s}^{-1}$ decade $^{-1}$ in the ECP over the past 30 years (Wu et al. 2017). More information about averaged trends in regional SWS in China can be found in Table 2.

With the exception of East Asia, the studies of changes in terrestrial SWS in Asia have mainly focused on Central Asia and the Indian sub-continent. Mescherskaya et al. (2004) analyzed SWS data from 22 weather stations located in the basin of the Volga and Ural rivers and showed that the decreasing rate in annual mean SWS exceeded $-0.25 \mathrm{~m} \mathrm{~s}^{-1}$ decade $^{-1}$. Furthermore, Mescherskaya et al. (2006) found that the SWS declined $-0.17 \mathrm{~m} \mathrm{~s}^{-1}$ decade $^{-1}$ in Northern Russia, which was weaker than that in the above-mentioned regions. A similar decreasing trend was also reported at 64 stations in Russia during the period 1936-2006 (Gruza et al. 2008). Mahowald et al. (2007) found that the reduction in SWS over Kazakhstan was weaker than that over Russia by approximately $0.04 \mathrm{~m} \mathrm{~s}^{-1}$ decade $^{-1}$. In India, Jhajharia et al. (2007, 2009) emphasized the significant decrease in SWS from 1979 to 2000 with a decreasing rate between -0.10 and $-0.40 \mathrm{~m} \mathrm{~s}^{-1}$ decade $^{-1}$. Bandyopadhyay et al. (2009) further studied the changes in SWS at 133 weather stations in India, and the results showed that $85 \%$ of the total sites experienced significant decreases. The mean SWS declined approximately $0.27 \mathrm{~m} \mathrm{~s}^{-1}$ decade $^{-1}$ from 1971 to 2002. In addition, Choudhary et al. (2009) indicated that the most significant decrease in SWS over India occurred in Rajasthan, where the decreasing rate reached $-0.39 \mathrm{~m} \mathrm{~s}^{-1} \mathrm{decade}^{-1}$.

\subsubsection{Oceania}

Studies of changes in wind speed in Oceania have mainly focused on Australia, due to a lack of observed datasets in the Southern Hemisphere. Decreases in wind speed have been observed in Australia over the last 30 years. A weak decreasing trend of $-0.03 \mathrm{~m} \mathrm{~s}^{-1}$ decade $^{-1}$ was found in Central Australia (Mahowald et al. 2007). Roderick et al. (2007) found that the SWS at $2 \mathrm{~m}$ height declined by approximately $0.10 \mathrm{~m} \mathrm{~s}^{-1}$ decade $^{-1}$ during the period 1975-2004. McVicar et al. (2008) reported a similar decreasing trend in SWS at $2 \mathrm{~m}$ height at approximately 194 stations. Troccoli and Muller (2012) further revealed that wind speed trends for the periods 1975-2006 and 1989-2006 were sensitive to the observing height of the station. The wind speed decreased at a height of $2 \mathrm{~m}$ but increased at a height of $10 \mathrm{~m}$. For the periods of 1975-2006 and 1989-2006, the mean trends of the $2 \mathrm{~m}$ stations were $-0.10 \pm 0.03$ and $-0.36 \pm 0.04 \%$ year $^{-1}$, respectively, whereas the mean trends of the $10 \mathrm{~m}$ stations were $0.90 \pm 0.03$ and $0.69 \pm 0.04 \%$ year $^{-1}$, respectively. However, the linear SWS trends based on NCEP-NCAR and ERA-Interim reanalysis datasets at $10 \mathrm{~m}$ over Australia for the period 1989-2006 were negative. Therefore, Troccoli and Muller (2012) advocated that the magnitudes of the SWS trends in Australia were sensitive to the study period selected and that significant discrepancies in the SWS trends exist among the different wind datasets (Fig. 6).

\subsubsection{Africa}

Fewer studies have been performed on the SWS changes in Africa because observational data are lacking in this region, and the published results have mainly focused on North Africa. Mahowald et al. (2007) revealed that the terrestrial SWS showed an average decreasing rate of $-0.14 \mathrm{~m} \mathrm{~s}^{-1}$ decade $^{-1}$ in North Africa for the period 1973-2003. However, the long-term and short-term changes of wind speed in North Africa differed regionally and temporally. Short-term decreases in SWS were mainly observed in Cameroon and Libya. Tchinda et al. (2000) noted that the SWS in Cameroon decreased by approximately $0.8 \mathrm{~m} \mathrm{~s}^{-1}$ from 1991 to 1995 . Similar results were also reported by Nfah and Ngundam (2008). In addition, Tchinda and Kaptouom (2003) found that both the annual and monthly mean SWSs decreased in northern Cameroon from 1990 to 1999, and a decreasing rate of $-0.29 \mathrm{~m} \mathrm{~s}^{-1}$ decade $^{-1}$ in annual mean SWS was observed. Furthermore, during the period 1979-1988, the SWS decreased by $-1.16 \mathrm{~m} \mathrm{~s}^{-1}$ decade $^{-1}$ in Zwara, Libya, and by $-0.87 \mathrm{~m} \mathrm{~s}^{-1}$ decade $^{-1}$ in Tripoli (El-Osta et al. 1995; Mohamed and Elmakrouk 2009). Himri et al. (2009) discovered that the SWS in Algeria from 2002 to 2006 decreased at a linear rate of $-0.91 \mathrm{~m} \mathrm{~s}^{-1}$ decade $^{-1}$. 

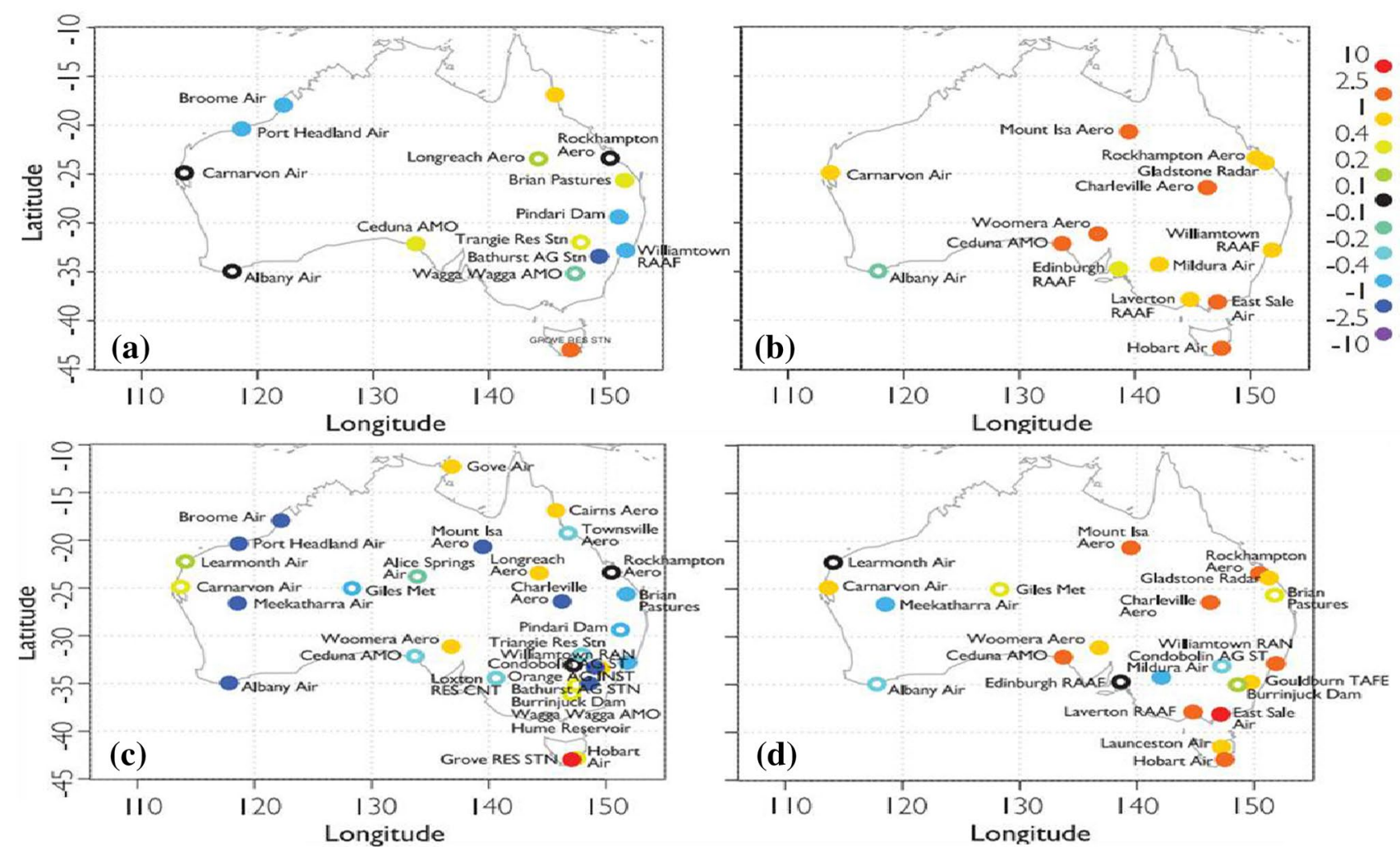

Fig. 6 Relative wind trend (i.e., trend divided by the mean wind) of the mean a, c $2-\mathrm{m}$ wind run (15 stations), b, d 10-m wind speed (14 stations) data in Australia. Solid circles are used for stations where

Long-term reductions in SWS were mainly observed in Nigeria and Ethiopia. Oguntunde et al. (2012) showed that the annual and monthly mean SWSs decreased significantly in Ibadan, Nigeria, during the period 1973-2008, with the annual mean SWS decreasing by $28 \%(0.01$ level) over the study period. Furthermore, slowdowns in the monthly mean SWS were observed in 11 months of the year, and 5 months (June-October) had trends with significant slopes $(0.05$ level). In these 5 months, the SWS decreased at rates between 9.5 and $12.2 \%$ decade $^{-1}$. Gebreegziabher (2004) revealed that the SWS at Awassa station, Ethiopia, decreased from $1.47 \mathrm{~m} \mathrm{~s}^{-1}$ in 1973 to $0.79 \mathrm{~m} \mathrm{~s}^{-1}$ in 2003 at a linear rate of $-0.22 \mathrm{~m} \mathrm{~s}^{-1} \mathrm{dec}-$ $\mathrm{ade}^{-1}$ (McVicar et al. 2012a). In addition to North Africa, changes in the SWS in South Africa have also been studied. During the period 1993-2010, a mean decreasing trend of $-0.21 \mathrm{~m} \mathrm{~s}^{-1}$ decade $^{-1}$ was observed at 29 meteorological stations in South Africa (Kruger et al. 2010). Hoffman et al. (2011) discovered an average decline of $26.9 \%$ (at an average rate of $0.0188 \pm 0.002 \mathrm{~m} \mathrm{~s}^{-1}$ year $^{-1}$ ) at 20 climate stations in the Cape Floristic region of South Africa between 1974 and 2005. Furthermore, Hoffman et al. (2011) also found wind speeds were greater in the dry summer months than the winter months but that the the trend is significant at the $95 \%$ confidence level. a, b For $1975-$ 2006, and c, d for 1989-2006. (Copied from Troccoli and Muller (2012))

wind speed differences among seasons were not significant. Although some studies have revealed that the SWS has mainly decreased in Africa on both short- and long time scales, some results were obtained based on data from a single station. Furthermore, long-term observational data are lacking in this region, so the uncertainty in the longterm trend of SWS is high.

The detailed studies on the SWS have been summarized in Table 2 in McVicar et al. (2012a). Furthermore, a synthesis of some decreasing rates in terrestrial SWS at the global scale are shown in Fig. 7. Notably, the most rapid decreases in SWS are found in Asia and North Africa, with considerable SWS decreases in India, Kazakhstan, Iran, and Saudi Arabia. The second-largest magnitude SWS reductions occurred in America, Australia, and Canada (except for the northeastern part) (Fig. 7a). Furthermore, $73.6 \%$ of total studies have focused on Asia, Europe, and North America (Fig. 7b).

\subsection{Evident declines in extreme wind speed in some regions}

Climate extremes have received increasing attention in recent decades, as they are potentially more sensitive to 

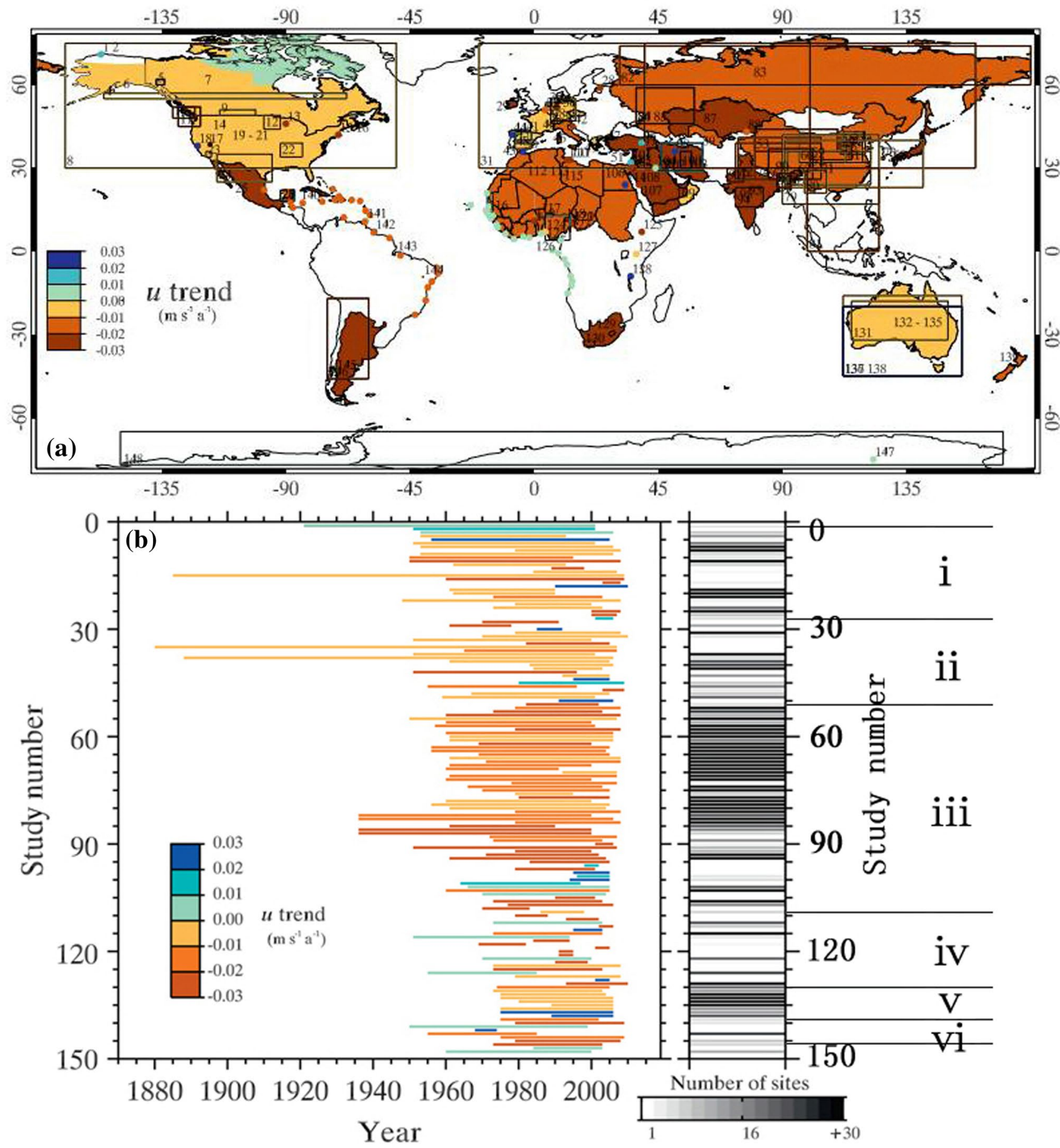

Fig. 7 a Global distribution of observed terrestrial near-surface wind speed trends. The values refer to the study numbers provided in Table 2 in McVicar et al. (2012a). If there are multiple studies for a country then the average trend for that country is used. b Temporal distribution of observed near-surface wind speed trends. The val-

change and more directly linked to natural disasters than mean climate conditions (Yan et al. 2002a, b). Recent studies have advocated for the necessity of studying extreme wind ues refer to the study numbers provided in Table 2 in McVicar et al. (2012a) (a copied from Fig. 2 in McVicar et al. (2012a), b modified from Fig. 3 in McVicar et al. (2012a).i, ii, iii, iv, v, vi in b for the studies in North America, Europe, Asia, Africa, Oceania, and central and South America, respectively)

speed (Pryor et al. 2012) because extreme wind speeds and events may affect air quality in populated regions, which may be highly relevant to the long-term establishment and 
planning of wind farms (Malloy et al. 2015). In addition to the significant decrease in the global mean SWS, a pronounced reduction in extreme SWS has also been observed in many regions. Recent studies of changes in extreme SWS have mainly focused on Europe. Yan et al. (2002a, b) analyzed the daily maximum wind speed (DMWS) in northwestern Europe using the maximum of instantaneous NCEP-NCAR wind speeds measured at four points during a day $(6,12,18$, and $24 \mathrm{~h})$ during the period 1958-1998. The authors inferred that the DMWS was lower over continental Europe than over the ocean. Moreover, they found increasing and decreasing trends of 0.2 and $-0.1 \mathrm{~m} \mathrm{~s}^{-1}$ decade $^{-1}$ over the ocean and over inland Europe, respectively; thus, the long-term changes in DMWS over inland areas were not consistent with those over the ocean. Yan et al. (2006) further found DMWS events dramatically decreased in summer at a decreasing rate of $-0.2 \mathrm{~m} \mathrm{~s}^{-1}$ decade $^{-1}$. However, Pryor et al. (2012) reported that extreme SWS over northern Europe showed an increasing trend in a dynamical downscaling of the 5th generation European Centre for MediumWeather Forecast Hamburg Atmospheric circulation model (ECHAM5) and that these results were consistent with the probabilistic downscaling of the 90th percentile wind speed from multiple ECHAM5 simulations, which showed weak increases in wind speed at the end of the twenty-first century (Pryor and Schoof 2010). Therefore, the studies of extreme SWS over northern Europe exhibit considerable uncertainty, and as such, in-depth investigations of observed extreme SWS over continental Europe are necessary in the future. Extreme wind speeds and wind events in local areas of continental Europe have also declined. Earl et al. (2013) analyzed the 10th, 50th, and 90th percentiles of the hourly mean wind speeds from 1980 to 2010, and the results showed that the 10th and 50th percentiles of the hourly mean wind speeds declined significantly over the 1980-2010 period.

Changes in extreme SWS over the United States have also been reported in recent decades. Pryor et al. (2007) noted that the 50th and 90th percentiles of SWS decreased throughout the United States from 1973 to 2005 and that the regions with significant decreases were located in the eastern United States. The 50th (90th) percentile wind speeds exhibited statistically significant negative trends at 118 (105) stations, accounting for 75\% (67\%) of the total stations. A comprehensive comparison of historical wind speed trends over the contiguous United States was performed by Pryor et al. (2009) based on two observational datasets (the first being observations of wind speed from the National Climate Data Center (NCDC) 6421 dataset, i.e., the NCDC-6421 dataset, and the second being a dataset of wind speeds from land-based sites across the contiguous United States, which was extracted from the online data archive held by the NCDC, i.e., the NCDC-DS3505 dataset). The NCDC-DS3505 dataset revealed that the 50th percentile values at 0000 UTC decreased at 150 of the 193 stations ( $77.7 \%$ of the total). Additionally, the 90th percentile wind speed values at 1200 UTC decreased at 146 stations ( $75.6 \%$ of the total). Similar results have been found using the NCDC-6421 dataset (Fig. 8). Therefore, the SWS trends over the United States in these datasets are predominantly negative. However, Pryor and Ledolter (2010) also suggested that the paper referenced above may be biased because it did not address the possible temporal auto-correlation in the annual wind speed statistics.

In the Southern Hemisphere, studies of extreme wind speed have mainly focused on Australia. Troccoli and Muller (2012) found that the characteristics of the linear trends for the 10th and 90th percentile wind speeds differed between the 2 and 10-m mean wind speeds. For the $10-\mathrm{m}$ wind speed, the 10th percentile trends increased more rapidly than the mean, whereas the 90th percentile increased less rapidly than the mean. For the 2-m wind speed, the variations in both the 10th and 90th percentile trends corresponded with the mean trends, which exhibited a clear decline during the 1989-2006 period (Fig. 9).

Some previous studies on extreme wind speeds have focused on the regional scale. Kumar et al. (2015) noted that regional models are rarely run using the full suite of global climate model (GCM) ensembles and that regional models may therefore not be able to capture the most likely changes in extreme wind speeds. To address these limitations and drawbacks, Kumar et al. (2015) used data from the latest generation of global circulation models, the Coupled Model Intercomparison Project phase 5 (CMIP5), to evaluate historical and future changes in extreme wind speeds at the global scale. They found that the trends in the ERA-Interim reanalysis dataset for the historical period (1979-2005) showed large spatial variability but no spatially consistent pattern. Compared to the ERA-Interim dataset, the trends in the annual maximum wind speeds in the CMIP5 multi-model ensemble (MME) were clearly weaker (Fig. 10a, b). Moreover, with respect to the historical period (1979-2005), the CMIP5 MME mean changes in the annual maximum wind speeds (AMWS) at the end of this century (2074-2100) are projected to decrease over the contiguous United States and most regions of Asia in the high latitudes and to increase over Amazonia, India, Africa, and Southeast Asia, whereas few changes are projected to occur over Europe (Fig. 10c, d). Additionally, the CMIP5 MME mean projected AMWS will change by more than $95 \%$ for grid points within -10 to $10 \%$ (Fig. 10e). Also, the simulated spatial distributions of the SWS in the historical period (1979-2005) (Fig. 10b) are consistent with those the projected AMWS for the end of the twentyfirst century (2074-2100) (Fig. 10f).

As mentioned above, the uncertainty in the results based on reanalysis data is high at the global scale. At 
NCDC-6421 1973-2000: 50th percentile
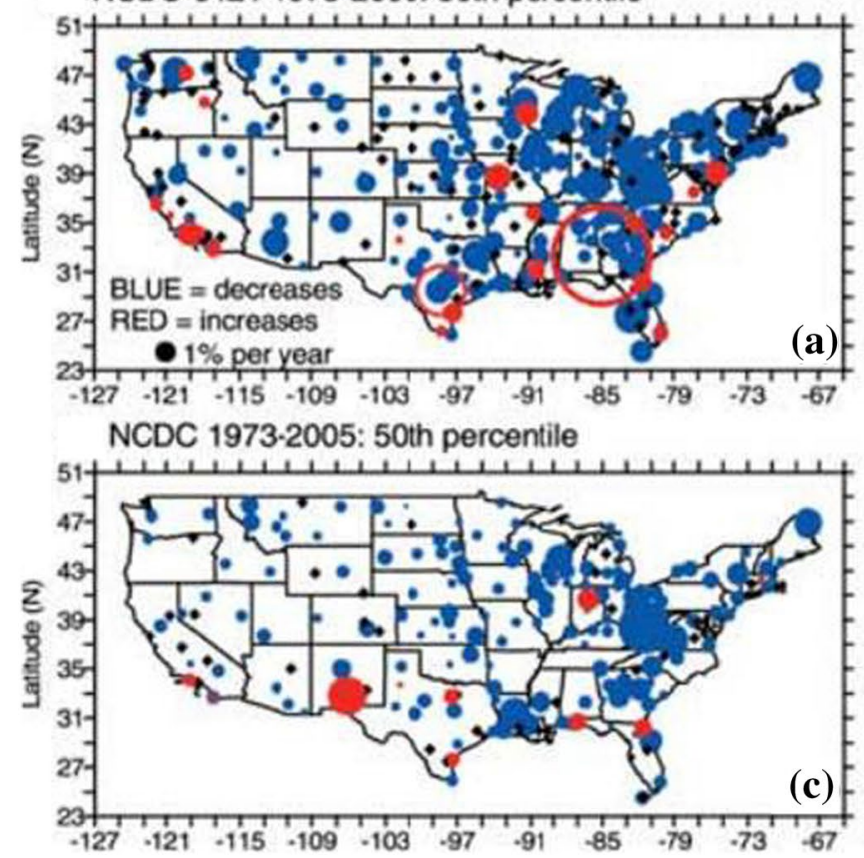

NCDC-6421 1973-2000: 50th percentile
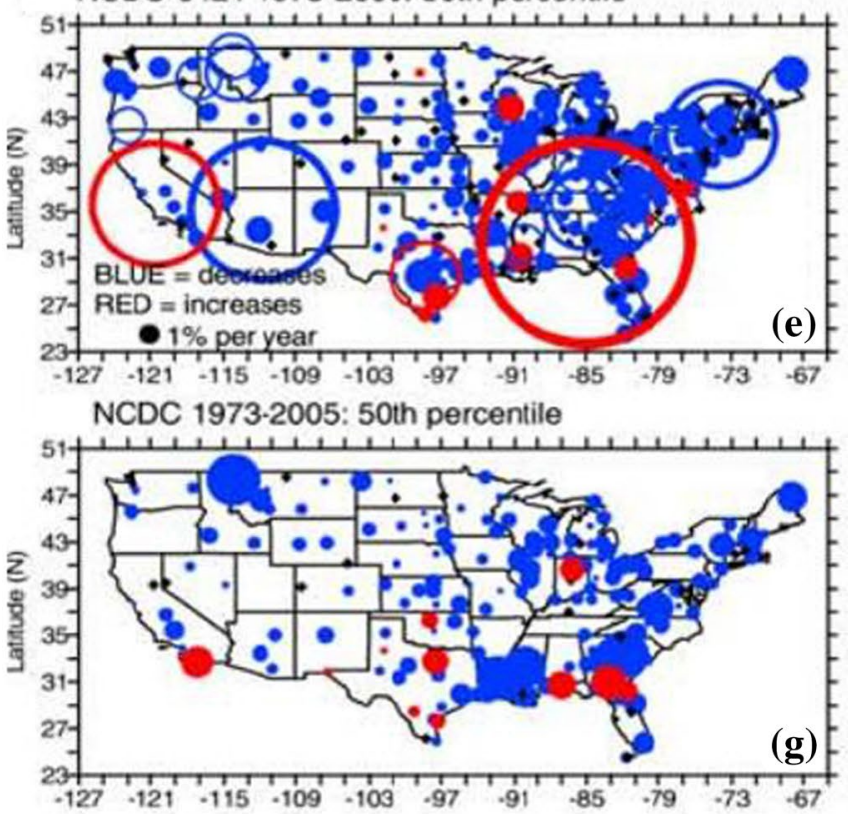

Fig. 8 Results of the trend analysis applied to data from 0000 UTC (a-d) and 1200UTC (e-h) in U.S. The individual frames show results for the 50th percentile wind speed from a and e NCDC-6421 (19732000), c, g NCDC-DS3505 (1973-2005), and the 90th percentile wind speed from b, f NCDC-6421 (1973-2000), d, h NCDC-DS3505 (1973-2005). In each frame the size of the dot scales linearly with the
NCDC-6421 1973-2000: 90th percentile

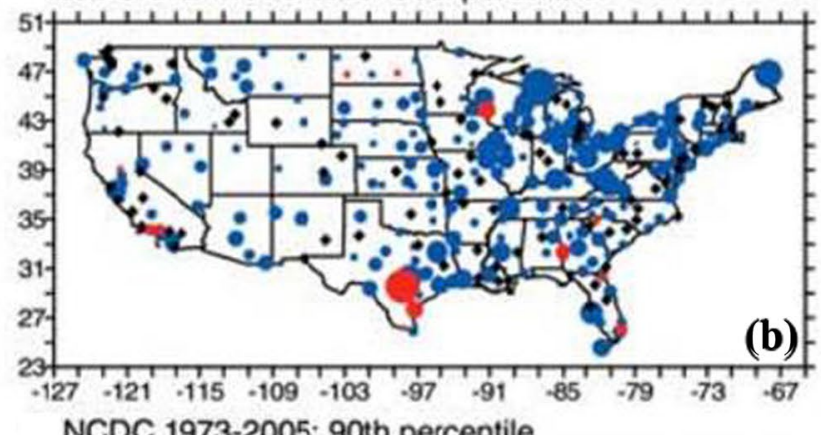

NCDC 1973-2005: 90th percentile

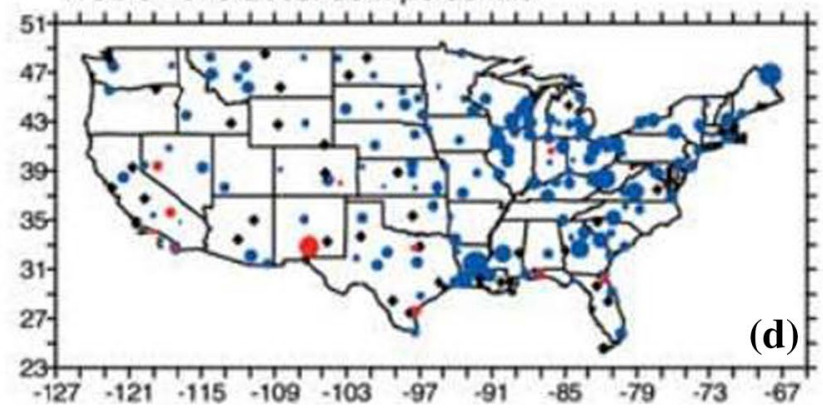

NCDC-6421 1973-2000: 90th percentile

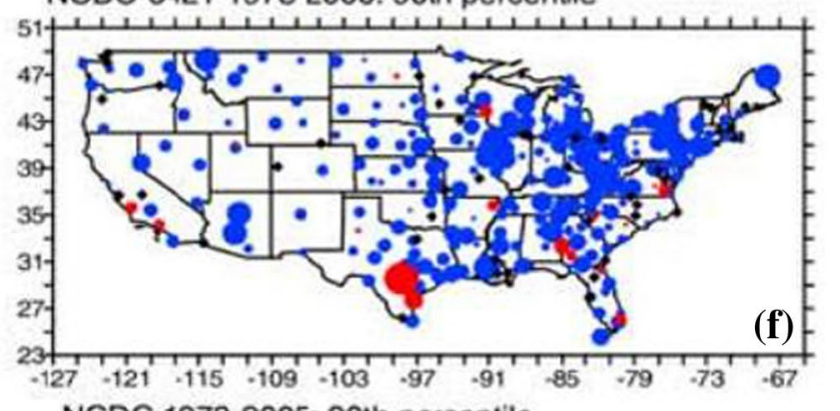
NCDC 1973-2005: 90th percentile

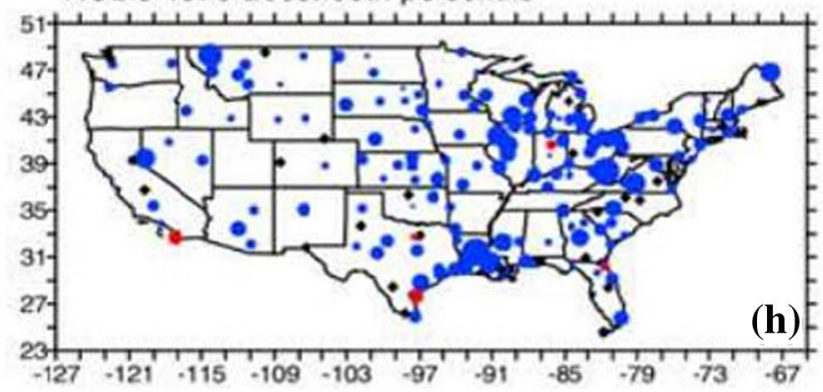

magnitude of the trend and the color of the dot indicates the sign of the trend (scale as shown in Fig. 8a, e). Stations that exhibit a trend in excess of $2 \%$ year $^{-1}$ are shown by open circles. Where the station time series did not indicate a statistically significant trend a plus symbol is shown. (Copied from Pryor et al. (2009)) 

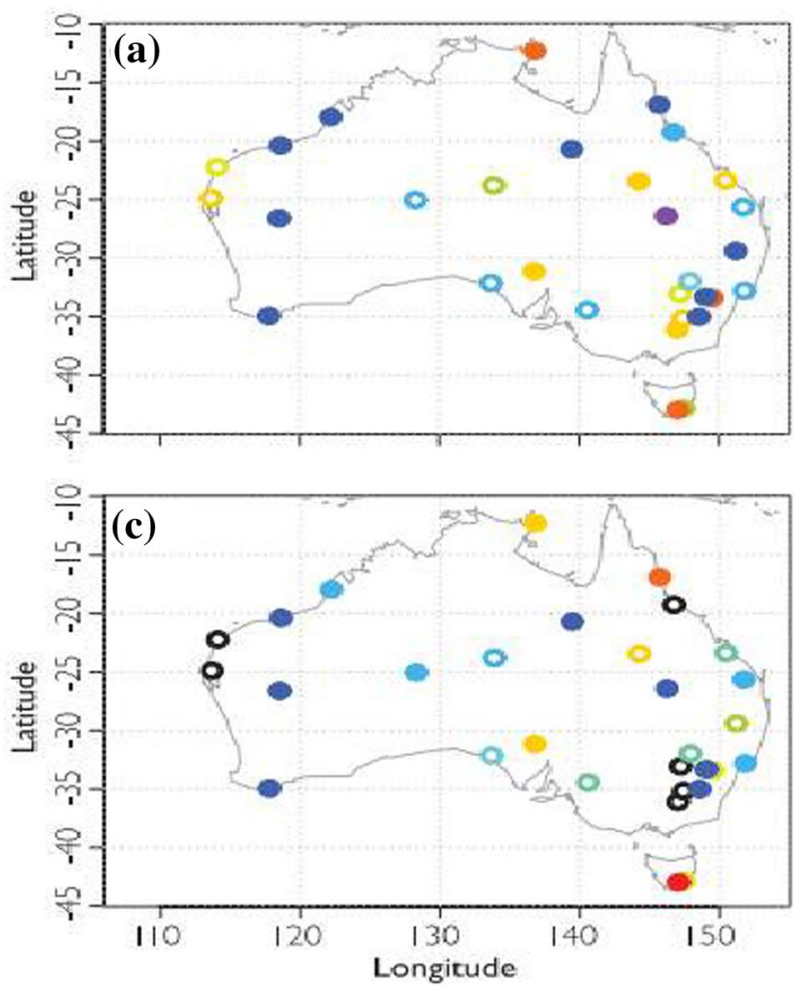

Fig. 9 Relative wind trend (i.e., trend divided by the mean wind) of the mean (a, b) 10th percentile, and (c, d) 90th percentile wind speed data over Australia for 1989-2006 expressed as percent per annum. $((\mathbf{a}, \mathbf{c})$ for 30 2-m wind-run stations and (b, d) for 22 10-m wind

the regional scale, the results show that the DMWS trend is $-0.1 \mathrm{~m} \mathrm{~s}^{-1}$ decade $^{-1} \mathrm{~m} \mathrm{~s}^{-1}$ decade $^{-1}$ over continental Europe and that it is larger in spring $\left(-0.2 \mathrm{~m} \mathrm{~s}^{-1}\right.$ decade $\left.^{-1}\right)$. In the United States, more than $70 \%$ of the studied stations have experienced a slowdown in extreme wind speed. However, studies on extreme wind speed in Asia, Africa, and South America are lacking.

\subsection{Changes in wind speed with different seasonal characteristics}

The long-term decrease in SWS is composed of clear seasonal changes, which differ among different regions.

\subsubsection{Europe}

During the period of 1961-2005, the most significant reduction in SWS $\left(-0.1 \mathrm{~m} \mathrm{~s}^{-1}\right.$ decade $\left.^{-1}\right)$ occurred in winter in the Czech Republic (Brazdil et al. 2009), and an increase in the frequency of lower SWSs was matched by a decrease in the frequency of higher SWSs during the warm season (i.e., April-June) and cold season (i.e., October to March) in northern France from 1974 to 2002 (Najac et al. 2009). The decreasing rates of the U component of the SWS in
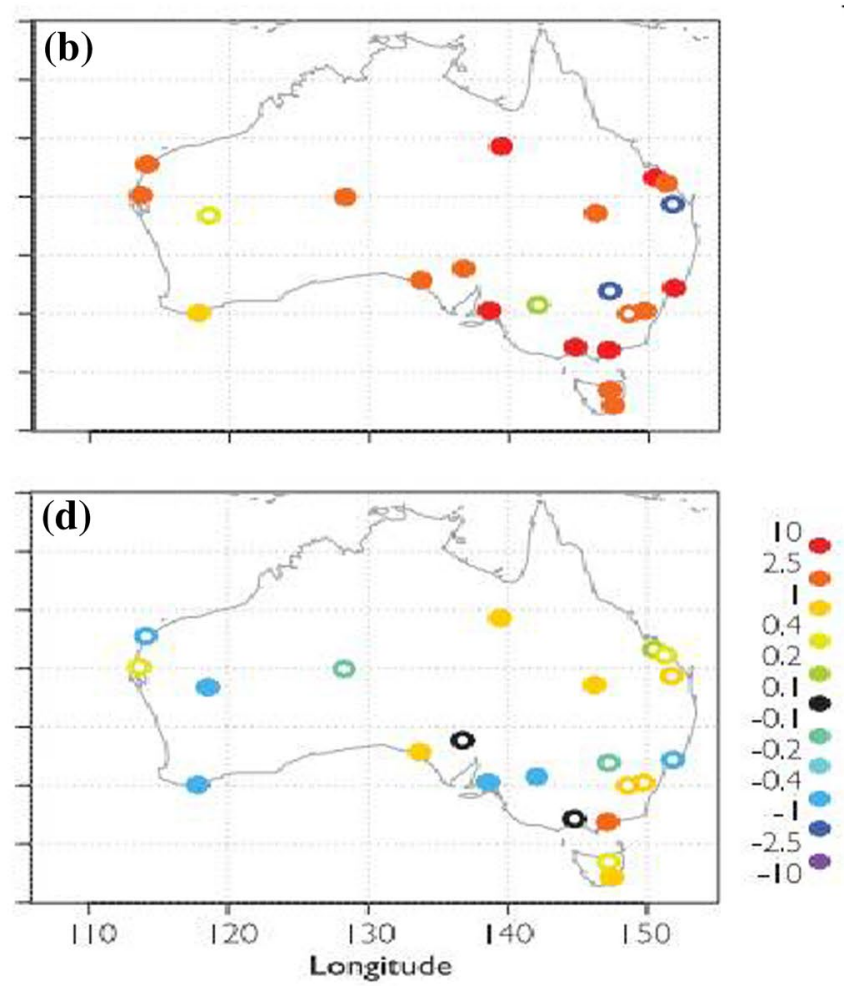

speed stations. In addition, solid circles are used for stations where the trend is significant at the 95\% confidence level. Details can be found in Fig. 5 in Troccoli and Muller (2012)). (Copied from Troccoli and Muller (2012))

Switzerland during winter and summer are -0.25 and $-0.05 \mathrm{~m} \mathrm{~s}^{-1}$ decade $^{-1}$, respectively, and greater decreases in the $\mathrm{U}$ component are observed at higher observation heights (McVicar et al. 2010). Azorin-Molina et al. (2014) observed that the interannual change in SWS is weaker in summer than in the other three seasons both in Portugal and Spain, resulting in large differences in the seasonal wind speed anomaly series (Fig. 11). For instance, winter exhibits the most significant decline $\left(-0.054 \mathrm{~m} \mathrm{~s}^{-1}\right.$ decade $\left.^{-1}\right)$, especially in Portugal $\left(-0.096 \mathrm{~m} \mathrm{~s}^{-1}\right.$ decade $\left.^{-1}\right)$ (Fig. 11a), and spring features a lower-magnitude but still statistically significant change (-0.022 $\mathrm{m} \mathrm{s}^{-1}$ decade $\left.^{-1}\right)$ (Fig. 11b). In contrast, fairly positive wind speed trends with less statistical significance are observed in summer $\left(0.009 \mathrm{~m} \mathrm{~s}^{-1}\right.$ decade $\left.^{-1}\right)$ (Fig. 11c) and in autumn $\left(0.006 \mathrm{~m} \mathrm{~s}^{-1}\right.$ decade $\left.^{-1}\right)$ (Fig. 11d). Moreover, the decreasing trends in winter and spring over Portugal are significantly stronger than those over Spain. Minola et al. (2016) also reported a slowdown in SWS during spring, summer and autumn and weaker changes during winter in Sweden from 1959 to 2013. Furthermore, decreasing trends are found at $91.7 \%$ of the stations during summer, whereas decreasing trends are observed at only $58.3 \%$ of the stations during winter. Dadaser-Celik and Cengiz (2014) found the trends in the seasonal average SWS over Turkey from 


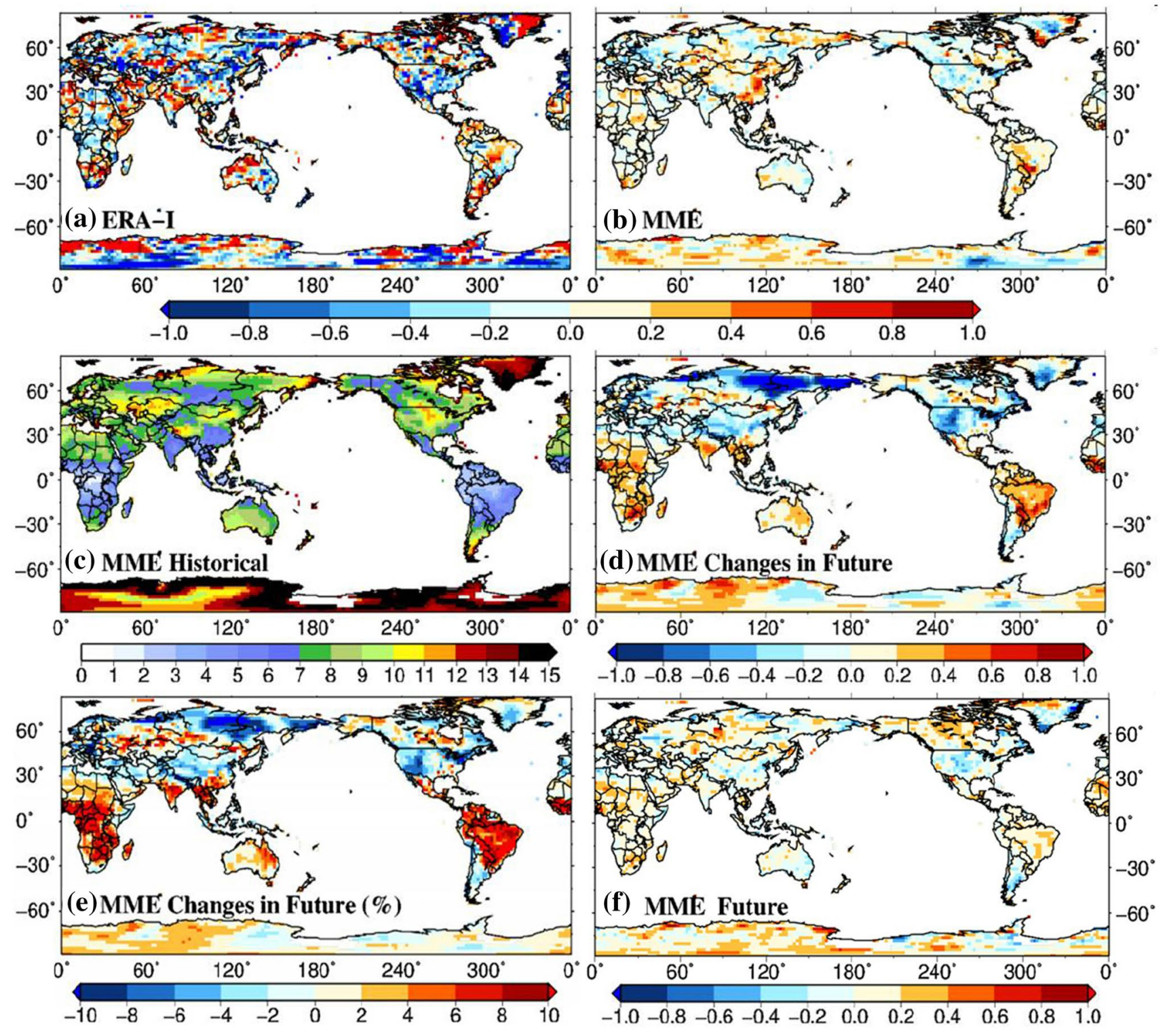

Fig. 10 Historical trends (unit: $\mathrm{m} \mathrm{s}^{-1}$ per 27 year) of annual maximum wind speeds in ERA-Interim (a) and the multimodel ensemble mean (15 models) in CMIP5 b for the period of 1979-2005; c 27-year multimodel ensemble mean of annual maximum wind speeds for the historical reference period (1979-2005), d multimodel ensem-

1975 to 2006 to be inconsistent. The mean change in the seasonal SWS ranges between -0.11 and $-0.16 \mathrm{~m} \mathrm{~s}^{-1}$ dec$\mathrm{ade}^{-1}$, with the largest decrease occurring during winter $\left(-0.16 \mathrm{~m} \mathrm{~s}^{-1}\right.$ decade $\left.^{-1}\right)$ and the weakest decreases occurring during spring and summer $\left(-0.11 \mathrm{~m} \mathrm{~s}^{-1}\right.$ decade $^{-1}$ ) (all of these trends are significant at the 0.05 level). Moreover, the percentages of stations recording significant ( 0.05 level) downward trends were $57 \%$ in fall, 59\% in winter, and 54\% in both spring and summer.

ble mean change in projected wind speeds at the end of this century (2074-2100) with respect to the reference period of 1979-2005; e percentage change; $\mathbf{f}$ is same as $\mathbf{b}$ but for the period of 2074-2100. (a and $\mathbf{b}$ copied from Fig. 2, c-e copied from Fig. 5; f copied from Fig. 6 in Kumar et al. (2015))

\subsubsection{North America}

The terrestrial SWS in the United States is high during winter and spring and low during summer, with the annual maximum and minimum SWSs occurring during spring and summer, respectively. The seasonal average of the maximum SWS has exhibited a large positive trend during summer and autumn, whereas the seasonal average of the minimum SWS has exhibited a significant negative trend during spring (Klink 1999a, b). In addition, the seasonal changes in the extreme wind speeds are not 

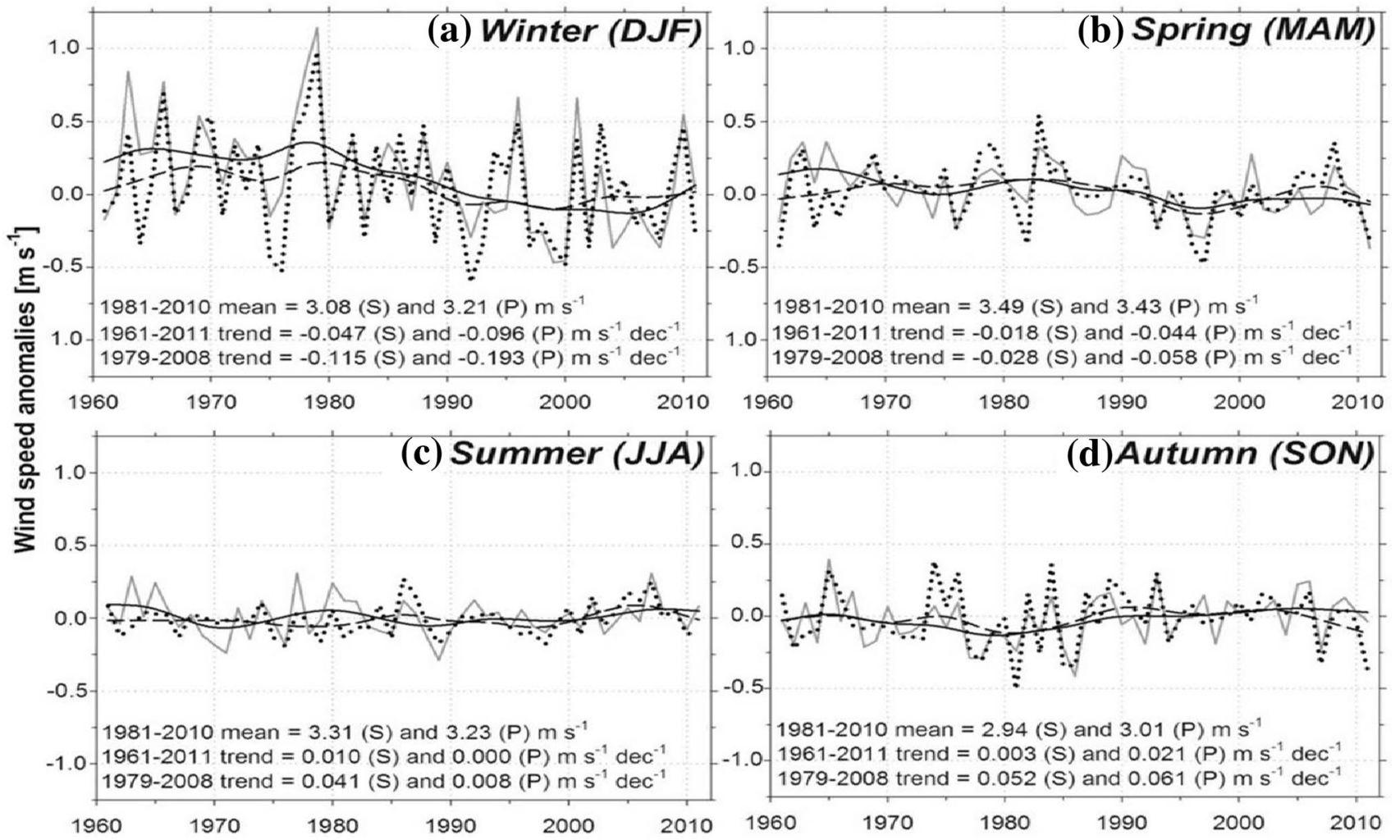

Fig. 11 Seasonal wind speed anomalies (unit: $\mathrm{m} \mathrm{s}^{-1}$ ) series for Spain (S; black dotted line) and Portugal (P; dark gray solid line) from 1961 to 2011. The 15-year Gaussian low-pass filter is also shown with a

consistent with those of the mean wind speed. The annual mean wind speed integrates significantly different seasonal changes in SWS, whereas the 90th percentile wind speed has decreased uniformly in the different seasons (Pryor et al. 2009).

\subsubsection{Asia}

Seasonal differences in the changes in SWS have also been observed in Korea and China over the last 30 years. In Korea, the greatest (weakest) decrease in SWS occurred during spring (summer) at a rate of $-0.19(-0.10) \mathrm{m} \mathrm{s}^{-1}$ decade $^{-1}$ during the period 1954-2003 (Kim and Paik 2015). The SWS changes in China also include significant seasonal differences. Jiang et al. (2010) found the decreasing trends in SWS during spring, summer, autumn, and winter in China from 1956 to 2004 to be $-0.149,-0.085,-0.111$, and $-0.124 \mathrm{~m} \mathrm{~s}^{-1}$ decade $^{-1}$, respectively. Another study found that, in China, spring features both the highest SWS and the most distinct decrease in SWS (Guo et al. 2011). Li et al. (2011) noted significant seasonal differences in the long-term changes in the seasonal average SWS in Beijing for 1960-2008; for example, the strongest and weakest black dashed line for Spain and with a black solid line for Portugal. The series are expressed as anomalies from the 1981-2010 mean. (Copied from Fig. 5 in Azorin-Molina et al. (2014))

decreases in SWS occurred during winter and summer, respectively. In addition, on the $\mathrm{TP}$, a significant reduction in springtime SWS has occurred at a rate of $-0.08 \mathrm{~m} \mathrm{~s}^{-1} \mathrm{dec}-$ $\mathrm{ade}^{-1}$, whereas nonsignificant decreases have occurred during the other seasons (Lin et al. 2013). Yang et al. (2012) found that the seasonal mean SWS in southwestern China was high in spring $\left(2.15 \mathrm{~m} \mathrm{~s}^{-1}\right)$ and winter $\left(1.78 \mathrm{~m} \mathrm{~s}^{-1}\right)$ and low in summer $\left(1.61 \mathrm{~m} \mathrm{~s}^{-1}\right)$ and autumn $\left(1.47 \mathrm{~m} \mathrm{~s}^{-1}\right)$ and that the trends of the changes in winter, spring, summer, and autumn from 1969 to 2009 were $-0.22,-0.28,-0.16$, and $-0.14 \mathrm{~m} \mathrm{~s}^{-1}$ decade $^{-1}$, respectively. Furthermore, Yang et al. (2012) reported that the seasonal maximum (minimum) wind speeds are $5.0(0.35), 4.80(0.64), 3.96(0.59)$, and $3.71(0.35) \mathrm{m} \mathrm{s}^{-1}$ in winter, spring, summer, and autumn, respectively. Therefore, based on a number of studies on the changes of seasonal SWS in China, we conclude that the slowdown in seasonal SWS is more significant in southwestern China than in China overall (Liu et al. 2009; You et al. 2010; Guo et al. 2011).

As mentioned above, the seasonal SWSs in both Europe and Asia mainly show downward trends. However, over most regions in Europe, the slowdown in SWS is most significant in winter. For example, the most significant 


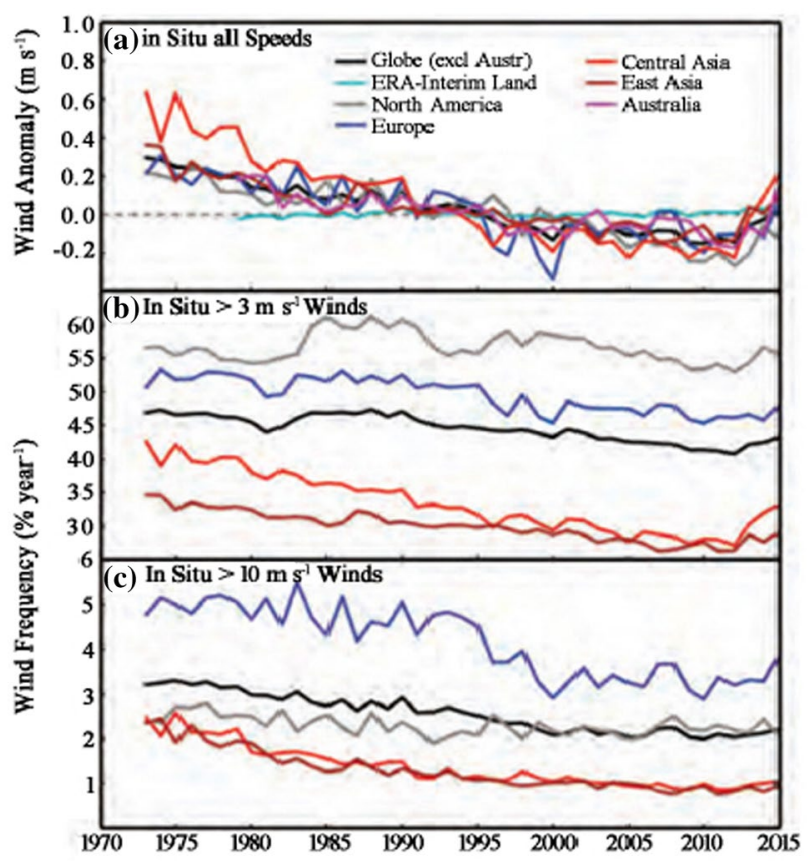

Fig. 12 Global (excluding Australia) and regional annual time series of land surface wind speed for 1981-2015 using HadISD and ERA-Interim showing a wind speed anomaly (unit: $\mathrm{m} \mathrm{s}^{-1}$ ) relative to 1981-2010, and occurrence frequencies (in \%) for wind speeds $\mathrm{b}>3 \mathrm{~m} \mathrm{~s}^{-1}$ and $\mathrm{c}>10 \mathrm{~m} \mathrm{~s}^{-1}$. Frequencies for Australia are not shown in $\mathbf{b}$ and $\mathbf{c}$ (Modified from Dunn et al. (2016)) decrease occurred in winter in Switzerland at a rate of $-0.25 \mathrm{~m} \mathrm{~s}^{-1}$ decade $^{-1}$. In Asia, the decreasing trends in SWSs are most significant in spring, and the most significant decrease occurred in spring in southwestern China $\left(-0.28 \mathrm{~m} \mathrm{~s}^{-1}\right.$ decade $\left.^{-1}\right)$. In the United States, the SWS is higher during winter and spring and lower during summer. Therefore, the seasonal changes in SWSs differ distinctly among seasons and regions. Little research has been conducted on the seasonal SWS changes in Africa, but such studies should be carried out in the future.

\subsection{Recent increases in terrestrial SWS in some regions}

The widespread reductions in terrestrial wind speeds have been significant at the global scale (Vautard et al. 2010, 2012; McVicar et al. 2012a), but slight increases in terrestrial SWS have also been found in recent years (Tobin et al. 2014; Berrisford et al. 2015; Dunn et al. 2016). Figure 12 shows the global (excluding Australia) and regional annual mean SWS values over land, which include an upward trend after 2010 (Fig. 12a). This short-term strengthening of mean SWS relative to previous years has been induced by an increase in the frequency of low and moderate wind speeds $\left(>3 \mathrm{~m} \mathrm{~s}^{-1}\right.$ ), especially over Asia (Fig. 12b). However, this SWS recovery is not accompanied by an increase in the frequency of strong wind $\left(>10 \mathrm{~m} \mathrm{~s}^{-1}\right)$, similar to previous years in all the regions. Additionally, the increase in strong
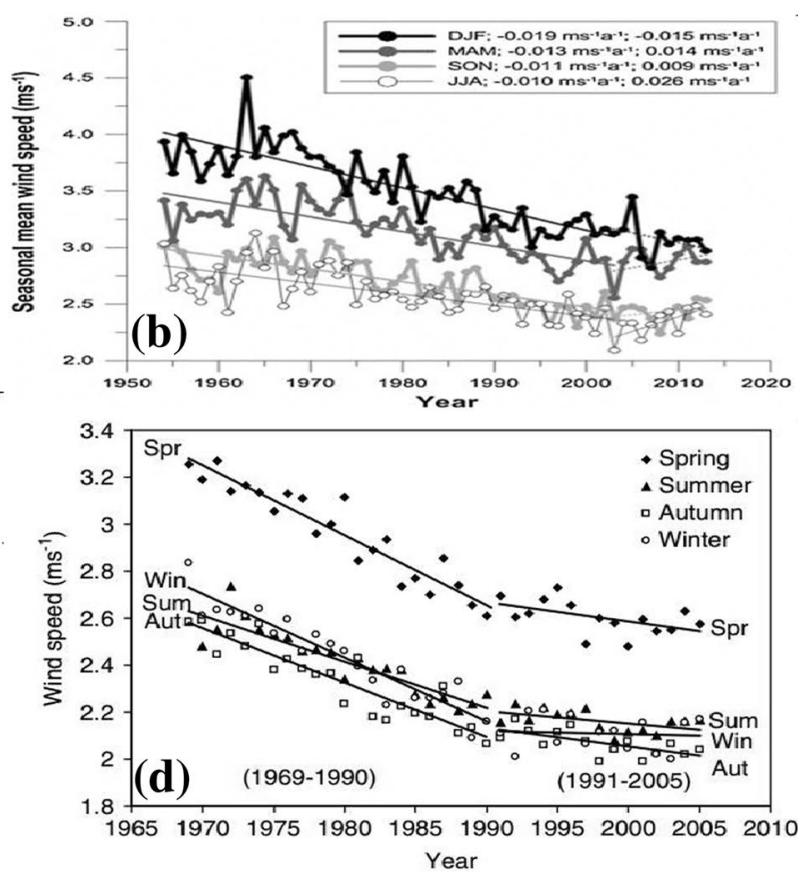

variation and trend (solid line) of annual mean and seasonal mean wind speed averaged in China from 1969 to 2005 (c, d). (a, b copied from Kim and Paik (2015); c, d copied from Guo et al. (2011))
Fig. 13 Annual mean and seasonal mean of surface wind speed averaged over 14 ground stations in South Korea $(\mathbf{a}, \mathbf{b})$ (Solid linear fit line indicates statistically significant trends whereas dashed line is statistically insignificant trend at $90 \%$ confidence level). Temporal 
winds is more significant in Europe than in other regions (Fig. 12c). Some studies also observed SWS strengthening over land at the local scale in recent decades. Kousari et al. (2013) discovered that more stations measured an increase in SWS than a decrease in Eastern Iran from 1975 to 2005. Kim and Paik (2015) found a deceleration in the decreasing trend of the SWS in South Korea after the 1990s, which was followed by an increase in the SWS after 2003 at a rate of $0.08 \mathrm{~m} \mathrm{~s}^{-1}$ decade $^{-1}$ at all stations (Fig. 13a). At the same time, the recovery of SWS is stronger at inland stations than at coastal stations, corresponding to mean increasing trends of 0.1 and $0.06 \mathrm{~m} \mathrm{~s}^{-1}$ decade $^{-1}$, respectively. In addition to the mean wind speed, the daily maximum and seasonal mean wind speeds in South Korea have also increased since 2003. Figure $13 \mathrm{~b}$ shows that the seasonal wind speed decreased until 2003, followed by a transition thereafter. The recovery of the seasonal mean wind speed in South Korea is most significant in summer, which features the largest increasing trend of $0.26 \mathrm{~m} \mathrm{~s}^{-1}$ decade $^{-1}$. In addition, Guo et al. (2011) discovered that the decrease in annual and seasonal mean SWS slowed in China after 1991 (Fig. 13c, d) and that the decreasing rate of the annual SWS was significantly weaker after 1991 than before, with similar results found for the seasonal mean SWS (Fig. 13d). Moreover, Yang et al. (2012) reported that the annual and seasonal mean SWSs showed pronounced increases after 2000. Before 2000, annual mean, winter, spring, summer, and autumn SWSs in southwestern China decreased at rates of $-0.37,-0.38,-0.35,-0.26$, and $-0.30 \mathrm{~m} \mathrm{~s}^{-1}$ decade $^{-1}$, respectively; however, after 2000 , they have increased at rates of $0.55,0.60,0.13,0.82$, and $0.65 \mathrm{~m} \mathrm{~s}^{-1}$ decade $^{-1}$, respectively. Therefore, we infer that the recovery of SWS is significantly stronger in southwestern China than in China as a whole.

The above-mentioned studies have revealed that the shortterm strengthening of SWS is mainly caused by increases in the frequency of low and moderate winds $\left(>3 \mathrm{~m} \mathrm{~s}^{-1}\right)$, which have increased the most in Central Asia and East Asia. At the same time, the short-term strengthening of the SWS has differed in different areas. The recovery of seasonal mean SWS is also evident during the most recent decade at the regional scale. These various temporal changes in SWS indicate that the variability in SWS can be affected by different factors that differ regionally and seasonally. These factors are discussed further in the following sections.

\subsection{Changes in gust wind speeds and events}

As mentioned above, most studies addressing climate variability in mean and extreme wind speeds have analyzed long-term trends, but the study of gust wind speeds and events has only received minimal attention over the last two decades. Knowledge of the local characteristics of gust wind is important, for example, to workers interested in the design of structures, the implementation of wind energy, and the forestry industry (Usbeck et al. 2010a; Hewston and Dorling 2011).

In Europe, Usbeck et al. (2010b) found an average of $0.21,0.85$, and 2.51 days year $^{-1}$ with a daily maximum gust speed (DMGS) of at least $30 \mathrm{~m} \mathrm{~s}^{-1}$ in the Zurich region of Switzerland during the periods 1891-1929, 1930-1968, and 1969-2007, respectively. At the same time, the extremes of DMGS increased by roughly $12 \mathrm{~m} \mathrm{~s}^{-1}$ between the first and last time periods. Hewston and Dorling (2011) reported an evident decline in DMGS in England since 1993, with observed values dropping more than $6 \%$ by 2005 compared to the long-term average. Additionally, they also found that the annual anomalies of DMGS showed a very similar pattern, with an approximately $15 \%$ decrease in the observed values from 1993 to 2005. Azorin-Molina et al. (2016) assessed the trends in the observed daily peak wind gusts (DPWG) in Spain and Portugal during the period 1961-2014 and found a declining trend in the frequency of annual peak wind events. This declining trend is approximately two times higher in magnitude in Spain $\left(-1.55\right.$ days decade $\left.{ }^{-1}\right)$ than in Portugal $\left(-0.79\right.$ days decade $\left.{ }^{-1}\right)$. Additionally, the long-term variability could be divided into three phases in terms of the occurrence of DPWG episodes: (1) a weak increase from 1961 to $1980,(2)$ a significant decrease from 1980 to 1998 , and (3) a slight increase from 1998 to 2014 (Fig. 14a).
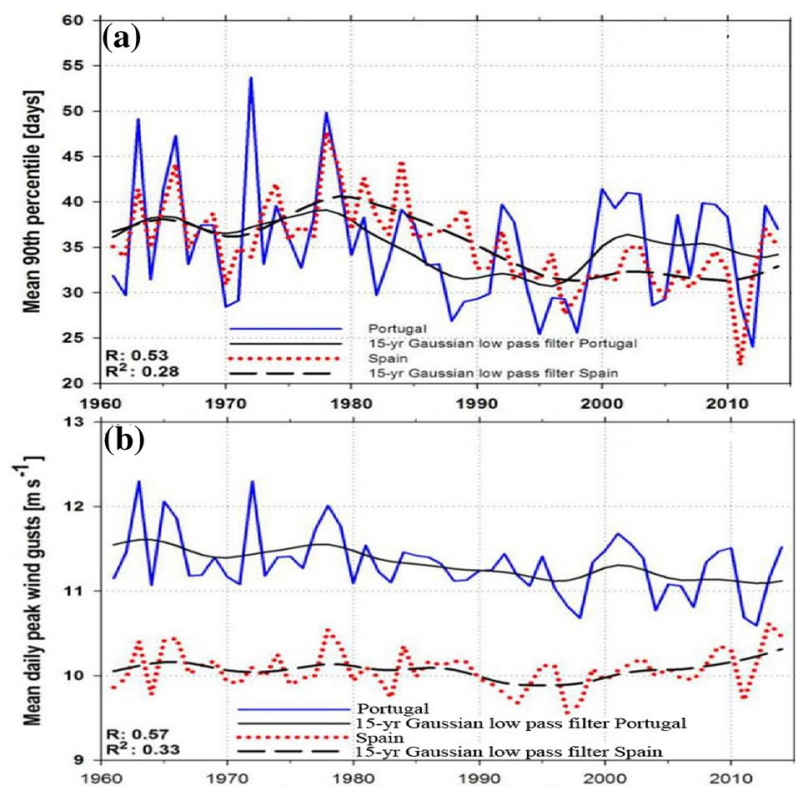

Fig. 14 Mean annual number of days exceeding the 54-year 90th percentile for Spain (red dotted line) and Portugal (blue solid line) from 1961 to 2014 (a). The 15-year Gaussian low-pass filter is also shown with a black dashed line for Spain and with a black solid line for Portugal; $\mathbf{b}$ is same as a but for annual mean wind speed of DPWG. (Copied from Azorin-Molina et al. (2016)) 
In addition, in the Portuguese series, both the magnitude $\left(-0.091 \mathrm{~m} \mathrm{~s}^{-1}\right.$ decade $^{-1}$; significance $\left.<0.05\right)$ and the frequency of extreme wind gusts decrease, whereas in the Spanish series, the magnitude of DPWG shows no such trend, despite the significant decrease in the frequency of extreme wind events (Fig. 14b).

In the United States, Enloe et al. (2004) documented a general reduction in peak wind gusts during El Niño periods, a reduction in the occurrences of gale-force wind gusts, and a reduction in mean peak wind gusts in autumn and winter in the Great Plains region. Klink (2015) found that the fastest 2-min SWS data showed a positive trend along the Atlantic coast and a negative trend along the Pacific coast.

\section{Main causes of the changes in the terrestrial SWS}

Some studies have represented the potential causes of decreases in the terrestrial SWS in terms of global and regional perspectives (McVicar et al. 2012a; Klink et al. 1999a, b, 2002, 2007). However, it is difficult to separate and quantify the respective effects of various mechanisms on SWS changes. From a dynamics perspective, motion in the atmosphere should obey the dynamical equations presented in Eq. (1):

$\frac{\mathrm{d} \overrightarrow{\mathrm{V}}}{d t}=\vec{G}+\vec{F}+\vec{g}+\vec{f}$

Equation (1) is the Lagrangian form of the wind equation. In this equation, $\overrightarrow{\mathrm{V}}$ is the wind speed, and $\vec{G}=-\frac{1}{\rho} \nabla p$ is the pressure-gradient force (PGF), which is the driving force for atmospheric motion. The terms $\rho$ and $\mathrm{P}$ represent the air density and air pressure, respectively. $\vec{F}=-2 \vec{\Omega} \times \vec{V}$ is the Coriolis force, which is a passive force that is related to the wind speed. The term $\vec{g}$ is the gravitational force, and $\vec{f}$ is the drag force. Therefore, Eq. (1) shows that the causes of the decreases in SWS potentially include increases in the drag force and decreases in the driving force. A change in any influential factor will ultimately induce changes in the driving and drag forces; therefore, we further discuss the effects of driving and drag forces on SWS in the following sections.

\subsection{Influence of the changes in the large-scale driving force on the terrestrial SWS}

One of the possible causes of SWS changes is air temperature because air temperature changes can affect surface pressure gradients and therefore the SWS (Dadaser-Celik and Cengiz 2014). Some researchers have noted correlations between rising temperatures and decreases in SWS and have tended to explain decreases in SWS as a reduction in the driving force in the atmosphere associated with the changes in air temperature (Gadgil 2007; Trenberth et al. 2007). Klink (1999a) concluded that the downward trends in SWS over the United States could be explained by an increase in the mean air temperature at higher latitudes relative to the tropics. Pirazzoli and Tomasin (2003) found that the changes in SWS in the Mediterranean and Adriatic areas were similar to the changes observed in air temperatures. Xu et al. (2006b) showed that the correlation coefficient between the winter SWS and the daily minimum air temperature reaches 0.75 and that an increase of $1{ }^{\circ} \mathrm{C}$ in the minimum air temperature can cause a decrease of $0.15 \mathrm{~m} \mathrm{~s}^{-1}$ in SWS over North China. In fact, Yang et al. (2012) also revealed the annual mean SWS to be negatively correlated with the annual mean, minimum, and maximum temperatures in

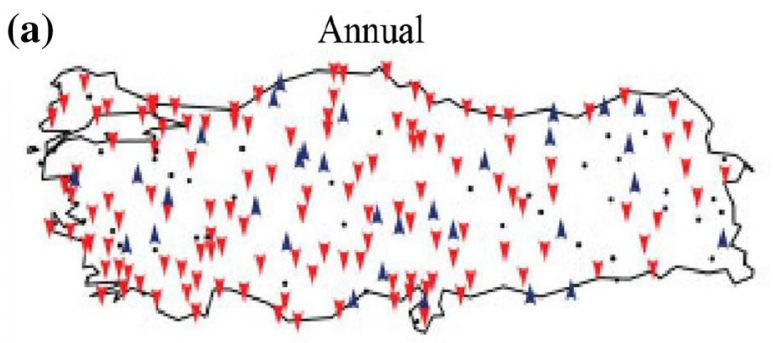

I Sig. Upward Trend Y Sig. Downward Trend * No Change

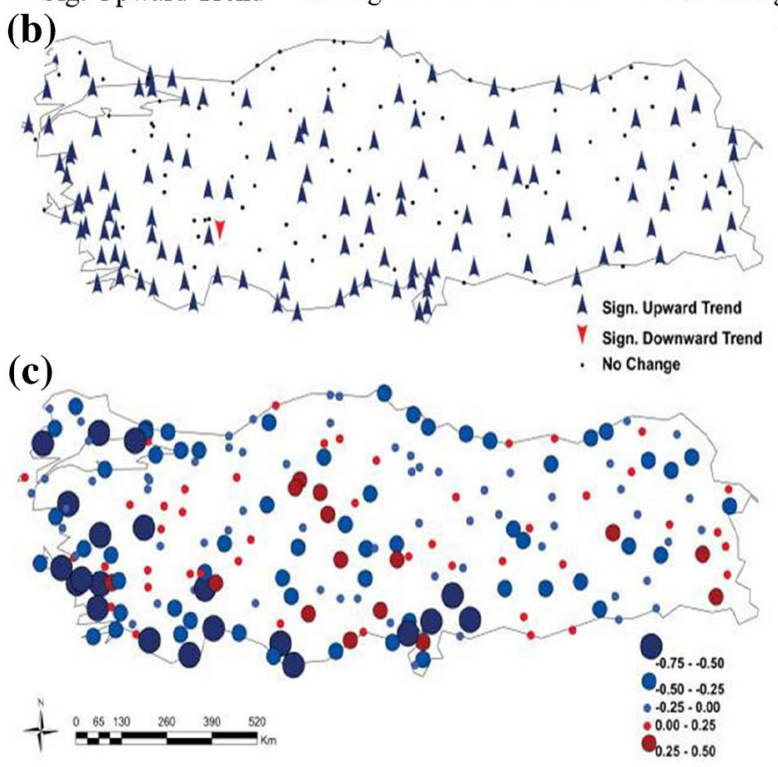

Fig. 15 Trends (significant at the 0.05 level) in annual average wind speed data at 206 stations in Turkey from 1975 to 2006, data were plotted at station locations (a). Trends (significant at the 0.05 level) in air temperatures at 206 stations (b). Correlation coefficients calculated between annual average wind speeds and annual average air temperatures (c). (Copied from Dadaser-Celik and Cengiz (2014)) 
southwestern China, with the largest negative correlation coefficient reaching -0.54 . Relatively greater wind speeds (i.e., $>1.5 \mathrm{~m} \mathrm{~s}^{-1}$ ) in Japan are negatively correlated with temperature, and lower wind speeds (i.e., $<1.0 \mathrm{~m} \mathrm{~s}^{-1}$ ) are positively correlated with temperature during daytime (Fujibe 2009). Fujibe (2011) found a negative correlation between SWS changes $(\Delta \mathrm{U})$ and air temperature changes $(\Delta \mathrm{T})$, and this correlation is more significant for lower wind speeds. Similarly, a negative correlation between SWS and air temperature in South Korea prior to 2003 has also been reported by Kim and Paik (2015). Dadaser-Celik and Cengiz (2014) showed that almost all stations showing a decreasing SWS trend had upward trends in air temperature over Turkey during the period 1975-2006. The air temperature trends are particularly strong in western and southern Turkey, where downward trends in SWS are also significant (Fig. 15a, b). To conduct a further analysis, Dadaser-Celik and Cengiz (2014) also correlated annual mean SWS with mean temperature for the period 1975-2006 (Fig. 15c) and obtained correlation coefficients between -0.75 and 0.49 , with an average of -0.15 . In addition, $71 \%$ of the stations were found to have a negative correlation coefficient, thus reflecting a connection between SWS and air temperature in Turkey. According to the above-mentioned studies, we note that a pronounced negative correlation exists between air temperature and SWS. In addition to the Northern Hemisphere temperatures, the Southern Hemisphere temperatures have also significantly affected continental DMWS trends. Yan et al. (2002a, b) suggested that the steady warming in the Southern Hemisphere between 1958 and 1998 may have shifted North Atlantic storm tracks in such a way that storms have weakened over most regions of the European continent, possibly resulting in a persistent decline in the DMWS over the European continent.

The main changes in the driving force appear to be the variability in the circulation patterns, which have distinctly influenced decreases in SWS (Pryor et al. 2006; Sušelj et al. 2010). Knippertz et al. (2000) showed that mean and extreme winds in the Mediterranean regions decreased due to a decrease in the westerly mean current. To analyze the effects of large-scale circulation patterns on SWS, DadaserCelik and Cengiz (2014) studied the zonal and meridional wind speed composites at $500 \mathrm{hPa}$ in Turkey from 1975 to 2006 from the NCEP-NCAR reanalysis data. The results indicate that zonal (meridional) winds mainly exhibit negative (positive) trends. Therefore, the SWS changes in Turkey were related to the changes in the circulation pattern, particularly the weakening of zonal circulation. On the global scale, Vautard et al. (2010) proposed that the weakening of large-scale circulation can account for $10-50 \%$ of the observed reduction in SWS.

Because changes in circulation patterns differ between different regions, the impacts of circulation patterns on SWS show regional differences. Yan et al. (2002a, b) reported that high DMWS values almost everywhere in the Northern Hemisphere are associated with a strong Arctic Oscillation (AO)-North Atlantic Oscillation (NAO) year. Changes in the NAO were also found to greatly affect the SWS in Europe. Some studies have revealed that changes in SWS in Switzerland and England are mainly controlled by the NAO (Beniston 2005; Earl et al. 2013). Jerez et al. (2013) found that the winter SWS, the daily maximum SWS, and the frequency of higher wind speeds over the Iberian Peninsula are significantly affected by the NAO. Azorin-Molina et al. $(2014,2016)$ further revealed that the NAO partly accounts for the decadal fluctuations in both the frequency and magnitude of the observed near-surface DPWG in Spain and Portugal, particularly during winter, with the negative correlation between the NAO and DPWG reaching - 0.6. In summer, the NAO exerts moderate to significant impacts on the SWS, with correlation coefficients of -0.33 and -0.51 during 1961-2011 and 1979-2008, respectively. This relationship explains the SWS increase observed in summer over the last 30 years, particularly in Spain. However, AzorinMolina et al. (2016) also suggested that the strength of the NAO-DPWG relationship is weaker in spring, summer, and autumn than in winter; hence, the changes in both largescale circulation patterns and local to mesoscale atmospheric dynamics are likely important factors in the changes in gust wind speeds and event frequencies. Beyond Europe, Clifton and Lundquist (2012) discovered that $6 \%$ of the changes in the SWS in the state of Colorado in the United States can be attributed to the AO. In China, Chen et al. (2013) found that the mean correlation coefficient between SWS and AO reached -0.47 (0.05 level) from 1971 to 2007 and that lower (higher) SWSs were observed in the southern region of the Yangtze River in China when the AO was in a positive (negative) phase. In addition, Fu et al. (2011) reported that the SWS usually does not decrease during negative Pacific decadal oscillation (PDO) phases but does decrease during positive PDO phases.

In addition to the changes in SWS that are correlated with the NAO and AO over North America and China, changes in SWS over these regions are also correlated with the El NiñoSouthern Oscillation (ENSO). Enloe et al. (2004) noted that higher (lower) daily SWS values occur in the Pacific Northwest, the Southwest, and the Central Plains in the United States in association with a cool (warm) ENSO phase. Monthly mean peak wind gusts, as well as the frequency of gale-force gusts, increase (decrease) during ENSO cold (warm) phases over the western regions of United States. When the ENSO is in a positive phase, the observed SWSs at $55 \%$ of the stations in China are lower than those when the ENSO is in a negative phase (Chen et al. 2013). Nevertheless, the quantitative relationships between changes in SWS and the NAO, AO, and ENSO remain unknown. In 
addition, Lin et al. (2013) found that the trends of AO and NAO are not in phase with the changes in SWS over all of China. These authors also argued that the PDO can modulate the influences of ENSO on the East Asian atmospheric circulation but that no significant correlation between the PDO and SWS exists over China. Therefore, Lin et al. (2013) concluded that the wind speed changes over China are not simply linked to oscillation indexes, such as AO, NAO, and PDO. Nevertheless, they could not exclude the possibility that some other climate indexes are responsible for the SWS variability in China.

In East Asia, changes in the large-scale circulation pattern are mainly represented by changes in the East Asian Monsoon (EAM) system, which includes the East Asian Summer Monsoon (EASM) and the East Asian Winter Monsoon (EAWM). Some studies have documented decreasing trends in the EASM and EAWM over the past 50 years $(\mathrm{Li}$ and Zeng 2002; Zhu et al. 2012; Ding et al. 2008, 2014; Wang and Chen 2014; Wang 2014). Because China is located in the EAM region, the effects of the EAM on the SWS over China have been examined. Xu et al. (2006b) documented a depression in the activity of the EASM due to a decrease in the latitudinal temperature gradient resulting from temperature decreases over central South China and increases over the South China Sea and the western North Pacific Ocean in boreal summer. Hence, Xu et al. (2006b) attributed the reduction in SWS over China from 1969 to 2000 to the steady decline in the EAM. The ECP region is significantly affected by the EAM (Xu et al. 2006b); therefore, if the changes in the SWS are mainly controlled by the EAM, the correlation between the EAM and the SWS should be more significant in the ECP region than in other regions. A weak decreasing (increasing) trend of EASM (EAWM) from 1981 to 2011 is shown in Fig. 16a, b. However, the summer and winter decreases in SWS are significant in the ECP region, and the inter-decadal changes in the normalized winter and summer SWS values are not consistent with those of the normalized EASM and EAWM indexes (Fig. 16b, d) (Wu et al. 2016). Furthermore, a composite analysis yields an SWS difference of $0.017 \mathrm{~m} \mathrm{~s}^{-1}$ in summer between strong and weak EASM years and an SWS difference of $-0.008 \mathrm{~m} \mathrm{~s}^{-1}$ in winter between strong and weak EAWM years, neither of which
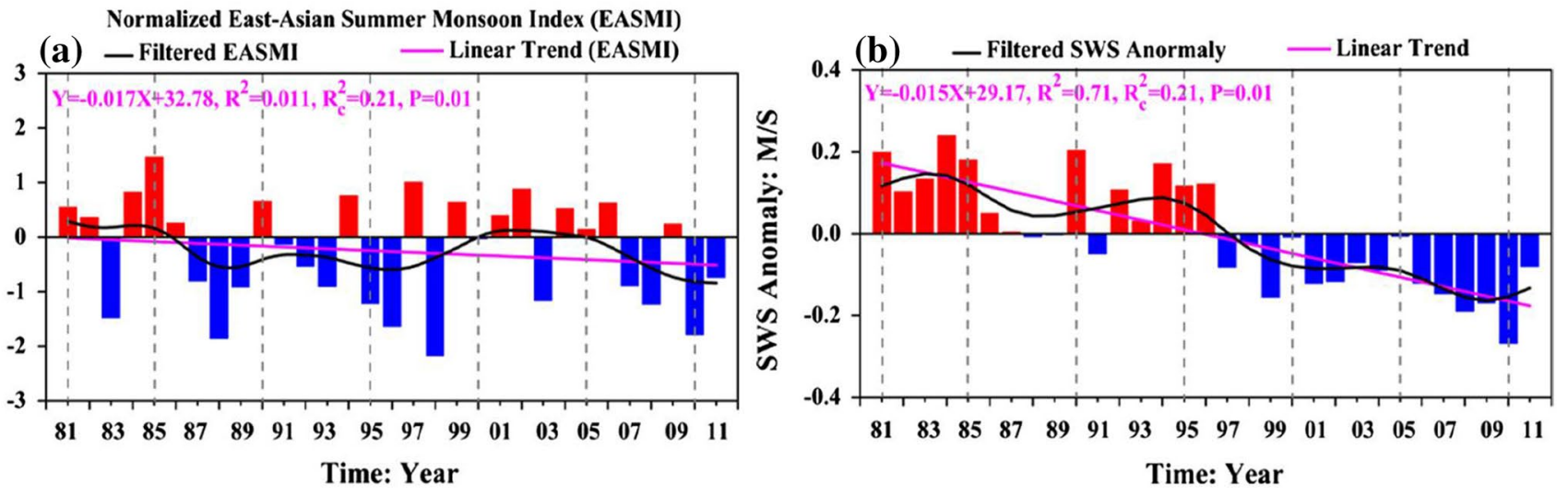

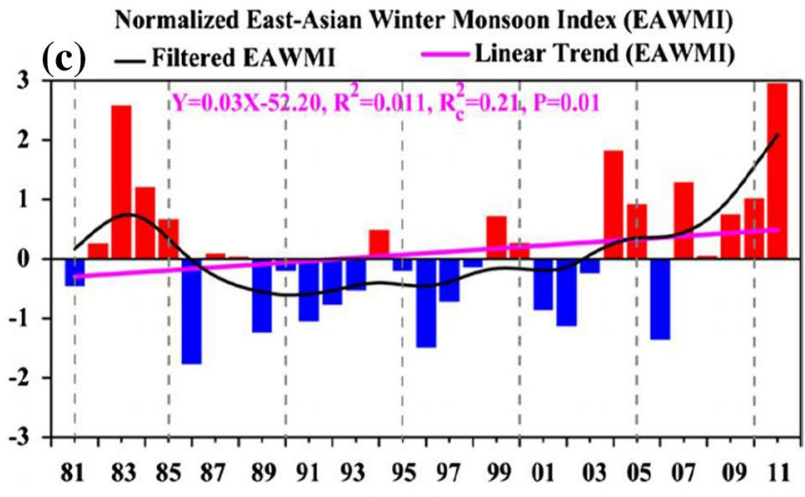

Time: Year

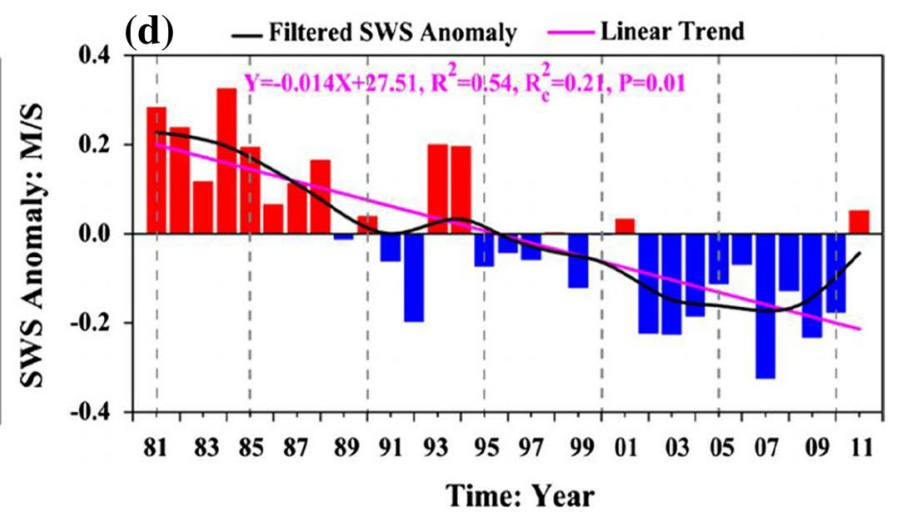

$\mathrm{Rc}$ is the threshold, $\mathrm{P}$ is the significance level, the black lines denote a 9-year low-pass-filtered time series with a Gaussian-type filter, and the pink solid lines denote the linear trend). (Copied from Wu et al. (2016))
Fig. 16 a Temporal changes in the East Asian Summer Monsoon index; b observed wind speed during summer in ECP region, China (unit: $\mathrm{m} \mathrm{s}^{-1}$ ); $\mathbf{c}$ same as a, but for the East Asian Winter Monsoon index; $\mathbf{d}$ same as $\mathbf{b}$, but for winter ( $\mathrm{R}$ is the correlation coefficient, 
are significant at the 0.10 level (Wu et al. 2016). Therefore, long-term changes in the EAM system are not a predominant factor in controlling the observed decrease in SWS in the ECP region. In addition, SWS decreases have also been found in regions with little influence from the EAM system, such as the TP and some deserts in western China (Table 2). Furthermore, South Korea is also affected by the EAM system, but the SWS over South Korea has increased since 2000 (Kim and Paik 2015). These results indicate that the actual influence of the circulation changes in East Asia on the longterm changes in SWS remain unclear.

Changes in circulation patterns can alter the PGF, which can directly alter the SWS, so some studies have also examined the correlation between the SWS and the PGF. Tuller (2004) found a correlation between long-term decreases in SWS and PGF at most stations in western Canada's inshore regions. A close correlation between the monthly average SWS and PGF in the United States has also been documented (Klink 1999a). Based on calculations, approximately $22-47 \%$ of the changes in the monthly mean SWS have been induced by changes in the longitudinal PGF in Minnesota (Klink 2007), and $40 \%$ of the changes in the average SWS have been induced by changes in the PGF in Colorado (Clifton and Lundquist 2012). In China, a correlation between a decrease in SWS and changes in latitudinal PGF was also found on the TP from 1980 to 2005 (You et al. 2010; Lin et al. 2013). To examine the changes in PGF, Guo et al. (2011) calculated the geostrophic wind (Vg) at $850 \mathrm{hPa}$ from 1969 to 2005 . They used the PGF at $850 \mathrm{hPa}$ as a proxy for the near-surface PGF and used Vg values to describe the PGF because Vg is directly related to the PGF. Their results show that the strongest decrease in Vg in spring has occurred over northern China from southern Xinjiang to Inner Mongolia and east-central China. These regions are also where the strongest decreases in SWS were observed in 1969-1990 (Fig. 17a, e). At the same time, the weakening in the wind speed decrease during spring from 1991 to 2005 coincided with an increase in the $\mathrm{Vg}$ during spring in northeastern China (Fig. 17b, f). In summer, the spatial distribution of SWS was consistent with that of $\mathrm{Vg}$ (Fig. 17); therefore, Guo et al. (2011) argued that the decrease in the observed SWS in recent decades is mainly attributable to changes in the lower-tropospheric PGF. To investigate the actual influences of PGF on SWS, Wu et al. (2017) compared the wind speeds near the surface, at $925 \mathrm{hPa}$, and at $850 \mathrm{hPa}$ over the ECP region and found different spatio-temporal characteristics at different heights. The authors also found inconsistent spatial characteristics of the wind speed variances at these levels: much greater variance was observed in the SWS data than in the 925 and $850 \mathrm{hPa}$ data (Wu et al. 2017). They compared the PGF values at these three levels and found that the PGF has increased significantly at the near-surface level (corresponding to a significant decrease in observed SWS values) and that the PGF has increased slightly at 925 and $850 \mathrm{hPa}$ (Fig. 18). However, the differences in the observed SWS values between years with stronger and weaker PGF conditions are not statistically significant, whereas the differences in the wind speeds at 925 and $850 \mathrm{hPa}$ between years with stronger and weaker PGF conditions are statistically significant $(\mathrm{Wu}$ et al. 2017). These results suggest that the effects of PGF on the SWS include distinctly regional differences and that the changes in SWS cannot be explained by changes in the PGF everywhere. Furthermore, changes in the PGF at high levels do not explain the observed long-term decrease in SWS in the ECP region.

If the changes in terrestrial SWS are mainly determined by the driving force, SWS decreases should be observable over both land and ocean. However, SWSs over oceans around the globe have shown no significant decreasing trends in recent decades, whereas the SWSs over land have decreased at a rate of $-0.087 \mathrm{~m} \mathrm{~s}^{-1}$ decade $^{-1}$ (Fig. 19) (Tobin et al. 2014; Dunn et al. 2016). In addition, reanalysis data has been used to successfully identify the main signals in large-scale circulation patterns (Kalnay et al. 1996; Simmons et al. 2010, 2014; Dee et al. 2011); therefore, the longterm slowdown in terrestrial SWS, if primarily caused by changes in large-scale circulation patterns, should be evident in the reanalysis data. However, Vautard et al. (2010) found that the NCEP-NCAR data does not exhibit any decreasing trend in the terrestrial SWS and that the recent ERAInterim reanalysis yields downward trends with magnitudes between 10\% (for North America) and 50\% (for Europe) of the observed magnitudes over the past two decades (Fig. 20). Therefore, the decreasing trends in the reanalysis data are significantly weaker than those of the observations. Furthermore, Zha et al. (2017a) made a thorough comparison of the long-term changes in the ERA-Interim and observed SWS datasets for China. They found that the two wind speed datasets exhibit consistent annual and seasonal changes over China but that the changes in the ERA-Interim dataset were greater than the changes in the observed SWS dataset. Additionally, a significant decrease over the past 30 years was detected in the observed SWS data, but no similar trend was observed in the ERA-Interim wind speed data. In addition, the observed SWS values differ greatly between large and small cities, with an average difference of $0.33 \mathrm{~m} \mathrm{~s}^{-1}$; however, the SWS differences between large and small cities in the ERA-Interim dataset are not significant (Zha et al. 2017a). These results indicate that large-scale circulation patterns may control the seasonal and annual changes in SWS but are likely not the only factor influencing the conspicuous long-term decline in the SWS. 

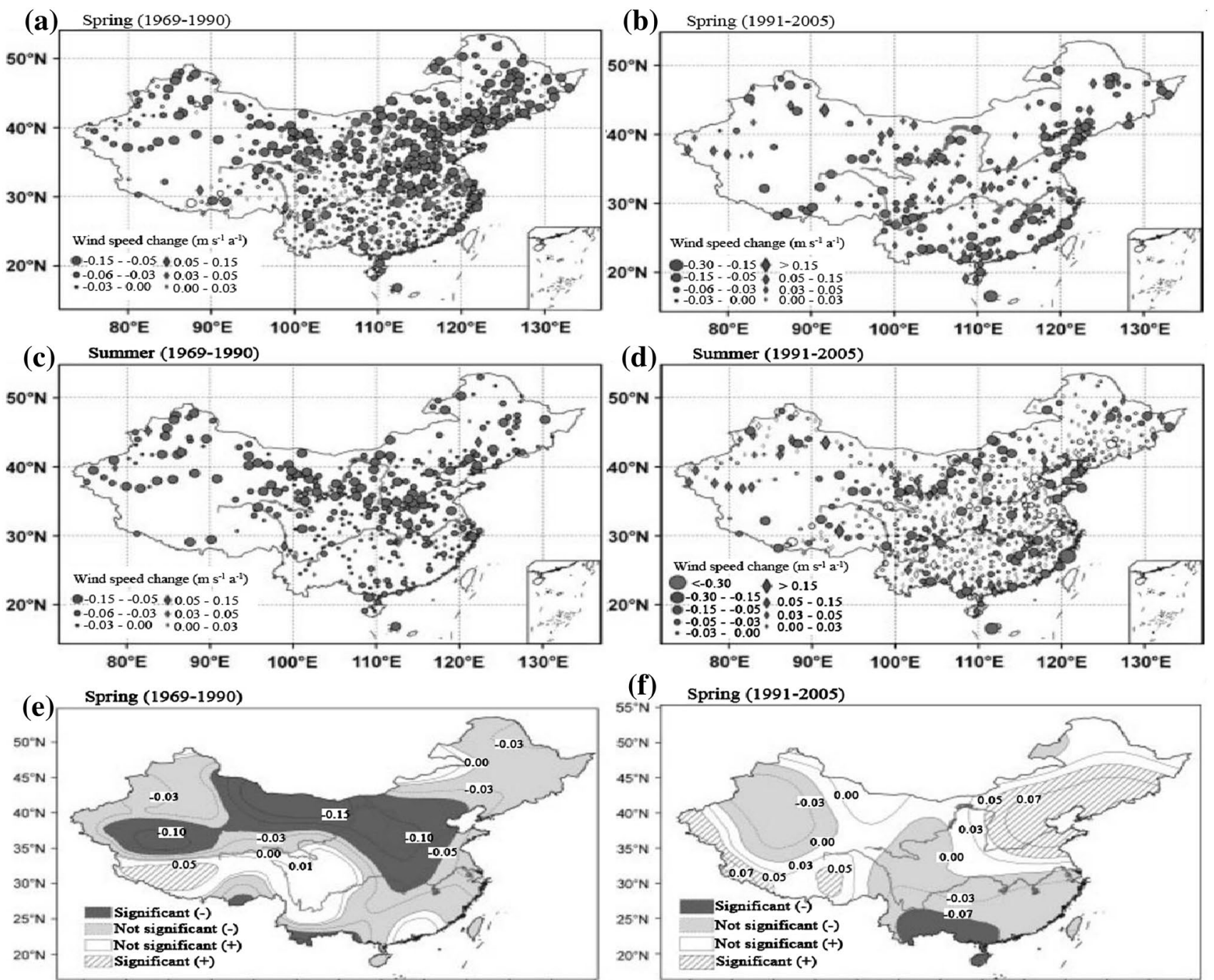

(g) ${ }^{75^{\circ} \mathrm{E}} 80^{\circ} \mathrm{E} 85^{\circ} \mathrm{E} 90^{\circ} \mathrm{E}$ S5

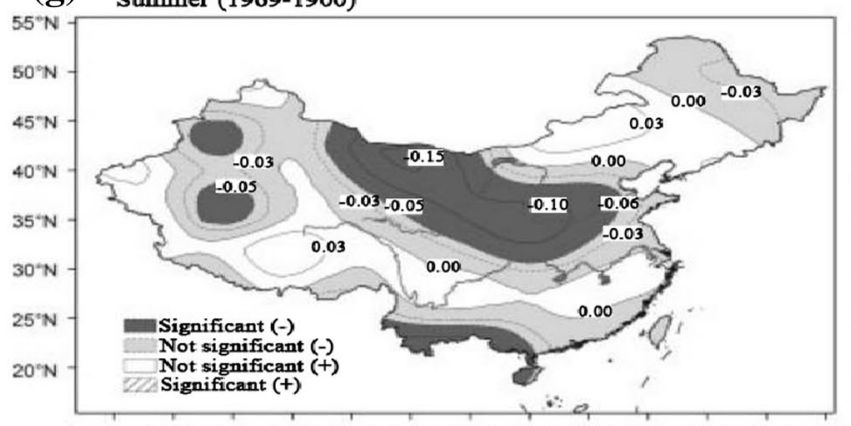

(h)

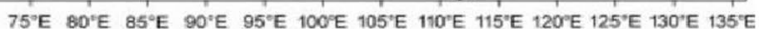

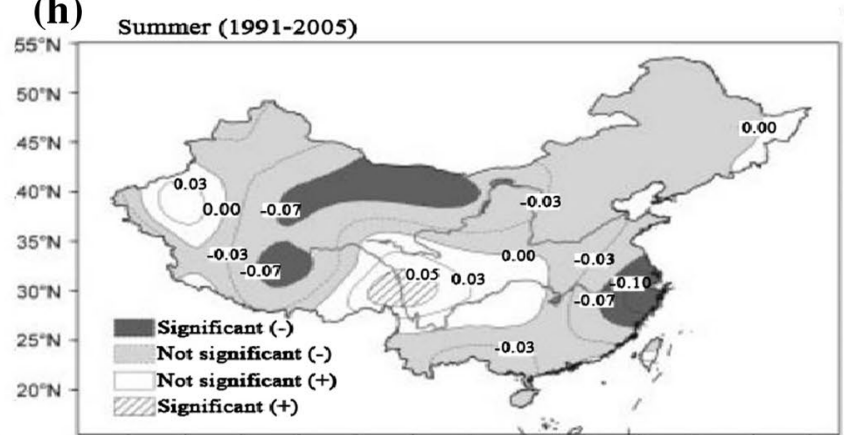

$75^{\circ} \mathrm{E}$ 80 $\mathrm{E} 85^{\circ} \mathrm{E} 90^{\circ} \mathrm{E} 95^{\circ} \mathrm{E} 100^{\circ} \mathrm{E} 105^{\circ} \mathrm{E} 110^{\circ} \mathrm{E} 115^{\circ} \mathrm{E} 120^{\circ} \mathrm{E} 125^{\circ} \mathrm{E} 130^{\circ} \mathrm{E} 135^{\circ} \mathrm{E}$

Fig. 17 Trends of seasonal mean wind speed changes at stations in China for a spring of 1969-1990, b spring of 1991-2005, c summer of 1969-1990 and d summer of 1991-2005 (unit: $\mathrm{m} \mathrm{s}^{-1} \mathrm{a}^{-1}$ ). Filled circles or diamonds show trends significant at the $95 \%$ confidence level. Trends of seasonal mean geostrophic wind speed change for e spring of 1969-1990, f spring of 1991-2005, g summer of 1969-

1990 and h summer of 1991-2005 (unit: $\mathrm{m} \mathrm{s}^{-1} \mathrm{a}^{-1}$ ). Shading indicates decreasing wind speed, and darker shading indicates decrease significant at the 95\% confidence level. Blank indicates increasing wind speed, and stippled areas have increasing wind speed significant at the 95\% confidence level. (Modified from Guo et al. (2011)) 


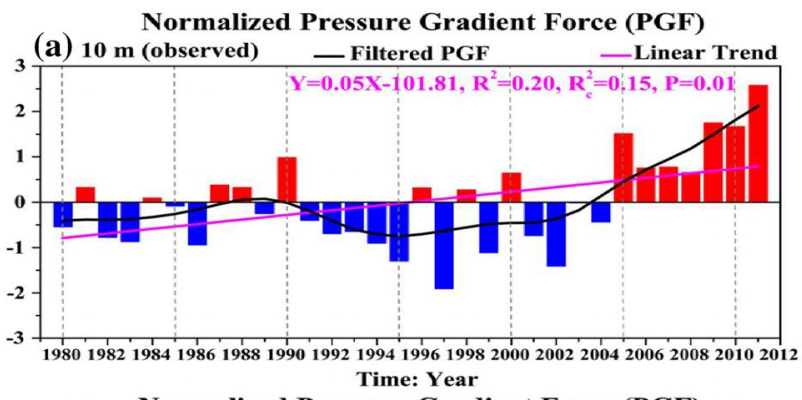

Normalized Pressure Gradient Force (PGF)

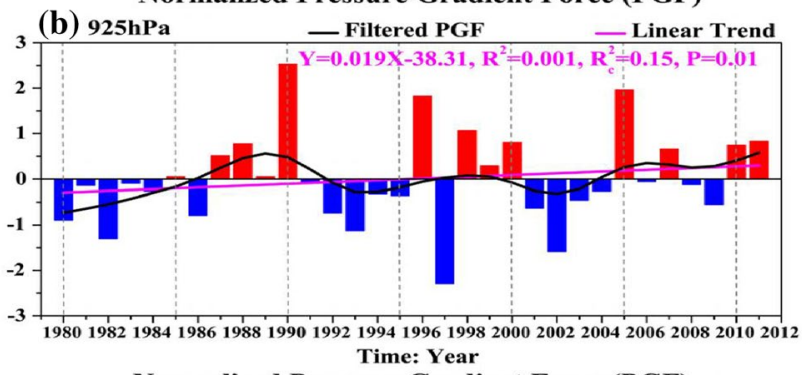

Normalized Pressure Gradient Force (PGF)

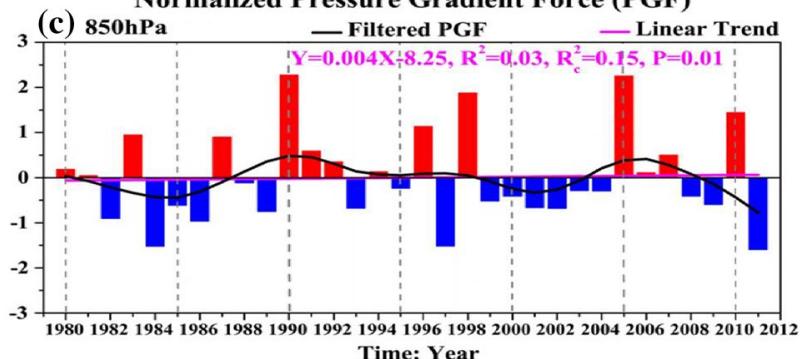

Time: Year

Fig. 18 Temporal changes in the normalized pressure-gradient force in ECP region, China during the period 1980-2011 at the near-surface (a), 925 (b), and $850 \mathrm{hPa}$ levels (c), respectively. The black solid lines denote a 9-year low-pass-filtered time series with a Gaussiantype filter, and the pink solid lines denote the linear trend of a normalized PGF ( $\mathrm{R}$ is the correlation coefficient, $\mathrm{Rc}$ is the threshold, and $\mathrm{P}$ is the $99 \%$ significance level). (Copied from Wu et al. (2017))

\subsection{Effects of changes in the drag force on the terrestrial SWS}

As mentioned above, the driving force $\vec{G}$ is not the only factor affecting terrestrial SWS, so changes in other factors should be important to the reduction of SWS. In contrast to the driving force, the drag force $\vec{f}$ in Eq. (1) should greatly influence the SWS, and some studies have focused on the effects of the drag force on changes in SWS. In fact, the effects of drag force include the surface drag force (also known as external friction effects (EFEs)) and internal friction effects (IFEs). The EFEs are mainly attributed to changes in the surface roughness due to LUCC or urbanization. The IFEs are mainly attributed to changes in the boundary layer conditions, including changes in the static stability, vertical wind shear, vertical momentum transport, and local circulation, and such changes can be induced by some anthropogenic activities.

\subsubsection{Effects of the surface drag force on terrestrial SWS}

As discussed above, SWS decreases have been observed over various landmasses in recent decades, whereas SWS increases have been observed over oceans (McVicar et al. 2013; Tobin et al. 2014; Berrisford et al. 2015; Dunn et al. 2016). This discrepancy may be proof of the effects of LUCC on SWS (Vautard et al. 2010, 2012; Peterson et al. 2011; Bichet et al. 2012). Vautard et al. (2010) proposed that a $25-60 \%$ reduction in the terrestrial SWS can be explained by an increase in the surface roughness in the Northern Hemisphere. Wever (2012) found that the increase in surface roughness in Europe could explain 70\% of the decrease in the SWS from 1981 to 2009. No regular observations of surface roughness or the surface drag force exist, so quantifying the contribution of the drag force to the observed reduction in the SWS is difficult. In previous studies, researchers have used various methods to examine the effects of drag force on the long-term decrease in the terrestrial SWS.

\subsubsection{A comparison of rural and urban SWSs A com-} parison of rural and urban SWSs via the CRU method has been conducted to investigate the effects of LUCC, especially urbanization. In recent decades, urbanization has become one of the main types of LUCC in the context of economic development in some regions (Klaic et al. 2002; Zhou et al. 2004; Liu et al. 2014b). Klaic et al. (2002) noted that in Zagreb, the capital of Croatia, increases in urban area of $12.5 \%$ and $37.5 \%$ have resulted in decreases in the SWS by $8 \%$ and $18 \%$, respectively. Dadaser-Celik and Cengiz (2014) classified 206 stations in Turkey as either urban stations (14 stations) or rural stations (192 stations) based on the nearby population. The average wind speeds for both urban and rural stations show negative trends, with mean decreasing rates of -0.09 and $-0.16 \mathrm{~m} \mathrm{~s}^{-1}$ decade $^{-1}$, respectively. Although the average trend at urban stations is slightly smaller than that at rural stations, the authors argued that urbanization is a factor influencing the SWS decrease in Turkey because western regions in Turkey experienced rapid urbanization, which probably caused some changes in SWS from 1975 to 2006 . Over the last 30 years, the gross domestic product of China has increased at an average annual rate of $9.5 \%$, compared to $2.5 \%$ for developed countries and $5 \%$ for developing countries around the world (Zhou et al. 2004). During this period, extreme LUCC has occurred in China, including the loss of farmland and the expansion of urban areas (Liu and Tian 2010; Liu et al. 2014b). Additionally, Liu and Tian (2010) revealed that China has lost more than $10 \%$ of its cropland and that its total urban area has expanded by more than $20 \%$. Consequently, the influence of urbanization on SWS in China should be distinct. A comparison of SWS in 30 large and 275 small cities in 

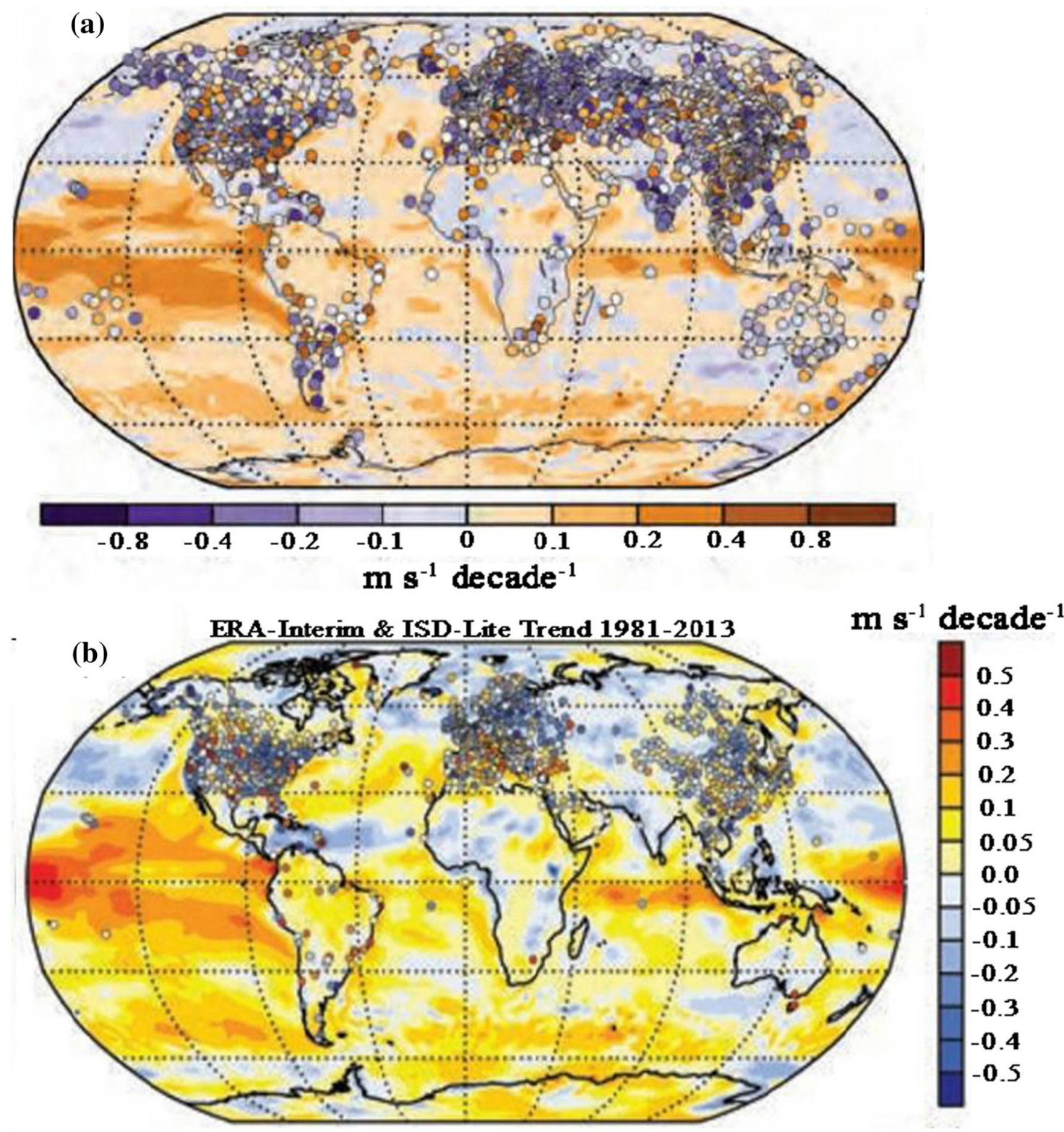

Fig. 19 Land surface wind speed trends for the observational Hadley Centre Integrated Surface Database (HadISD) and Australian datasets (points) and the ERA-Interim reanalysis (worldwide grids) over a 1979-2015 period and b 1981-2013 period (a copied from Dunn et al. (2016), and b copied from Tobin et al. (2014))
China indicates that the SWS has declined in both, with rates of -0.2 and $-0.18 \mathrm{~m} \mathrm{~s}^{-1}$ decade $^{-1}$, respectively (Xu et al. 2006b). Another SWS comparison between 174 urban and 180 rural stations, including some small-town stations, suggests that the urban SWS is significantly lower than the rural SWS and that urban and rural SWSs are decreasing at rates of -0.13 and $-0.12 \mathrm{~m} \mathrm{~s}^{-1}$ decade $^{-1}$, respectively (Jiang et al. 2010). Li et al. (2011) reported that a decreasing trend of $-0.05 \mathrm{~m} \mathrm{~s}^{-1}$ decade $^{-1}$ has been induced by LUCC in Beijing and that the magnitude of the decreasing SWS trend is highest at urban stations, second highest at suburban stations, and lowest at rural stations. A similar comparison was performed by Guo et al. (2011), who found the decreasing trends prior to 1990 to be -0.31 and $-0.28 \mathrm{~m} \mathrm{~s}^{-1} \mathrm{dec}-$ $\mathrm{ade}^{-1}$ at urban and rural stations, respectively. After 1990, these decreasing trends changed to $-0.06 \mathrm{~m} \mathrm{~s}^{-1}$ decade $^{-1}$ at urban stations and $-0.04 \mathrm{~m} \mathrm{~s}^{-1}$ decade $^{-1}$ at rural stations (Fig. 21a). A comparison of long-term changes in SWS in 136 large and 240 small cities in China from 1979 to 2010 revealed a decrease of $0.47 \mathrm{~m} \mathrm{~s}^{-1}$ in the SWS due to the 


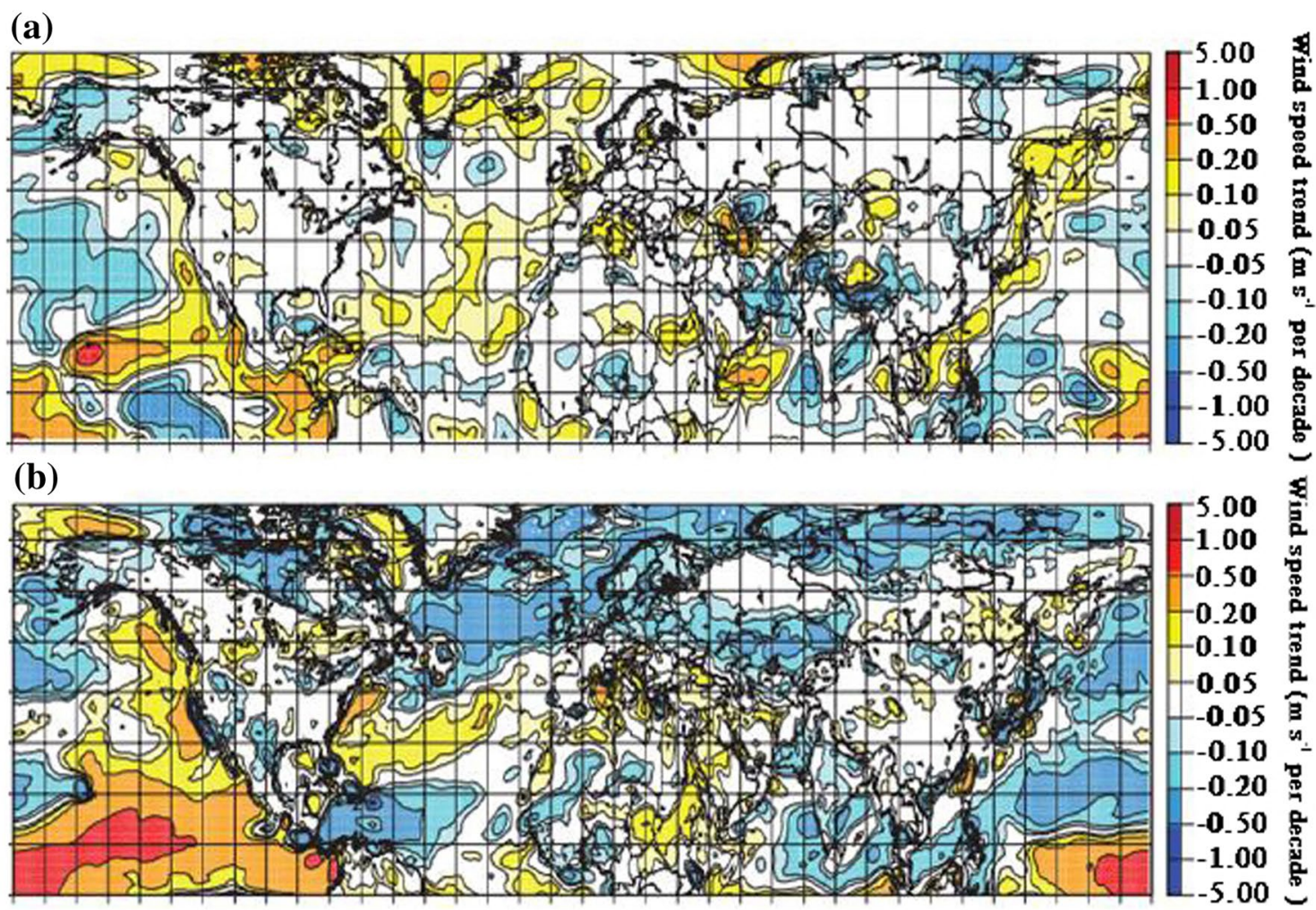

Fig. 20 a NCEP-NCAR reanalyses trends calculated using mean daily $10 \mathrm{~m}$ wind speed values available over a grid of $193 \times 47$ grid points over the Northern Hemisphere. $\mathbf{b}$ is same as in a but for ERA-

increase in surface roughness associated with LUCC over the past 30 years (Zha et al. 2017a). In addition, Zha et al. (2017a) also reported that LUCC is becoming more distinct in small cities. Consequently, changes in the SWS due to LUCC in large cities, as evaluated by the CRU method, may include the effects of neglected LUCC in small cities. Therefore, a revised CRU method has been proposed and involves a comparison of adjacent large and small cities at distances of less than $1^{\circ}$ in latitude and longitude. The results of this proposed method show that the mean SWS difference between adjacent small and large cities in China from 1979 to 2010 was $-0.55 \mathrm{~m} \mathrm{~s}^{-1}$ (Fig. 21b) (Zha et al. 2017a).

\subsubsection{Establishing a reference SWS dataset with-} out LUCC effects Another possible method used to study the effects of LUCC on SWS is the establishment of a reference SWS dataset without LUCC effects. In this method, the impacts of LUCC on the SWS can be taken as the difference between the observed data and the reference data. Some previous studies revealed that the reanalysis data include good long-term natural climate change signals as well as some important anthropogenic signals but that these reanalysis data are not sensitive to LUCC (Kalnay and Cai 2003; interim reanalyses trends calculated over the past 20 years alone. (Modified from Vautard et al. (2010))

Zhou et al. 2004; Frauenfeld et al. 2005; Li et al. 2008). Therefore, some researchers have estimated the impacts of urbanization and other land use changes on climate change by comparing the results of the observation minus reanalysis (OMR) method. Kalnay and Cai (2003) first employed the OMR method to quantify the effects of urbanization and other land uses on surface warming in order to effectively obtain a quantitative estimate of the anthropogenic impacts of LUCC/urbanization on climate changes. Furthermore, the OMR method has also been used to evaluate the influences of LUCC on SWS. Li et al. (2008) used the OMR method to evaluate the contribution from LUCC to decreases in the wind energy density in China, and the results showed that the observed SWS has significantly weakened and that the near-surface wind power has decreased due to urbanization and other types of LUCC over the last 40 years. Anthropogenic LUCC has caused the mean wind energy to decrease by $-3.84 \mathrm{~W} \mathrm{~m}^{-2} \mathrm{decade}^{-1}$, which is close to the magnitude of the decreasing trend due to the combined effects of natural and human impacts $\left(-4.51 \mathrm{~W} \mathrm{~m}^{-2}\right.$ decade $\left.^{-1}\right)$. Zha et al. (2017a) used the OMR method to estimate the effects of LUCC on SWS and found that LUCC can cause a decreasing trend of $-0.12 \mathrm{~m} \mathrm{~s}^{-1}$ decade $^{-1}$ in SWS, possibly accounting for portions of the -0.57 and $-0.30 \mathrm{~m} \mathrm{~s}^{-1}$ decreases in the 

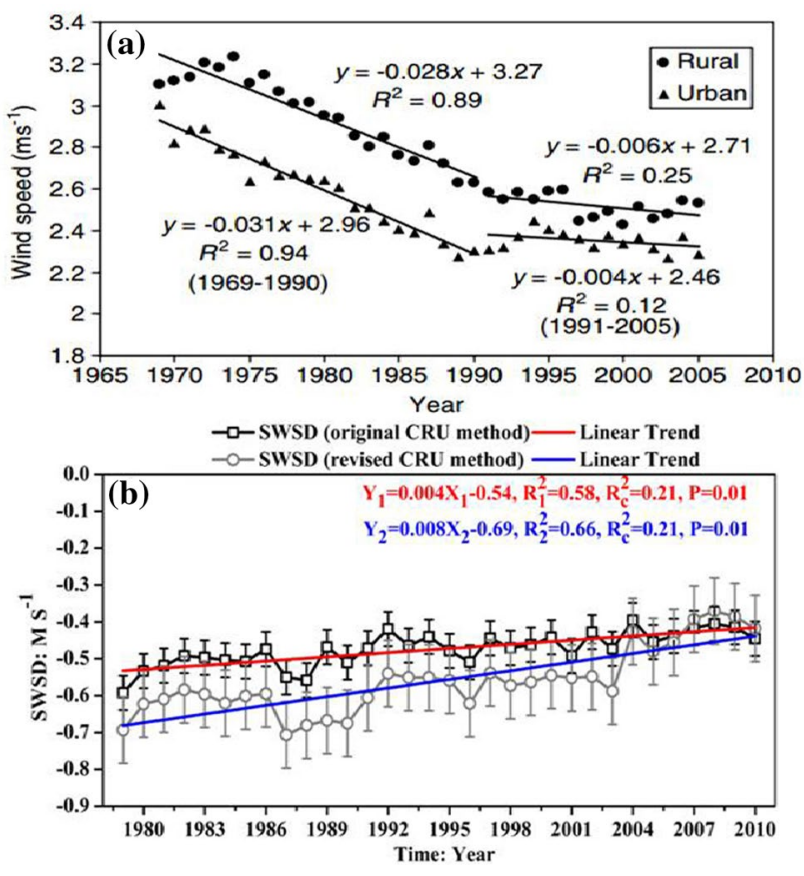

Fig. 21 a Variations of wind speed averaged over rural and large urban stations in China for 1969-2005. The rates of wind decrease and their $\mathrm{R}^{2}$ values are shown in the margin. $\mathbf{b}$ Temporal changes in the annual SWS difference (SWSD) based on the CRU method in China from 1979 to 2010. ( $\mathrm{R}$ is the correlation coefficient, $\mathrm{Rc}$ is the threshold, and P represents the significance level. SWSD denotes the SWS in a large city minus that in a small city) (a copied from Guo et al. (2011); b copied from Zha et al. (2017a))

SWSs in large and small cities, respectively. In addition, the impacts of LUCC on SWS in the Beijing-Tianjin-Tangshan region (BTTR; with a decrease of $-0.95 \mathrm{~m} \mathrm{~s}^{-1}$ ), Yangtze River Delta region (YRDR; with a decrease of $-0.73 \mathrm{~m}$ $\mathrm{s}^{-1}$ ), and Pearl River Delta region (PRDR; with a decrease of $-1.26 \mathrm{~m} \mathrm{~s}^{-1}$ ) are more significant than those in China overall over the past 30 years. These three regions in China are economically developed, and their urban areas and populations are much larger than those in other regions in China (Liu et al. 2013). In addition, Zha et al. (2017a) also discussed the uncertainty of the OMR method and concluded that an error of $0.01 \mathrm{~m} \mathrm{~s}^{-1}$ decade $^{-1}$ should be included in the results of the OMR method. This error represents only $9.1 \%$ of the SWS decreasing rate of $-0.11 \mathrm{~m} \mathrm{~s}^{-1}$ decade $^{-1}$. However, different assimilation schemes, assimilation datasets, and data resolutions can influence the quality of the reanalysis data, and these deficiencies can also contribute to discrepancies between the observational and reanalysis datasets. Hence, this error in the OMR method may originate in the initial bias of the reanalysis data and could be mistaken for the effects of LUCC. Consequently, the OMR method has been improved by the use of a statistical downscaling method (SDM) to calibrate the ERA-Interim rea- nalysis data before its application to the OMR method. This enhanced OMR method, known as the SDM-OMR method, yields an SWS decreasing rate of $-0.17 \mathrm{~m} \mathrm{~s}^{-1}$ decade $^{-1}$ in the ECP region in China (Wu et al. 2017).

The CRU and OMR methods are simple statistical methods that cannot identify the physical mechanism of the effects of LUCC on long-term changes in SWS. Therefore, a dynamical method known as the frictional wind model (FWM) has been used in a recent study to quantify the influences of LUCC on terrestrial SWS, and balanced amounts of the PGF $\vec{G}$, the Coriolis force $\vec{F}$, and the drag force $\vec{f}$ were determined (Wu et al. 2016). The authors of that study used the FWM to successfully distinguish between the individual effects of the PGF and the drag force on the SWS. The results showed that the PGF is not the predominant factor affecting the long-term decrease in SWS over the ECP region and that the observed reduction in SWS is better explained by the long-term and significant rise in the drag coefficient from 1979 to 2010. Also using the FWM, Zha et al. (2016) found that LUCC causes the probability density function curve for the observed SWS to be higher and narrower than that for the model wind speed (which only includes the effects of PGF). In addition, the probability of wind speeds greater than $3.8 \mathrm{~m} \mathrm{~s}^{-1}$ is only $1.8 \%$ when LUCC effects are included but is $20.6 \%$ when the LUCC effects are excluded. Such pronounced differences indicate that LUCC has significant impacts on the terrestrial SWS.

While the CRU, OMR, SDM-OMR, and FWM methods have been used to evaluate the effects of LUCC on the terrestrial SWS, their results have been very different due to the use of different approaches. These methods were compared for the ECP region in China, and the results are as follows: First, researchers using the OMR method reported the largest LUCC-induced SWS difference (SWSD), which was twice as large as the SDM-OMR SWSD. Second, the most rapid decrease in SWS was obtained using the FWM method, and this decrease was more than twice as large as the decreases obtained using the SDM-OMR and OMR methods. Lastly, the patterns and values of the linear trends in the OMR and SDM-OMR methods were found to be very similar $(\mathrm{Wu}$ et al. 2017).

3.2.1.3 The advantages and disadvantages of different methods The advantages and disadvantages of the CRU, OMR, SDM-OMR, and FWM methods can be summarized as follows:

1. The CRU method is widely adaptable to any region and can capture differences in the SWSs in different-sized cities, but this method suffers from great uncertainty in the selection of stations used in the comparison. In addition, this method cannot determine the effects of LUCC on the SWS in small cities or rural stations because no 
reference standard exists. The CRU method is also a statistical method, so it cannot supply a physical mechanism for the reduction in SWS.

2. The OMR method has broader applications than the CRU method because it can determine the effects of LUCC on the SWS in small cities or rural stations. With the recent enhancements made to numerous types of reanalysis data, the results of the OMR method should be more reliable than in the past. Despite the increasing quality of reanalysis data, errors from different sources in the reanalysis data remain unavoidable, and this error can be falsely attributed to LUCC. In addition, the OMR method is difficult to use to evaluate the small-scale influences of LUCC due to the coarse resolution of reanalysis data.

3. The SDM-OMR method can produce much more reliable results compared to the OMR method due to the reduction of the errors in the reanalysis data when using an SDM. Consequently, the evaluation results of this method depend on the choice of SDM and the length of the period used to establish correlations between the reanalysis and observation data. Therefore, different SDMs may produce different results for the same region.

4. The FWM method is a simple dynamical method that can quantitatively separate the effects of the PGF and the drag force and supply a physical mechanism for the observed reductions in SWS. However, the FWM method is difficult to use in regions with complex terrain and ignores the effects of turbulent fluxes and horizontal advection, as well as the temporal change term in various equations. These factors can also affect the SWS. The effects of the drag force on SWS should be derived using different methods, which have their own disadvantages. Hence, the influence of the drag force remains uncertain.

3.2.1.4 Numerical simulation studies Some numerical simulations also discovered that an increase in surface roughness can cause a significant slowdown in terrestrial SWS. Bichet et al. (2012) used a GCM (ECHAM5) that was coupled to the fully interactive Hamburg Aerosol Module (HAM) to simulate the influences of surface roughness on SWS at the global scale. The results showed that global increases in the vegetation roughness length by factors of 1.5, 2 and 4 in the ECHAM5-HAM model decrease the global terrestrial SWS by averages of -0.15 , -0.26 and $-0.55 \mathrm{~m} \mathrm{~s}^{-1}$, respectively (Fig. 1b). Zhang et al. (2010) used the Weather Research and Forecasting (WRF) regional climate model to simulate the impacts of the urbanization-induced changes in surface roughness on SWS in China and found that the friction and drag of buildings can decrease the SWS in high-density urban areas by as much as $1.5 \mathrm{~m} \mathrm{~s}^{-1}$. Compared with suburban regions, the increase in surface roughness induced by urban expansion can cause a 50\% wind speed decrease in the YRDR, China. Similar results were also reported by Wang et al. (2013), who used the same model in the same region and found that the building-induced friction leads to decreases in the SWS. The SWS over urban areas has decreased by approximately $1.2-1.5 \mathrm{~m} \mathrm{~s}^{-1}$ in the YRDR, and these values are similar to the results of Zha et al. (2017a). In addition, Zhang et al. (2016a) also used the WRF model to simulate the effects of urbanization on the SWS in the PRDR and found that urbanization can increase the surface roughness and reduce the SWS. The SWS differences between the urban and nonurban areas reach $-0.27 \mathrm{~m} \mathrm{~s}^{-1}$, and the maximum wind speed has decreased by $1.13 \mathrm{~m} \mathrm{~s}^{-1}$ due to the increase in the surface roughness. Hou et al. (2013) also used the WRF model to simulate the effects of urbanization on the SWS in the greater Beijing metropolitan area, China. Their results suggested that a $20 \%$ increase in urbanized land can cause a 7-16\% decrease in SWS. During the period 1961-2008, the proportion of urbanized land in the greater Beijing metropolitan area increased from 1.3 to $11.9 \%$ and caused a $0.4 \mathrm{~m} \mathrm{~s}^{-1}$ reduction in regional mean SWS, accounting for approximately 35\% of the SWS decrease (Hou et al. 2013).

As mentioned above, the effects of LUCC and urbanization on SWS are significant at the global and regional scales because an increase in surface roughness results in a decrease in the SWS. However, no regular observations of surface roughness or surface drag force exist, so quantifying the contribution from drag force to the observed reduction in the SWS is difficult. In addition, the uncertainty in the estimation of the effects of LUCC on SWS is high because the various methods include various limitations.

\subsubsection{Effects of changes in boundary layer characteristics on terrestrial SWS}

Some previous studies have shown that an increase in the surface drag force can significantly affect the SWS, but Bichet et al. (2012) found that increases in the surface roughness are not able to explain the observed decreases in SWS in all regions. Other forcing mechanisms, such as changes in atmospheric aerosol (AA) emissions and greenhouse gas (GHG) concentrations, may therefore also play a role. Changes in these factors can alter the boundary layer characteristics, which can in turn affect the atmospheric stability and the SWS (Ramanathan et al. 2005; Bichet et al. 2012; Zhang et al. 2016b; Li et al. 2016). The absorbing and scattering properties of aerosol particles are known to increase atmospheric stability by reducing the amount of solar radiation reaching the ground, and an increase in the atmospheric stability due to aerosols can reduce vertical turbulent exchange, thereby reducing the vertical flux 

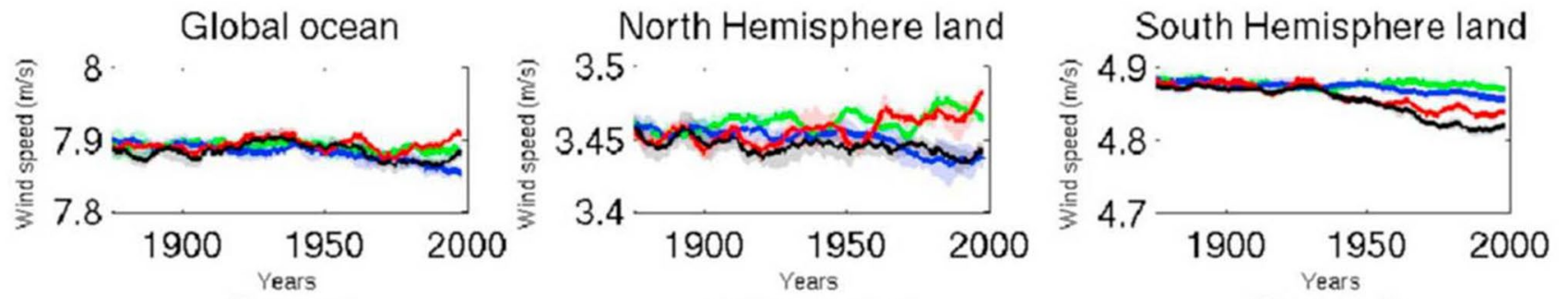

Europe

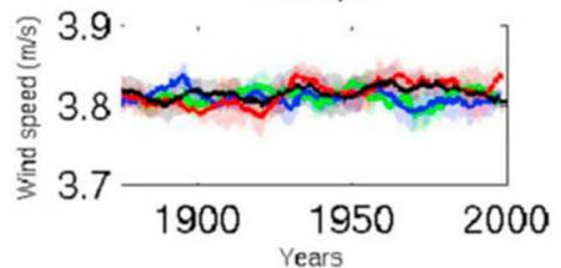

Central Asia
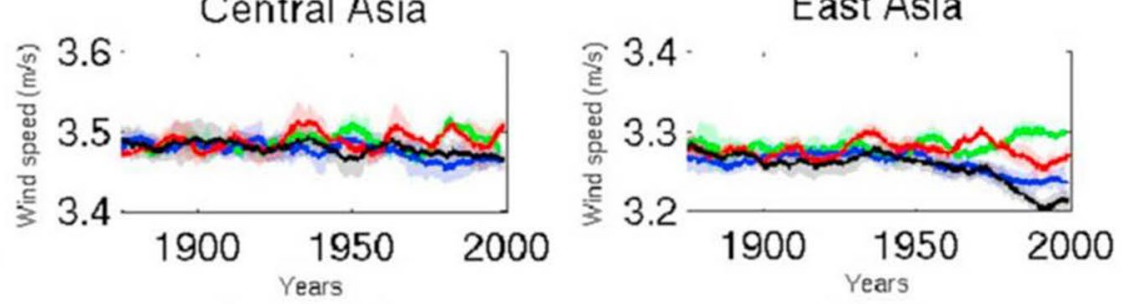

North America

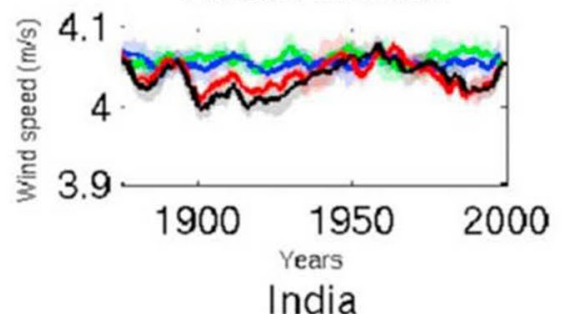

South Asia

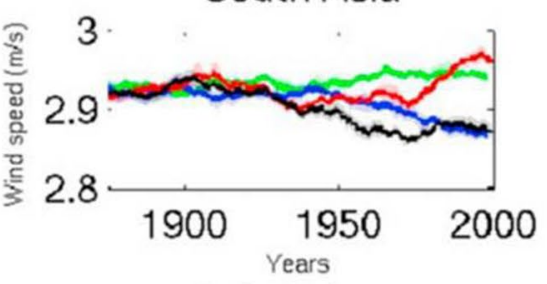

China

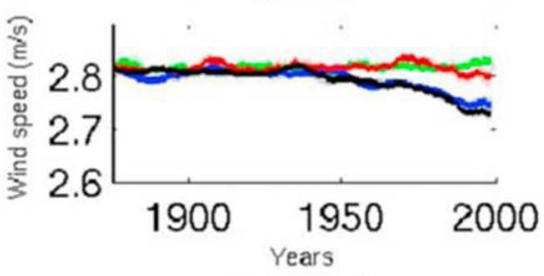

Sub-Sahara
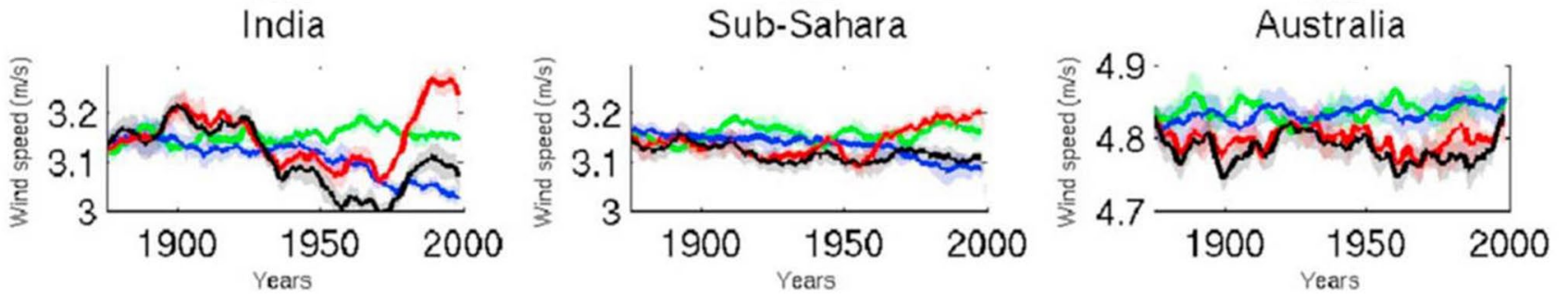

Fig. 22 Mean annual wind speed over the land portion of selected areas (unit: $\mathrm{m} \mathrm{s}^{-1}$ ), as simulated with transient solar, green-house gases, aerosol and SST forcings (black) in comparison to selected sensitivity experiments: constant aerosol emissions (red), constant

of horizontal momentum. Since winds are generally faster aloft than near the surface, reduced vertical fluxes decrease the transport of fast horizontal momentum from aloft to the surface, which reduces the SWS (Jacobson and Kaufman 2006). Zhang and Li (2016) argued that AAs can alter thermodynamic and dynamic processes in the atmosphere and that these changes can cause variability in the wind speed. Jacobson and Kaufman (2006) proposed that the emission of anthropogenic aerosol particles and precursor gases increases the aerosol optical depth and cloud optical depth, thereby decreasing near-surface air temperatures, increasing stability, reducing turbulent kinetic energy (TKE), and reducing the vertical transport of horizontal properties. Reduced TKE is associated with reduced wind speeds over land. Additionally, Jacobson and Kaufman (2006) also used the Moderate-resolution Imaging
SSTs (blue) and constant aerosol emissions and SSTs (green). The bold lines show the respective ensemble means, the shaded region the standard deviation of the simulations. (Copied from Bichet et al. (2012))

Spectroradiometer (MODIS)/NCEP datasets to analyze the influences of aerosols on the SWS over Southeast China and found that the SWS declines by $0.8 \%$ in February and $10.2 \%$ in August when MODIS aerosol optical depth increases from its lowest value to its highest value. Bichet et al. (2012) used the ECHAM5-HAM to simulate the effects of aerosols on SWS at the global scale. Based on the sensitivity experiments with varying (black curves) and constant (red curves) aerosol emissions (Fig. 22), they found that the aerosol emissions have caused wind speed reductions of $-0.13,-0.05,-0.03$, and $-0.05 \mathrm{~m} \mathrm{~s}^{-1}$ over the past 30 years in India, Sub-Saharan Africa, China and Europe, respectively. Additionally, aerosols tend to have a larger impact in summer, resulting in maximum SWS declines of -0.3 and $-0.25 \mathrm{~m} \mathrm{~s}^{-1}$ in most regions in India since 1950 and 1975, respectively. Therefore, the effects of 
aerosols on SWS are more significant in India than in other regions. Peng and Sun (2014) investigated the exchanges of momentum, heat and mass between urban surfaces and the atmosphere and revealed that complex urban surfaces can significantly impact the drag coefficient in the roughness sub-layer, resulting in a lower SWS due to the increase in the drag coefficient in the roughness sub-layer. Numerous other studies have shown that anthropogenic activities, including anthropogenic LUCC and increases in anthropogenic heat release (AHR), can also reduce the stability of the atmospheric boundary layer. Zhang et al. (2016a) suggested that both LUCC and AHR increase the potential temperature in the bottom layer of the planetary boundary layer (PBL), possibly leading to an increase in the PBL height. The increase in potential temperature in the bottom level of the PBL can destabilize the boundary layer and enhance vertical mixing, thereby increasing wind speed near the surface and decreasing it at higher altitudes.

In recent decades, one of the most important external forcing mechanisms in the climate system has been the emission of GHGs associated with anthropogenic activities. Zhang and Li (2016) showed that GHGs can alter the thermodynamic and dynamic processes of the atmosphere and that these changes can cause variability in the PBL and, consequently, the SWS. GHGs can not only alter the PBL characteristics but can also alter global- and regionalscale circulation patterns. Bichet et al. (2012) found that the atmospheric response to external forcings (i.e., increasing GHGs and total solar irradiance) is an increase in the SWS but that the effects of GHGs were relatively small after 1950 (green curves in Fig. 22). These authors noted that GHGs had only a small direct impact on the SWS in the atmosphere-only case. Zhang et al. (2016b) considered the air-sea interaction in the CMIP5 model and found that the emission of GHGs can reduce sea-surface temperatures (SSTs) in the subtropical North Pacific (SNP), which results in a decrease in the SWS in boreal winter near Taiwan. The following mechanism was proposed: (1) reduced warming in the SNP induces large-scale anomalous anti-cyclonic flow in this region; (2) during boreal winter, low-level northeasterly wind prevails over the tropical western North Pacific (WNP), and anomalous northeasterlies to the southeast of the WNP anti-cyclonic anomaly reinforce the mean wind; (3) as a result, the total wind speed is enhanced, leading to greater latent heat fluxes released from the surface and strengthening the cold SST anomalies; (4) to the northwest of the anticyclonic anomaly, the anomalous wind (southwesterly) is oriented counter to the mean wind (northeasterly), thereby reducing the SWS in Taiwan. Therefore, compared to the mean prevailing circulation, the anomalous circulation pattern associated with the emission of GHGs has a damping effect.
As mentioned above, AHR, LUCC, and emissions of AAs and GHGs can significantly affect SWS. However, the uncertainty in the effect of GHGs on SWS is high. Because GHGs affect SWS at the regional scale, it may be necessary to consider oceanic feedback and air-sea interaction. However, the mechanism by which the emission of GHGs influences the SWS at the global scale remains uncertain. Furthermore, quantifying the influences of AAs, GHGs, AHR and LUCC on changes in SWS is very difficult, and little such work has been performed in previously published studies.

The main causes of changes in SWS and their significance are summarized in Table 3. Atmospheric circulation, LUCC, and AAs can all decrease the SWS at the globalscale. In Europe, the reduction in SWS was mainly induced by the NAO, LUCC and AAs. In Asia, numerous factors have induced changes in SWS, and AAs, GHGs, and LUCC (including urbanization) have played significant roles in the SWS decline. However, quantifying the effects of different factors on SWS in Asia has been difficult due to the simultaneous involvement of multiple complex factors in this region. In general, the main difficulty in exploring the causes of SWS decrease lies in isolating and individually quantifying these causes, which should become the focus of future study.

\section{Other causes of decreased terrestrial SWS}

As mentioned above, terrestrial SWS decreases are mainly caused by reductions in the driving force and increases in the drag force. However, some studies have observed that SWS reductions can also be induced by other factors, such as those discussed below.

\subsection{Changes in observation instrument}

Wind observations are very sensitive to changes in the location of the observation site and the height of the anemometer. Changes in these factors can cause large discontinuities in the wind data series. However, such changes are often inevitable, especially in a long-term record (Wan et al. 2010). DeGaetano (1998) investigated the observational biases in hourly SWS from 41 stations in the northeastern United States and found that the wind speed biases were greater than the wind direction biases. Furthermore, the biases were also greater for the calm and light wind classes. These authors also found that abrupt decreases in light wind and abrupt increases in calm wind in the record tended to be due to instrumentation effects and systematic observation biases associated with the weather service stations in the early 1960s. Feng et al. (2004) examined daily meteorological data in China from the period 1951-2000 and discovered that the number of stations measuring wind speed 
Table 3 The main causes of the changes in the terrestrial SWS across the globe

\begin{tabular}{|c|c|c|c|c|c|}
\hline $\begin{array}{l}\text { Study } \\
\text { Number }\end{array}$ & Regions & Influence factor & Relationship & $\begin{array}{l}\text { Study } \\
\text { period }\end{array}$ & Original paper \\
\hline 1 & Northern Hemisphere & Atmospheric circulation & $\begin{array}{l}\text { Explain } 10-50 \% \text { of slowdown } \\
(-)\end{array}$ & 1979-2008 & Vautard et al. (2010) \\
\hline 2 & & LUCC & $\begin{array}{l}\text { Explain } 25-60 \% \text { of slowdown } \\
(-)\end{array}$ & 1979-2008 & Vautard et al. (2010) \\
\hline 3 & & AAs & $-0.03(-)$ & $1975-2005$ & Bichet et al. (2012) \\
\hline & Europe & & & & \\
\hline 4 & All & LUCC & $\begin{array}{l}\text { Explain } \mathbf{2 5 - 6 0 \%} \text { of variability } \\
(0.05 \text { level })\end{array}$ & $1962-2009$ & Wever (2012) \\
\hline 5 & All & AAs & - $\mathbf{0 . 0 5} \mathrm{m} \mathrm{s}^{-1}(0.20$ level $)$ & 1975-2005 & Bichet et al. (2012) \\
\hline 6 & Mediterranean and Adriatic & Air temperature & Positive correlation $(-/-)$ & $1951-1996$ & Pirazzoli and Tomasin (2003) \\
\hline 7 & Northwest & $\mathrm{AO} / \mathrm{NAO}$ & Positive correlation $(-/-)$ & $1958-1998$ & Yan et al. (2002) \\
\hline 8 & England & NAO & Positive correlation $(-/-)$ & 1980-2010 & Earl et al. (2013) \\
\hline 9 & $\begin{array}{l}\text { Iberian } \\
\text { Peninsula }\end{array}$ & NAO & $\begin{array}{l}\text { Explain 10-15\% of variability } \\
(0.10 \text { level })\end{array}$ & 1959-2007 & Jerez et al. (2013) \\
\hline 10 & $\begin{array}{l}\text { Spain/ } \\
\text { Portugal }\end{array}$ & NAO & $\begin{array}{l}\text { Negative correlation } \\
(-\mathbf{0 . 5 5} / \mathbf{0 . 5 2} / 0.05 \text { level })\end{array}$ & $1961-2011$ & Azorin-Molina et al. (2014) \\
\hline \multirow[t]{2}{*}{11} & Turkey & Air temperature & $\begin{array}{l}\text { Negative correlation }(-0.15 / \\
\text { non.) }\end{array}$ & $1975-2006$ & $\begin{array}{l}\text { Dadaser-Celik and Cengiz } \\
\text { (2014) }\end{array}$ \\
\hline & Asia & & & & \\
\hline 12 & Eastern Asia & AAs & - $\mathbf{0 . 0 2} \mathrm{m} \mathrm{s}^{-1}(0.20$ level $)$ & 1975-2005 & Bichet et al. (2012) \\
\hline 13 & India & AAs & $-0.13 \mathrm{~m} \mathrm{~s}^{-1}$ (non.) & $1975-2005$ & Bichet et al. (2012) \\
\hline 14 & Taiwan & GHGs & $\begin{array}{l}\text { - } \mathbf{0 . 1 4} \mathrm{m} \mathrm{s}^{-1} \text { decade }^{-1}(0.05 \\
\text { level })\end{array}$ & $1871-2010$ & Zhang et al. (2016b) \\
\hline 15 & China & AAs & - $\mathbf{0 . 0 3} \mathrm{m} \mathrm{s}^{-1}(0.20$ level $)$ & 1975-2005 & Bichet et al. (2012) \\
\hline 16 & China & PDO & Negative correlation $(-/-)$ & 1960-2010 & Fu et al. (2011) \\
\hline 17 & China & ENSO & Negative correlation $(-/-)$ & 1971-2007 & Chen et al. (2013) \\
\hline 18 & China & EAMs & Positive correlation $(-/-)$ & $1969-2000$ & Xu et al. (2006b) \\
\hline 19 & China & PGF & Positive correlation (-/-) & 1960-2009 & Lin et al. (2013) \\
\hline 20 & China & PGF & Positive correlation $(-/-)$ & 1969-2005 & Guo et al. (2011) \\
\hline 21 & China & $\begin{array}{l}\text { Urbanization } \\
\text { (CRU method) }\end{array}$ & $\begin{array}{l}\text { Large city: } \mathbf{- 0 . 0 2} \mathrm{m} \mathrm{s}^{-1} \mathrm{a}^{-1} \\
\quad(0.01 \text { level }) \\
\text { Small city: }-\mathbf{0 . 0 1 8} \mathrm{m} \mathrm{s}^{-1} \mathrm{a}^{-1} \\
\quad(0.01 \text { level })\end{array}$ & $1969-2000$ & Xu et al. (2006b) \\
\hline 22 & China & $\begin{array}{l}\text { Urbanization } \\
\text { (CRU method) }\end{array}$ & $\begin{array}{l}\text { Large city: } \mathbf{- 0 . 0 1 2} \mathrm{m} \mathrm{s}^{-1} \mathrm{a}^{-1} \\
\quad(0.01 \text { level }) \\
\text { Small city: }-\mathbf{0 . 0 1 3} \mathrm{m} \mathrm{s}^{-1} \mathrm{a}^{-1} \\
\quad(0.01 \text { level })\end{array}$ & $1956-2004$ & Jiang et al. (2010) \\
\hline 23 & China & $\begin{array}{l}\text { Urbanization } \\
\text { (CRU method) }\end{array}$ & $\begin{array}{l}\text { Large city: } \mathbf{- 0 . 0 3} \mathrm{m} \mathrm{s}^{-1} \mathrm{a}^{-1} \\
\quad(0.01 \text { level }) \\
\text { Small city: } \mathbf{- 0 . 0 2 8} \mathrm{m} \mathrm{s}^{-1} \mathrm{a}^{-1} \\
\quad(0.01 \text { level })\end{array}$ & $1969-1990$ & Guo et al. (2011) \\
\hline 24 & China & LUCC & $\begin{array}{l}-\mathbf{0 . 1 2} \mathrm{m} \mathrm{s}^{-1} \text { decade }^{-1}(0.01 \\
\text { level) }\end{array}$ & 1979-2010 & Zha et al. (2017a) \\
\hline 25 & China (ECP) & LUCC & $\begin{array}{l}-\mathbf{0 . 1 7} \mathrm{m} \mathrm{s}^{-1} \text { decade }^{-1}(0.01 \\
\text { level })\end{array}$ & 1980-2011 & Wu et al. (2017) \\
\hline 26 & China (ECP) & LUCC & 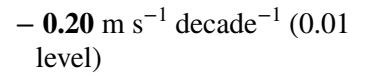 & $1980-2011$ & Wu et al. (2016) \\
\hline 27 & China (ECP) & LUCC & $\begin{array}{l}-\mathbf{0 . 1 0} \mathrm{m} \mathrm{s}^{-1} \mathrm{decade}^{-1}(0.01 \\
\text { level })\end{array}$ & $1980-2011$ & Wu et al. (2016) \\
\hline 28 & China (YRDR) & LUCC & Explain $50 \%$ of variability (-) & 2003-2007 & Zhang et al. (2010) \\
\hline 29 & China & Air temperature & $\begin{array}{l}\text { Negative correlation } \\
(\mathbf{- 0 . 7 0 / 0 . 0 0 1 ~ l e v e l )}\end{array}$ & 1969-2000 & Xu et al. (2006b) \\
\hline
\end{tabular}


Table 3 (continued)

\begin{tabular}{|c|c|c|c|c|c|}
\hline $\begin{array}{l}\text { Study } \\
\text { Number }\end{array}$ & Regions & Influence factor & Relationship & $\begin{array}{l}\text { Study } \\
\text { period }\end{array}$ & Original paper \\
\hline 30 & $\begin{array}{l}\text { China } \\
\text { (Southwest) }\end{array}$ & Air temperature & $\begin{array}{l}\text { Negative correlation } \\
(-\mathbf{0 . 4 0} / 0.05 \text { level })\end{array}$ & 1969-2009 & Yang et al. (2012) \\
\hline 31 & China (TP) & PGF & Positive correlation $(-l-)$ & 1980-2005 & You et al. (2010) \\
\hline 32 & Japan & Air temperature & $\begin{array}{l}\text { Negative correlation }(-0.13 / \\
\text { non.) }\end{array}$ & 1979-2008 & Fujibe $(2009,2011)$ \\
\hline 33 & $\begin{array}{l}\text { South Korea } \\
\text { North America }\end{array}$ & Air temperature & Negative correlation $(-/-)$ & 1954-2013 & Kim and Paik (2015) \\
\hline 34 & U.S & $\begin{array}{l}\text { Synoptic-scale } \\
\text { factor }\end{array}$ & Significant $(-/-)$ & 1961-1990 & Klink (1999a) \\
\hline 35 & Minnesota, America & PGF & $\begin{array}{l}\text { Explain } 22-47 \% \text { of variability } \\
(-)\end{array}$ & 1995-2003 & Klink (2007) \\
\hline 36 & Colorado, America & PGF & $\begin{array}{l}\text { Explain } \mathbf{4 0 \%} \text { of changes } \\
(0.01 \text { level })\end{array}$ & 1996-2001 & Clifton and Lundquist (2012) \\
\hline 37 & $\begin{array}{l}\text { California, America } \\
\text { Oceania }\end{array}$ & AAs & Explain $8 \%$ of slowdown (-) & 2002-2004 & Jacobson and Kaufman (2006) \\
\hline 38 & $\begin{array}{l}\text { Australia } \\
\text { Africa }\end{array}$ & AAs & $\mathbf{0 . 0 5} \mathbf{~ m ~ s}^{-1}$ (0.20 level) & $1975-2005$ & Bichet et al. (2012) \\
\hline 39 & Sub-Sahara & AAs & $-0.05 \mathrm{~m} \mathrm{~s}^{-1}$ (non.) & $1975-2005$ & Bichet et al. (2012) \\
\hline
\end{tabular}

column 3 denotes the main factors that induce the change in SWS, column 4 denotes the relationship between factors and changes in SWS. The values indicated in "bold" are statistically significant at different confidence levels (the confidence level is given in bracket). (-) denote the confidence level is not given in the original paper, non. denotes the correlation coefficient failure to pass the confidence level)

increased significantly from 1950 to 1970 then remained steady after 1970. Therefore, the SWS changes before 1970 may be significantly affected by the number of stations. Wan et al. (2010) discovered that the trends estimated from the raw SWS data from 117 stations in Canada from 1953 to 2006 were very different from the trends estimated from either the homogenized wind or Vg series, especially in the Arctic, Maritime, and western mountainous regions. Therefore, these authors emphasized that measurement biases can exert important effects on the results of trend analyses. The impacts of changes in anemometer height on SWS trends have also been reported by Thomas and Swail (2011).

\subsection{Extracting wind power to generate electricity}

Wind energy is a clean and renewable energy, and exploitation of this energy source is rapidly developing worldwide (Tobin et al. 2015). Large-scale use of wind power can alter local and global climate by extracting kinetic energy and altering turbulent transport in the atmospheric boundary layer (Keith et al. 2004). Therefore, some studies have shown SWS decreases associated with large- and regional-scale use of wind power (Keith et al. 2004; Wang and Prinn 2009; Miller et al. 2010). Wang and Prinn (2009) revealed that the installation of wind-powered generators over large areas of land or coastal ocean can increase the surface roughness, which can in turn cause a significant reduction in the SWS.

\section{Future study}

Many studies have examined the causes of decreases in terrestrial SWS, but some research deficiencies remain.

1. Almost no research has addressed wind speed changes at high altitudes relative to those at the surface, and the correlation between the SWS and high-altitude wind speeds should be analyzed using radiosonde data to determine the origin of changes in SWS. Some studies have noted the potential influences of the NAO, AO, ENSO, and EAM on decreases in the SWS over annual and decadal timescales, but changes in the driving force in the context of changes in these large-scale systems should be further explored. Many studies have generated only qualitative results related to the correlation between changes in SWS and these large-scale systems, and the sources of these changes in the driving force have not been clearly distinguished or quantified. The correlation between changes in the PGF and SWS has been addressed in some regions, but the global-scale influences of the PGF on terrestrial SWS should be probed in detail.

2. The effects of LUCC on the reduction of SWS have been qualitatively analyzed in most published studies, while quantitative evaluations of this issue are difficult due to the lack of regular LUCC observation data. Therefore, numerical simulations represent an important potential 
method to solve this problem, but as yet few numerical simulations have been used to do so. The effect of LUCC is mainly represented by a set of modified roughness data in the parameterization scheme of land surface models in place of the reasonable use of LUCC data to drive the land surface model, so simulations of actual scenes are lacking. In addition, the effects of LUCC should include a dynamical drag influence and a thermodynamic effect. The former mainly affects the surface roughness and drag coefficient, and the latter affects the surface albedo. The coefficient of thermal flux changes the stability, TKE, divergence, and thermodynamic circulation among different land use types. Both the dynamic and thermodynamic effects of LUCC can cause changes in the SWS, but existing research has yet to distinguish between these two mechanisms and their contributions to the observed decreases in SWS.

3. Urbanization has been the main type of LUCC during the rapid economic development in recent decades, but the effects of urbanization on SWS have been examined in previous studies through comparisons of urban and rural stations. Because of the rapid urbanization in some developing countries, such as China and India, rural stations that are paired with urban stations are hard to find, which could induce uncertainty into the evaluation results of the CRU method. Urbanization can alter many factors, and these changes have different effects on the SWS. For instance, increases in the surface roughness can decrease the SWS (Zhang et al. 2010; Guo et al. 2011); increases in building height and density can enhance the acceleration of wind in wind tunnels between buildings (Coceal and Belcher 2005); the emission of AAs and precursors can affect the SWS by altering convection patterns and the height of the boundary layer (Li et al. 2016); and increases in GHGs and AHR in cities can strengthen convection and momentum exchanges among different heights, thereby increasing the SWS (Zhang et al. 2016a). These mechanisms have not yet been properly distinguished, so their individual effects on the observed reductions in the SWS have not been thoroughly quantified, especially in East Asia and South Asia, where anthropogenic LUCC and AA and GHG emissions are significant.

4. Most previous studies have mainly focused on the terrestrial mean SWS, with few studies of extreme wind speeds. Most extreme wind studies have focused on Europe, North America, Oceania and, to a lesser degree, Asia. Additionally, there is much less confidence in generating a priori expectations about changes in extreme winds. For extreme winds associated with even smaller-scale phenomena, the level of understanding is essentially nascent from a climate change perspective. Furthermore, the dynamical mechanism and local features will affect the magnitude of extreme winds (Vose et al. 2014). In addition, previous studies have mainly detected historical changes in SWS, with few making future projections at global and regional scales. Horton et al. $(2012,2014)$ investigated the occurrence and persistence of future atmospheric stagnation events, and they noted that changes in near-surface wind occurrences varied globally, with the western United States and northern India exhibiting the largest increases and with northern and southern Africa, the eastern part of South America and Australia exhibiting decreases. Furthermore, a future projection of global-scale extreme wind speeds has been performed only in the study of Kumar et al. (2015) using CMIP5 datasets. Consequently, most previous studies have not made future projections regarding mean SWS and extreme wind speeds at regional scales. Additionally, while terrestrial SWS was observed to have generally decreased worldwide, increases in terrestrial SWS have also been found in some regions, such as China, South Korea, western United States and northern India (Guo et al. 2011; Kim and Paik 2015; Horton et al. 2012, 2014); however, no studies have yet addressed this recovery of terrestrial SWS or its possible causes.

Future research should focus on the following topics:

1. The influence of large-scale circulation should be more distinct at high altitudes than near the surface. Therefore, to address gaps in existing research, the temporal and spatial characteristics of wind speed at high and low altitudes and the correlations between these wind heights should be analyzed in detail. Changes in largescale circulation patterns due to changes in wind speed at different heights should also be quantitatively evaluated to determine the mechanisms that change the driving forces in atmospheric motion. Changes in the PGF at different heights and their relationships with changes in circulation patterns are key issues, and the effects of the PGF on terrestrial SWS changes should also be quantitatively evaluated. In addition, numerical simulations should be conducted with actual circumstances to simulate the influences of different circulation systems (such as NAO, AO, ENSO, and EAM etc.) on terrestrial SWS in different regions.

2. The surface of the Earth is the main source of the drag force on the atmosphere, and LUCC is a key factor that affects changes in many near-surface parameters. As such, the effects of LUCC on SWS should be analyzed in terms of the drag force. A statistical or dynamical downscaling method should be used to calibrate highresolution reanalysis data. Then, the OMR method can be employed to quantitatively evaluate the influences 
of LUCC on SWS. The spatial resolution of recent reanalysis data has increased, which will improve this evaluation. Dynamical models should shift from balance models to non-balance models: advection and local change in the dynamical equation should be included in a simple dynamical model to quantify the effects of different dynamical factors on SWS. In addition, a simulation should be conducted to identify the total effect, dynamic effect, and thermodynamic effect of LUCC, and it should be driven by an actual LUCC dataset. Obtaining ensemble results and comparing the results of different methods are important techniques for determining the most reasonable method and results.

3. The effects of urbanization on the terrestrial SWS are very complicated and differ significantly among different regions due to differences in urbanization and many other factors. More rural stations based on rigorous criteria should be established around central cities in order to use the CRU method to measure the quantitative effect of surface roughness associated with urbanization on SWS. In addition, some reliable models (including GCMs and RCMs) that involve complete physical processes should be used to simulate the effects of different factors (including AHR, GHG emissions and different AA emissions) to observe changes in SWS, especially in East Asia and South Asia. At the same time, an ensemble of results from many models would also be a valid approach to reduce uncertainty in the results.

4. Recent studies have indicated that the study of extreme wind speeds and their changes is necessary because extreme wind speeds and events may affect air quality in populated regions and are likely highly important in the planning of wind-farm operations and long-term estimation of extreme climate (Yan et al. 2002a, b; Pryor et al. 2012). In the near future, in-depth analyses of extreme wind speeds at global and regional scales are necessary. We need to improve observation of extreme winds to investigate the spatio-temporal characteristics and potential causes of changes in extreme wind speed. Reanalysis datasets can effectively capture large-scale signals but cannot identify some regional and local signals (Fan 2010; Fan et al. 2011, 2013; Huang et al. 2015). Accordingly, future work should focus on the application of the empirical downscaling technique for AOGCM simulations of the entire twenty-first century to provide a more complete description of decadal variability in downscaled wind speeds and more detailed comparisons of dynamically and empirically downscaled wind speeds (Pryor et al. 2005b). Additionally, innovations in high-resolution numerical modeling and the development of new reanalysis products with improved boundary layer parameterizations will also be necessary (Thorne and Vose 2010; Vose et al. 2014).
Furthermore, future work should also focus on the projection of mean SWS and extreme SWS at global and regional scales based on the latest generation GCMs, such as the CMIP5. Several key advancements in the CMIP5 suite of models have been made to better represent wind (Bracegirdle et al. 2013), and due to their higher reliability than the earlier generations of models, these should be used to study future changes in wind speed.

Acknowledgements The authors cordially thank the anonymous reviewers and the editor Dr. Lu Jian for their thorough comments and constructive suggestions, which significantly improved the quality of this paper. We also cordially thank Tim R. McVicar (CSIRO Land and Water, GPO Box 1666, Canberra, 2601 ACT, Australia) and Lei Zhang (Nanjing University of Information Science and Technology, Nanjing 210044, China), who provided some references for us. We also thank all the authors and publishers of the cited papers in this study. This study was sponsored by the Chinese Natural Science Foundation (41675149), the National Key Research and Development Program of China (2016YFA0600403), and the Yunnan Province Education Department Project (2017YJS106). In addition, this study was also supported by Program for Key Laboratory in University of Yunnan Province and the Chinese Jiangsu Collaborative Innovation Center for Climate Change.

Open Access This article is distributed under the terms of the Creative Commons Attribution 4.0 International License (http://creativecommons.org/licenses/by/4.0/), which permits unrestricted use, distribution, and reproduction in any medium, provided you give appropriate credit to the original author(s) and the source, provide a link to the Creative Commons license, and indicate if changes were made.

\section{References}

Abhishek A, Lee JY, Keener TC, Yang YJ (2010) Long-term wind speed variations for three mid-western U.S. cities. J Air Waste Manag Assoc 60(9):1057-1064. https://doi. org/10.3155/1047-3289.60.9.1057

Azorin-Molina C, Vicente-Serrano SM, McVicar TR, Jerez S, Sanchez-Lornzo A, Lopez-Moreno JI, Revuelto J, Trigo RM, Lopez-Bustins JA, Espirito-Santo F (2014) Homogenization and assessment of observed near-surface wind speed trends over Spain and Portugal, 1961-2011. J Clim 27:3692-3712

Azorin-Molina C, Guijarro JA, McVicar TR, Vicente-Serrano SM, Chen DL, Jerez S, Espirito-Santo F (2016) Trends of daily peak wind gusts in Spain and Portugal, 1961-2014. J Geophys Res Atmos. https://doi.org/10.1002/2015JD024485

Bandyopadhyay A, Bhadra A, Raghuwanshi NS, Singh R (2009) Temporal trends in estimates of reference evapotranspiration over India. J Hydrol Eng 14(5):508-515

Beniston M (2005) Mountain climates and climatic change: an overview of processes focusing on the European Alps. Pure Appl Geophys 162:1587-1606. https://doi.org/10.1007/ s00024-005-2684-9

Berrisford P, Tobin I, Dunn RJH, Vautard R, McVicar TR (2015) (Global climate; Atmospheric circulation; Surface winds) Land surface wind speed (in "State of the Climate in 2014"). Bull Am Meteorol Soc 95(7):S33-S34 
Bichet A, Wild M, Folini D, Schar C (2012) Causes for decadal variations of speed over land: sensitivity studies with a global climate model. Geophys Res Lett 39:L11701. https://doi. org/10.1029/2012GL051685

Bormann H (2011) Sensitivity analysis of 18 different potential evapotranspiration models to observed climatic change at German climate stations. Clim Change 104(3-4):729-753

Böwer C (2006) Die Entwicklung des Klimas in Münster/Westfalen. Diploma Thesis, Westfälischen Wilhelms-Universität Münster, Germany. http://kli.unimuenster.de/downloads/2006_boewer_ dipl.pdf. Accessed 4 Nov 2011 (in German)

Bracegirdle TJ, Shuckburgh E, Sallee JB, Wang ZM, Meijers AJS, Bruneau N, Phillips T, Wilcox LJ (2013) Assessment of surface winds over the Atlantic, Indian, and Pacific Ocean sectors of the Southern Ocean in CMIP5 models: historical bias, forcing response, and state dependence. J Geophys Res Atmos 118(118):547-562. https://doi.org/10.1002/jgrd.50153

Brazdil R, Chroma K, Dobrovolny P, Tolasz R (2009) Climate fluctuations in the Czech Republic during the period 1961-2005. Int J Climatol 29:223-242. https://doi.org/10.1002/joc.1718

Brouyaux F et al (2009) Chapitre 1. L'évolution du climat en Belgique (In French),Vigilance Climatique. Publié par l'Institut Royal Météorologique de Belgique, Bruxelles,pp. 6-24. http://www.meteo.be/meteo/view/fr/69130-Archives.html? view $=3236558 \& \mathrm{gt}$

Chen SB, Liu YF, Axel T (2006) Climatic change on the Tibetan Plateau: potential evapotranspiration trends from 1961 to 2000. Clim Change 76:191-319

Chen L, Li D, Pryor SC (2013) Wind speed trends over China: quantifying the magnitude and assessing causality. Int J Climatol 33:2579-2590. https://doi.org/10.1002/joc.3613

Choudhary RR, Jhajharia D, Lai M, Jain JK, Lunayach A et al (2009) Climate and its variations over Bikaner since 1951-2008. J Ind Geol Congr 1(2):79-86

Clifton A, Lundquist JK (2012) Data clustering reveals climate impacts on local wind phenomena. J Appl Meteorol Climatol 51:1547-1557

Coceal O, Belcher ES (2005) Mean winds through an inhomogeneous urban canopy. Bound Layer Meteorol 115:47-68

Cong ZT, Yang DW, Ni GH (2009) Does evaporation paradox exist in China? Hydrol Earth Syct Sci 13(3):357-366

Cusack S (2013) A 101 year record of windstorms in the Netherlands. Clim Change 116:693-704. https://doi.org/10.1007/ s10584-012-0527-0

Dadaser-Celik F, Cengiz E (2014) Wind speed trends over Turkey from 1975 to 2006. Int J Climatol 34:1913-1927. https://doi. org/10.1002/joc/3810

Dee DP, Uppala SM, Simmons AJ et al (2011) The ERA-Interim reanalysis: configuration and performance of the data assimilation system. Q J R Meteorol Sci 137(656):55-597

Degaetano AT (1998) Identification and Implications of Biases in U.S. Surface Wind Observation, Archival and Summarization Methods. Theor Appl Climatol 60:151-162

Ding YH, Wang Z, Sun Y (2008) Inter-decadal variation of the summer precipitation in east China and its association with decreasing Asian summer monsoon. Part I: observed evidences. Int J Climatol 28:139-161. https://doi.org/10.1002/ joc. 1615

Ding YH, Liu YJ, Liang SJ, Ma XQ, Zhang YX, Si D, Liang P, Song YF, Zhang J (2014) Interdecadal variability of the East Asian winter monsoon and its possible links to global climate change. J Meteor Res 28(5):693-713. https://doi.org/10.1007/ s13351-014-4046-y

Donohue RJ, McVicar TR, Roderick ML (2010) Assessing the ability of potential evaporation formulations to capture the dynamics evaporative demand within a changing climate. J Hydrol 386:186-197

Dunn RJH, Azorin-Molina C, Mears CA, Berrisford P, McVicar TR (2016) Surface winds (in "State of the climate in 2015"). Bull Am Meteorol Soc 97(8):S38-S40

Earl N, Dorling S, Hewston R, Von Glasow R (2013) 1980-2010 variability in U.K. surface wind climate. J Clim 26:1172-1191

EL-Osta W, Belhag M, Klat M, Fallah I, Kalifa Y (1995) Wind farm pilot project in Libya. Renew Energy 6(5-6):639-942

Enloe J, Brien JJO, Smith S (2004) ENSO impacts on peak wind gusts in the United States. J Clim 17:1728-1737

Fan LJ (2010) Preliminary study of statistically downscaled temperature ensemble predictions in Eastern China. Plateau Meteorol 29(2):392-402 (Chinese)

Fan LJ, Fu CB, Chen DL (2011) Long-term trend of temperature derived by statistical downscaling based on EOF analysis. Acta Meteorol Sinica 25(3):324-339. https://doi.org/10.1007/s13351011-0308-0 (Chinese)

Fan LJ, Chen DL, Fu CB, Yan ZW (2013) Statistical downscaling of summer temperature extremes in northern China. Adv Atmos Sci 30:1085-1095

Feng S, Hu Q, Qian WH (2004) Quality control of daily meteorological data in China, 1951-2000: a new dataset. Int J Climatol 24:853-870. https://doi.org/10.1002/joc. 1047

Frauenfeld OW, Zhang TJ, Serreze MC (2005) Climate change and variability using European Centre for Medium-Range Weather Forecasts reanalysis (ERA-40) temperatures on the Tibetan Plateau. J Geophys Res 110:D02101. https://doi. org/10.1029/2004JD005230

Fu GB, Yu JJ, Zhang YC, Hu SS, Quyang RL, Liu WB (2011) Temporal variation of wind speed in China for 1961-2007. Theor Appl Climatol 104:313-324

Fujibe F (2009) Relation between long-term temperature and wind speed trends at surface observation stations in Japan. SOLA 5:081-084. https://doi.org/10.2151/sola.2009-021

Fujibe F (2011) Review: urban warming in Japanese cities and its relation to climate change monitoring. Int J Climatol 31:162173. https://doi.org/10.1002/joc. 2142

Gadgil S (2007) The Indian monsoon: 3. Physics of the monsoon. Resonance 12:4-20

Garcia-Bustamante E, Gonzalez-Rouco JF, Navarro J, Xoplaki E, Jimenez PA, Montavez JP (2012) North Atlantic atmospheric circulation and surface wind in the Northeast of the Iberian Peninsula: uncertainty and long term downscaled variability. Clim Dyn 38:141-160. https://doi.org/10.1007/ s00382-010-0969-x

Gebreegziabher Y (2004) Assessment of the Water Balance of Lake Awassa Catchment, Ethiopia, ITC, Enschede, The Netherlands, p 92

Gerstengarbe FW, Werner PC, Hauf Y (2004) Bericht zum Werkvertrag Erstellung regionaler Klimaszenarien fur NordrheinWestfalen, Nr. 2-53710-2233, 29 pp. http://www.lanuv.nrw. de/klima/pdf/klimastudie_nrw.pdf. Accessed 4 Nov 2011 (in German)

Greene JS, Chatelain M, Morrissey M, Stadler S (2012) Estimated changes in wind Speed and wind power density over the western High Plains, 1971-2000. Theor Appl Climatol 109(3):507-518. https://doi.org/10.1007/s00704-012-0596-z

Gruza GV et al (2008) Assessment report on climate change and their impact on the territory of the Russian Federation (in Russian), Voeikov Main Geophysical Observatory,Roshydromet (MGO) and Institute of Global Climate and Ecology, Roshydromet and Russian Academy of Sciences (IGCE), Moscow, Russia, pp. 31-87. http://climate2008.igce.ru/v2008/v1/vI-3.pdf. Accessed 4 Nov 2011 (Chap. 3) 
Guo H, Xu M, Hu Q (2011) Changes in near-surface wind speed in China: 1969-2005. Int J Climatol 31:349-358. https://doi. org/10.1002/joc. 2091

He YP, Monahan AH, Jones CG, Dai A, Biner S, Caya D, Winger K (2010) Probability distributions of land surface wind speeds over North America. J Geophys Res Atmos 115:D04103. https://doi. org/10.1029/2008JD010708

Hewston R, Dorling SR (2011) An analysis of observed daily maximum wind gusts in the UK. J Wind Eng Ind Aerodyn 99:845-856

Himri Y, Himri S, Stambouli AB (2009) Assessing the wind energy potential projects in Algeria. Renew Sustain Energy Rev 13:2187-2191

Hobbins MT (2004) Regional evapotranspiration and pan evaporation: complementary interactions and long-term trends across the conterminous United States, Ph.D. thesis, Colo State Univ, Fort Collins

Hoffman MT, Cramer MD, Gillson L, Wallace M (2011) Erratum to: pan evaporation and wind run decline in the Cape Floristic Region of South Africa (1974-2005): implications for vegetation responses to climate change. Clim Change 109:453-454. https:// doi.org/10.1007/s10584-011-0113-x

Horton DE, Harshvardhan, and Diffenbaugh NS (2012) Response of air stagnation frequency to anthropogenically enhances radiative forcing. Environ Res Lett. https://doi. org/10.1088/1748-9326/7/4/044034

Horton DE, Skinner CB, Singh D, Diffenbaugh NS (2014) Occurrence and persistence of future atmospheric stagnation events. Nat Clim Change 4:698-703. https://doi.org/10.1038/nclimate2272

Hou AZ, Ni GH, Yang HB, Lei ZD (2013) Numerical analysis on the contribution of urbanization to wind stilling: an example over the greater Beijing metropolitan area. J Appl Meteorol Climatol 52:1105-1115

Huang HY, Capps SB, Huang SC, Hall A (2015) Downscaling nearsurface wind over complex terrain using a physically-based statistical modeling approach. Clim Dyn 44:529-542

Jacobson MZ, Kaufman YJ (2006) Wind reduction by aerosol particles. Geophys Res Lett 33:L24814. https://doi. org/10.1029/2006GL027838

Jerez S, Trigo RM, Vicente-Serrano SM, Pozo-Vazquez D, LorentePlazas R, Lorenzo-Lacruz J, Santos-Alamillos F, Montavez JP (2013) The impact of the North Atlantic Oscillation on the renewable energy resources in southwestern Europe. J Appl Meteorol Climatol 52:2204-2225. https://doi.org/10.1175/ JAMC-D-12-0257.1

Jhajharia D, Roy S, Ete G (2007) Climate and its variation: a case study of Agartala. J Soil Water Conserv 6(1):29-37

Jhajharia D, Shrivastava SK, Sarkar D, Sarkar S (2009) Temporal characteristics of pan evaporation trends under the humid conditions of northeast India. Agric Forest Meteorol 149(5):763-770

Jiang Y, Luo Y, Zhao ZC, Tao SW (2010) Changes in wind speed over China during 1956-2004. Theor Appl Climatol 99:421430. https://doi.org/10.1007/s00704-009-0152-7

Jiménez PA, González-Rouco JF, Navarro J, Montávez JP, GarcíaBustamante E (2010) Quality assurance of surface wind observations from automated weather stations. J Atmos Ocean Technol 27(7):1101-1122

Kalnay E, Cai M (2003) Impact of urbanization and land-use change on the climate. Nature 423:528-531

Kalnay E, Kanamitsu M, Kistler R, Collins W et al (1996) The NCEP/NCAR 40-year reanalysis project. Bull Am Meteorol Soc 77(3):437-472

Keevallik S, Soomere T (2009) Seasonal and diurnal variations of wind parameters at Pakri. Est J Eng 15(3):227-239

Keith DW, DeCarolis JF, Denkenberger DC, Lenschow DH, Malyshev SL, Pacala S, Rasch PJ (2004) The influence of large-scale wind power on global climate. Proc Natl Acad Sci USA 101:16115-16120. https://doi.org/10.1073/pnas.0406930101

Kim JC, Paik K (2015) Recent recovery of surface wind speed after decadal decrease: a focus on South Korea. Clim Dyn 45:16991712. https://doi.org/10.1007/s00382-015-2546-9

Klaic ZB, Nitis T, Kos I, Moussiopoulos N (2002) Modification of the local winds due to hypothetical urbanization of the Zagreb surroundings. Meteorol Atmos Phys 79(1):1-12

Klink K (1999a) Climatological mean and inter-annual variance of United States surface wind speed, direction and velocity. Int J Climatol 19:471-488

Klink K (1999b) Trends in mean monthly maximum and minimum surface wind speeds in the coterminous United States, 1961 to 1990. Clim Res 13:193-205

Klink K (2002) Trends and interannual variability of wind speeds distributions in Minnesota. J Clim 15:3311-3317

Klink K (2007) Atmospheric circulation effects on wind speed variability at turbine height. J Appl Meteorol 46(4):445-456. https://doi.org/10.1175/JAM2466.1

Klink K (2015) Seasonal patterns and trends of fastest 2-min winds at coastal stations in the conterminous USA. Int J Climatol 35:4167-4175

Knippertz P, Ulbrich U, Speth P (2000) Changing cyclones and surface wind speeds over the North-Atlantic and Europe in a transient GHG experiment. Clim Res 15:109-122

Kousari MR, Ahani H, Hakimelahi H (2013) An investigation of near-surface wind speed trends in arid and semiarid regions of Iran. Theor Appl Climatol 114:153-168. https://doi. org/10.1007/s00704-012-0811-y

Kruger AC, Goliger AM, Retief JV, Sekele S (2010) Strong wind climatic zones in South Africa. Wind Struct 13(1):37-55

Kumar D, Mishra V, Ganguly AR (2015) Evaluating wind extremes in CMIP5 climate models. Clim Dyn 45:441-453. https://doi. org/10.1007/s00382-014-2306-2

Li JP, Zeng QC (2002) A unified monsoon index. Geophys Res Lett 29(8):1274. https://doi.org/10.1029/2001GL013874

Li Y, Wang Y, Chu HY, Tang JP (2008) The climate influence of anthropogenic land-sue changes on near-surface wind energy potential in China. Chin Sci Bull 53(18):2859-2866. https://doi. org/10.1007/s11434-008-0360-Z

Li Z, Yan ZW, Tu K, Liu WD, Wang YC (2011) Changes in wind speed and extremes in Beijing during 1960-2008 based on homogenized observations. Adv Atmos Sci 28(2):408-420. https://doi. org/10.1007/s00376-010-0018-Z

Li ZQ, Lau WKM, Ramanathan V, Wu G et al (2016) Aerosol and monsoon climate interactions over Asia. Rev Geophys. https:// doi.org/10.1002/2015RG000500

Lin CG, Yang K, Qin J, Hu Y (2013) Observation coherent trends of surface and upper-Air wind speed over China since 1960. J Clim 26:2891-2903

Lin CG, Yang K, Huang JP, Tang WJ, Qin J, Niu XL, Chen YY, Chen DL, Lu N, Fu R (2015) Impacts of wind stilling on solar radiation variability in China. Sci Rep. https://doi.org/10.1038/srep15135

Liu Q, McVicar TR (2012) Assessing climate change induced modification of Penman potential evaporation and runoff sensitivity in a large water-limited basin. J Hydrol 464(465):352-362. https:// doi.org/10.1016/j.jhydrol.2012.07.032

Liu ML, Tian HQ (2010) China's land cover and land use change from 1700 o 2005: Estimations from high-resolution satellite data and historical archives. Global Biogeochem Cycle 24(3):285-286. https://doi.org/10.1029/2009GB003687

Liu S, Qiu J, Mo X (2009) Wind velocity variation from 1951 to 2006 in the north China Plain. Resour Sci 31(9):1486-1492 (in Chinese) 
Liu M, Shen YJ, Zeng Y, Liu CM (2010) Trend in pan evaporation and its attribution over the past 50 years in China. J Geogr Sci 20(4):557-568

Liu XM, Luo YZ, Zhang D, Zhang MH, Liu CM (2011a) Recent changes in pan-evaporation dynamics in China. Geophys Res Lett 38:L13404. https://doi.org/10.1029/2011GL047929

Liu XM, Zheng HX, Zhang MH, Liu CM (2011b) Identification of dominant climate factor for pan evaporation trend in the Tibetan Plateau. J Geogr Sci 21(4):594-608. https://doi.org/10.1007/ s11443-011-0866-1

Liu H, Shen Y, Liu K (2013) The financial services industry development level and spatial pattern of urban agglomeration in China. Acta Geogr Sin 38(2):186-198 (in Chinese)

Liu X, Zhang XJ, Tang Q, Zhang XZ (2014a) Effect of surface wind speed decline on modeled hydrological conditions in China. Hydrol Earth Syst Sci 18:2803-2813. https://doi.org/10.5194/ hess-18-2803-2014

Liu JY, Kuang WH, Zhang ZX et al (2014b) Spatiotemporal characteristics, patterns, and causes of land-use changes in China since the late 1980s. J Geog Sci 24(2):195-210. https://doi.org/10.1007/ s11442-014-1082-6

Lu X, McElroy MB, Kiviluoma J (2009) Global potential for windgenerated electricity. Proc Natl Acad Sci 106(27):10933-10938

Mahowald NM, Ballantine JA, Feddema J, Ramankutty N (2007) Global trends in visibility: implications for dust sources. Atmos Chem Phys 7(12):3309-3339

Mahowald NM, Engelstaedter S, Luo C et al (2009) Atmospheric iron deposition: global distribution, variability, and human perturbations. Ann Rev Mar Sci 1:245-278. https://doi.org/10.1146/ annurev.marine.010908.163727

Malloy JW, Krahenbuhl DS, Bush CE, Balling RC, Santoro MM, White JR, Elder RC, Pace MB, Cerveny RS (2015) A surface wind extremes ("Wind Lulls" and "Wind Blows") Climatology for Central North America and Adjoining Oceans (19792012). J Appl Meteorol Climatol 54:643-657

Mclnnes KL, Erwin TA, Bathols JM (2011) Global climate model projected changes in $10 \mathrm{~m}$ wind speed and direction due to anthropogenic climate change. Atmos Sci Lett 12:325-333. https://doi.org/10.1002/asl.341

McMahon TA, Peel MC, Lowe L et al (2013) Estimating actual, potential, reference crop and pan evaporation using standard meteorological data: a pragmatic synthesis. Hydrol Earth Syst Sci 17:1331-1363. https://doi.org/10.5194/ hessd-10-8781-2013

McVicar TR, Roderick ML (2010) Atmospheric science: winds of change. Nat Geosci 3(11):747-748

McVicar TR, Van Niel TG, Li LT, Hutchinson MF, Mu XM, Liu ZH (2007) Spatial distribution monthly reference evapotranspiration and pan evaporation considering topographic influences. J Hydrol 338:196-220

McVicar TR, Van Niel TG, Li LT, Roderick ML, Rayner DP, Ricciardulli L, Donohue R (2008) Wind speed climatology and trends for Australia, 1975-2006: capturing the stilling phenomenon and comparison with near-surface reanalysis output. Geophys Res Lett 35:L20403. https://doi.org/10.1029/2008GL035627

McVicar TR, Van Niel TG, Roderick ML, Li LT, Mo XG, Zimmermann NE, Schmatz DR (2010) Observational evidence from two mountainous regions that near-surface wind speed are declining more rapidly at higher elevations than lower elevations: 1960-2006. Geophys Res Lett 37:L06402. https://doi. org/10.1029/2009GL042255

McVicar TR, Roderick ML, Donohue RJ, Li LT, Van Niel TG, Thomas A, Grieser J, Jhajharia D, Himri Y, Mahowald NM, Mescherskaya AV, Kruger AC, Rehman S, Dinpashoh Y (2012a) Global review and synthesis of trends in observed terrestrial near-surface wind speeds: Implications for evaporation. J Hydrol 416(417):182-205. https://doi.org/10.1016/j.jhydrol.2011.10.024

McVicar TR, Roderick ML, Donohue RJ, Van Niel TGV (2012b) Less bluster ahead? Ecohydrological implications of global trends of terrestrial near-surface wind speeds. Ecohydrology 5:381-388. https://doi.org/10.1002/eco.1298

McVicar TR, Vautard R, Thepaut JN, Berrisford P, Dunn RJH (2013) (Global climate; atmospheric circulation; surface winds) land surface winds (in "State of the Climate in 2011"). Bull Am Meteorol Soc 94(8):S27-S29

Mescherskaya AV, Getman IF, Borisenko MM, Shevkunova EI (2004) Monitoring of wind-speed in the Volga River catchment and the Ural region in the twentieth century. Russ Meteorol Hydrol 3:83-97 (in Russian)

Mescherskaya AV, Eremin VV, Baranova AA, Maystrova VV (2006) Change in wind speed in northern Russia in the second half of the twentieth century, from surface and upper air data. Russ Meteorol Hydrol 9:46-58 (in Russian)

Miller LM, Gans F, Kleidon A (2010) Estimating maximum global land surface wind power extractability and associated climatic consequences. Earth Syst Dyn Discuss 1:169-189. https://doi. org/10.5194/esdd-1-169-2010

Minola L, Azorin-Molina C, Chen DL (2016) Homogenization and assessment of observed near-surface wind speed trends across Sweden, 1956-2013. J Clim 29(20):7397-7415. https://doi. org/10.1175/JCLI-D-15-0636.1

Mohamed AA, Elmakrouk AM (2009) Assessment of the wind energy potential on the coast of Tripoli, pp 10. http://www.ontario-sea. org/Storage/27/1865_Assessment_of_the_wind_Energy_Potential_on_the_Coast_of_Tripoli.pdf.. Accessed 4 Nov 2011

Munir S, Habeebullah TM, Seroji AR, Morsy EA, Mohammed AMF, Saud WA, Abdou AEA, Awad AH (2013) Modeling particulate matter concentrations in Makkah, applying a statistical modeling approach. Aerosol Air Qual Res 13:901-910

Najac J, Boe J, Terray L (2009) A multi-model ensemble approach for assessment of climate change impact on surface winds in France. Clim Dyn 32:615-634. https://doi.org/10.1007/ s00382-008-0440-4

Najac J, Lac C, Terray L (2011) Impact of climate change on surface winds in France using a statistical-dynamical downscaling method with meso-scale modelling. Int J Climatol 31:415-430. https://doi.org/10.1002/joc.2075

Nfah EM, Ngundam JM (2008) Modelling of wind/diesel/ battery hybrid power systems for far-north Cameroon. Energ Conv Manag 49(6):1295-1301

Niyogi D, Pyle P, Lei M, Arya SP, Kishtawal CM, Shepherd M, Chen F, Wolfe B (2011) Urban modification of thunderstorms: an observational storm climatology and model case study for the indianapolis urban region. J Appl Meteorol Climatol 50(5):1129_ 1144. https://doi.org/10.1175/2010JAMC1836.1

Oguntunde PG, Abiodun BJ, Olukunle OJ, Olufayo AA (2012) Trends and variability in pan evaporation and other climatic variables at Ibadan, Nigeria, 1973-2008. Meteorol Appl 19:464-472. https:// doi.org/10.1002/met.281

Onat B, Stakeeva B (2013) Personal exposure of commuters in public transport to PM2.5 and fine particle counts. Atmos Pollut Res 4(3):329-335

Palaiologou P, Kalabokidis K, Haralambopoulos D, Feidas H, Polatidis $\mathrm{H}$ (2011) Wind characteristics and mapping for power production in the Island of Lesvos, Greece. Comput Geosci 37(7):962-972

Peng Z, Sun JN (2014) Characteristics of the drag coefficient in the roughness sublayer over a complex urban surface. Bound Layer Meteorol 153:569-580. https://doi.org/10.1007/ s10546-014-9949-8

Peterson TC, Vautard R, McVicar TR, Thepaut JN, Berrisford P (2011) Surface winds over land. Bull Am Meteorol Soc 92(6):S57 
Pirazzoli PA, Tomasin A (1999) Recent abatement of easterly winds in the northern Adriatic. Int J Climatol 19(11):1205-1219

Pirazzoli PA, Tomasin A (2003) Recent near-surface wind changes in the central Mediterranean and Adriatic areas. Int J Climatol 23:963-973. https://doi.org/10.1002/joc.925

Pryor SC, Barthelmie RJ (2010) Climate change impacts on wind energy: A review. Renew Sustain Energy Rev 14:430-437. https://doi.org/10.1016/j.rser.2009.07.028

Pryor SC, Barthelmie RJ (2011) Assessing climate change impacts on the near-term stability of the wind energy resource over the United States. Proc Natl Acad Sci USA 108(20):8167-8171

Pryor SC, Ledolter J (2010) Addendum to "Wind speed trends over the contiguous United States". J Geophys Res Atmos 115(D10):1159-1171. https://doi.org/10.1029/2009JD013281

Pryor SC, Schoof JT (2010) Importance of the SRES in projections of climate change impacts on near-surface wind regimes. Meteorol Z 19(3):267-274

Pryor SC, Barthelmie RJ, Kjellstrom E (2005a) Potential climate change impact on wind energy resources in northern Europe: analyses using a regional climate model. Clim Dyn 25:815-835. https://doi.org/10.1007/s00382-005-0072-x

Pryor SC, Schoof JT, Barthelmie RJ (2005b) Climate change impacts on wind speeds and wind energy density in Northern Europe: empirical downscaling of multiple AOGCMs. Clim Res 29:183-198

Pryor SC, Schoof JT, Barthelmie RJ (2006) Winds of change?: Projections of near-surface winds under climate change scenarios. Geophys Res Lett 33:L11702. https://doi. org/10.1029/2006GL026000

Pryor SC, Barthelmie RJ, Riley ES (2007) Historical evolution of wind climates in the USA. J Phys. https://doi. org/10.1088/1742-6596/75/1/102065

Pryor SC, Barthelmie RJ, Young DT, Takle ES, Arritt RW, Flory D, Gutowski WJ, Nunes A, Roads J (2009) Wind speed trends over the contiguous United States. J Geophys Res Atmos 114(D14):1159-1171. https://doi.org/10.1029/2008JD011416

Pryor SC, Barthelmie RJ, Clausen NE, Drews M, MacKellar N, Kjellstrom E (2012) Analyses of possible changes in intense and extreme wind speeds over northern Europe under climate change scenarios. Clim Dyn 38(1):189-208

Räisänen J, Hansson U, Ullerstig A, Doscher R, Graham LP, Jones C, Meier HEM, Samuelsson P, Willen U (2004) European climate in the late twenty-first century: regional simulations with two driving global models and two forcing scenarios. Clim Dyn 22(1):13-31. https://doi.org/10.1007/s00382-003-0365-x

Ramanathan VC, Chung C, Kim D, Bettge T, Buja L, Kiehl JT, Washington WM, Fu Q, Sikka DR, Wild M (2005) Atmospheric brown clouds: Impacts on South Asian climate and hydrological cycle. Proc Natl Acad Sci 102(15):5326-5333. https://doi.org/10.1073/pnas.0500656102

Rasmussen DJ, Holloway T, Nemet GF (2011) Opportunities and challenges in assessing climate change impacts on wind energy - a critical comparison of wind speed projections in California. Environ Res Lett 6(2):1-9. https://doi. org/10.1088/1748-9326/6/2/024008

Rayner DP (2007) Wind run changes: the dominant factor affecting pan evaporation trends in Australia. J Clim 20:3379-3394. https://doi.org/10.1175/JCLI4181.1

Reba ML, Marks D, Seyfried M, Winstral A, Kumar M, Flerchinger $\mathrm{G}$ (2011) A long-term data set for hydrologic modeling in a snow-dominated mountain catchment. Water Resour Res 47(7):218-223. https://doi.org/10.1029/2010WR010030

Roderick ML, Rotstayn LD, Farquhar GD, Hobbins MT (2007) On the attribution of changing pan evaporation. Geophys Res Lett 34(34):251-270. https://doi.org/10.1029/2007GL031166
Shen YJ, Liu CM, Liu M, Zeng Y, Tian CY (2010) Change in pan evaporation over the past 50 years in the arid region of China. Hydrol Process 24(2):225-231

Simmons AJ, Willett KM, Jones PD et al (2010) Low-frequency variations in surface atmospheric humility, temperature and precipitation: inferences from reanalysis and monthly gridded observational datasets. J Geophys Res Atmos 115:1-21. https:// doi.org/10.1029/2009JD012442

Simmons AJ, Poli P, Dee DP, Berrisford P, Hersbach H, Kobayashi S, Peubey C (2014) Estimating low-frequency variability and trends in atmospheric temperature using ERA-Interim. Q J R Meteorol Soc 140:329-353. https://doi.org/10.1002/qj.2317

Soler-Bientz R, Watson S, Infield D (2010) Wind characteristics on the Yucatán Peninsula based on short term data from meteorological stations. Energy Conversat Manag 51(4):754-764

Song ZW, Zhang HL, Snyder RL, Anderson FE, Chen F (2010) Distribution and trends in reference evapotranspiration in the North China Plain. J Irrig Drain Eng 136(4):240-247

Sterk HAM, Steeneveld GJ, Vihma T, Anderson PS, Bosveld FC, Holtslag AAM (2015) Clear-sky stable boundary layers with low winds over snow-covered surface. Part 1: WRF model evaluation. Q J R Meteorol Soc 14:2165-2184. https://doi. org/10.1002/qj.2513

Sušelj K, Sood A, Heinemann D (2010) North Sea near-surface climate and its relation to the large-scale circulation pattern. Theor Appl Climatol 99:403-419. https://doi.org/10.1007/ s00704-009-0149-2

Tang B, Tong L, Kang SZ, Zhang L (2011) Impacts of climate variability on reference evapotranspiration over 58 years in the Haihe river basin of north China. Agric Water Manag 98:1660-1670. https://doi.org/10.1016/j.agwat.2011.06.006

Tchinda R, Kaptouom E (2003) Wind energy in Adamaoua and North Cameroon provinces. Energy Conversat Manag 44:845-857

Tchinda R, Kendjio J, Kaptouom E, Njomo D (2000) Estimation of mean wind energy available in far north Cameroon. Energy Conversat Manag 41:1917-1929

Thomas BR, Swail VR (2011) Buoy wind inhomogeneities related to averaging method and anemometer type: application to long time series. Int J Climatol 31:1040-1055. https://doi. org/10.1002/joc.2339

Thorne PW, Vose RS (2010) Reanalyses suitable for characterizing long-term trends: are they really achievable? Bull Am Meteorol Soc 91:353-361

Tobin I, Berrisford P, Dunn RJH, Vautard R, McVicar TR (2014) (Global climate; atmospheric circulation; surface winds) land surface wind speed (in "State of the Climate in 2013"). Bull Am Meteorol Soc 95(7):S28-S29

Tobin I, Vautard R, Balog I, Breon FM, Jerez S, Ruti PM, Thais F, Vrac M, Yiou P (2015) Assessing climate change impacts on European wind energy from ENSEMBLES high-resolution climate projections. Clim Change 128:99-112. https://doi. org/10.1007/s10584-014-1291-0

Tobin I, Jerez S, Vautard R, Thais F, Meijgaard EV, Prein A, Deque M, Kotlarski S, Maule CF, Nikulin G, Noel T, Teichmann C (2016) Climate change impacts on the power generation potential of a European mid-century wind farms scenario. Environ Res Lett 11(3):034013. https://doi. org/10.1008/1748-9326/11/3/034013

Trenberth KE, Jones PD, Ambenje P, Bojariu R, Easterling D et al (2007) Observations: surface and atmospheric climate change. Climate change 2007: The physical science basis, contribution of working group $i$ to the fourth assessment report of the intergovernmental panel on climate change, Cambridge University Press: Cambridge, United Kingdom and New York, 237-336 
Troccoli A, Muller K (2012) Long-term wind speed trends over Australia. J Clim 25:170-183. https://doi.org/10.1175/2011 JCL14198.1

Tuller SE (2004) Measured wind speed trends on the west coast of Canada. Int J Climatol 24:1359-1374. https://doi.org/10.1002/ joc. 1073

Usbeck T, Wohlgemuth T, Pfister C, Volz R, Beniston M, Dobbertin M (2010a) Wind speed measurements and forest damage in Canton Zurich (Central Europe) from 1891 to winter 2007. Int J Climatol 30:347-358. https://doi.org/10.1002/joc.1895

Usbeck T, Wohlgemuth T, Dobbertin M, Pfister C, Burgi A, Rebetez M (2010b) Increasing storm damage to forests in Switzerland from 1858 to 2007. Agric For Meteorol 150:47-55. https://doi. org/10.1016/j.agrformet.2009.08.010

Vautard R, Cattiaux JL, Yiou P, Thepaut JN, Ciais P (2010) Northern Hemisphere atmospheric stilling partly attributed to an increase in surface roughness. Nat Geosci 3(11):756-761. https://doi. org/10.1038/NGEO979

Vautard R, McVicar TR, Thepaut JN, Roderic ML (2012) (Global climate; atmospheric circulation; surface winds) land surface winds and atmospheric evaporative demand (in "State of the Climate in 2011”). Bull Am Meteorol Soc 93(7):S6-S38

Verma IJ, Jadhav VN, Erande RS (2008) Recent variations and trends in potential evapotranspiration (PET) over India. Mausam 59(1):119-128

Vose RS, Applequist S, Bourassa MA et al (2014) Monitoring and understanding changes in extremes. Bull Am Meteorol Soc 95(3):377-386

Walter A, Keuler K, Jacob D, Knoche R, Block A et al (2006) A high resolution reference data set of German wind velocity 1951-2001 and comparison with regional climate model results. Meteorol Z 15(6):585-596

Wan H, Wang XL, Swail VR (2010) Homogenization and Trend Analysis of Canadian Near-surface Wind Speeds. J Clim 23(5):1209-1225

Wang L (2014) An intensity index for the East Asian winter monsoon. J Clim 27:2361-2374. https://doi.org/10.1175/JCI-D-13-00086.1

Wang L, Chen W (2014) The East Asian winter monsoon: re-amplification in the mid-2000s. Chin Sci Bull 59:430-436. https://doi. org/10.1007/s11434-013-0029-0

Wang C, Prinn RG (2009) Potential climatic impacts and reliability of very large-sacle wind farms. Atmos Chem Phys 9(5):2053-2061

Wang XM, Liao JB, Zhang J, Shen C, Chen WH, Xia BC (2013) A numeric study of regional climate change induced by urban expansion in the Pearl River Delta, China. J Appl Meteorol Climatol 53:346-362. https://doi.org/10.1175/JAMC-D-13-054.1

Wever N (2012) Quantifying trends in surface roughness and the effect on surface wind speed observations. J Geophys Res Atmos 117(D11):1-12. https://doi.org/10.1029/2011JD017118

Wu J, Guo J, Zhao DM (2013) Characteristics of aerosol transport and distribution in East Asia. Atmos Res 132(133):185-198

Wu J, Zha JL, Zhao DM (2016) Estimating the impact of the changes in land use and cover on the surface wind speed over the East China Plain during the period 1980-2011. Clim Dyn 46:847863. https://doi.org/10.1007/s00382-015-2616-z

Wu J, Zha JL, Zhao DM (2017) Evaluating the effects of land use and cover change on the decrease of surface wind speed over China in recent 30 years using a statistical downscaling method. Clim Dyn 48(1):131-149. https://doi.org/10.1007/s00382-016-3065-z

Xu CY, Gong LB, Tong J, Chen DL (2006a) Decreasing reference evapotranspiration in a warming climate-a case of Changjiang (Yangtze) River catchment during 1970-2000. Adv Atmos Sci 23(4):513-520. https://doi.org/10.1007/s00376-006-0513-4

Xu M, Chang CP, Fu CB, Qi Y, Robock A, Robinson D, Zhang HM (2006b) Steady decline of East Asian monsoon winds, 1969-2000: evidence from direct ground measurements of wind speed. J Geophys Res Atmos 111:D24111. https://doi. org/10.1029/2006JD007337

Yan Z, Bate S, Chandler RE, Isham V, Wheater H (2002) An analysis of daily maximum wind speed in Northwestern Europe using generalized linear models. J Clim 15(15):2073-2088. https://doi. org/10.1175/1520-0442(2002)015<2073:AAODMW>2.0.CO:2

Yan Z, Bate S, Chandler RE, Isham V, Wheater H (2006) Changes in extreme wind speeds in NW Europe simulated by generalized linear models. Theor Appl Climatol 83:121-137. https://doi. org/10.1007/s00704-005-0156-x

Yang K, Ye BS, Zhou DG, Wu BY, Foken T, Qin J, Zhou ZY (2011) Response of hydrological cycle to recent climate changes in the Tibetan Plateau. Clim Change 109:517-534. https://doi. org/10.1007/s10584-011-0099-4

Yang XM, Li ZX, Feng Q, He YQ, An WL, Zhang W, Cao WH, Yu TF, Wang YM, Theakstone WH (2012) The decreasing wind speed in southwestern China during 1969-2009, and possible causes. Quatern Int 263:1-84

Yin Y, Wu S, Chen G, Dai E (2010a) Attribution analyses of potential evapotranspiration changes in China since the 1960s. Theor Appl Climatol 101(1-2):19-28

Yin YH, Wu SH, Dai EF (2010b) Determining factors in potential evapotranspiration changes over China in the period 1971-2008. China Sci Bullet 55(29):3329-3337

You QL, Kang SC, Flugel WA, Pepin N, Yan YP, Huang J (2010) Decreasing wind speed and weakening latitudinal surface pressure gradients in the Tibetan Plateau. Clim Res 42:57-64. https:// doi.org/10.3354/cr00864

Zha JL, Wu J, Zhao DM (2016) Changes of probabilities in different wind grades induced by land use and cover change in Eastern China Plain during 1980-2011. Atmos Sci Lett 17:264-269. https://doi.org/10.1002/asl.653

Zha JL, Wu J, Zhao DM (2017a) Effects of land use and cover change on the near-surface wind speed over China in the last 30 years. Prog Phys Geogr. https://doi.org/10.1177/0309133316663097

Zha JL, Wu J, Zhao DM, Yang QD (2017b) Changes of the probabilities in different ranges of near-surface wind speed in China during the period for 1970-2011. J Wind Eng Ind Aerodyn 169:156-167. https://doi.org/10.1016/j.jweia.2017.07.019

Zhang L, Li T (2016) Relative roles of anthropogenic aerosols and greenhouse gases in land and oceanic monsoon changes during past 156 years in CMIP5 Models. Geophys Res Lett 43:52955301. https://doi.org/10.1002/2016GL069282

Zhang YQ, Liu CM, Tang YH, Yang YH (2007) Trends in pan evaporation and reference and actual evapotranspiration across the Tibetan Plateau. J Geophys Res Atmos 112:D12110. https://doi. org/10.1029/2006JD008161

Zhang N, Gao ZQ, Wang XM, Chen Y (2010) Modeling the impact of urbanization on the local and regional climate in Yangtze River Delta, China. Theor Appl Climatol 102:331-342. https://doi. org/10.1007/s00704-010-0263-1

Zhang N, Wang XM, Chen Y, Dai W, Wang XY (2016a) Numerical simulations on influence of urban land cover expansion and anthropogenic heat release on urban meteorological environment in Pearl River Delta. Theor Appl Climatol 126:469-479. https:// doi.org/10.1007/s00704-015-1601-0

Zhang L, Li T, Lu MM (2016b) Trends of surface wind energy near Taiwan in winter since 1871. Terr Atmos Ocean Sci. https://doi. org/10.3319/TAO.2016.04.29.01(A)

Zheng H, Liu X, Liu C, Dai X, Zhu R (2009) Assessing contribution to pan evaporation trends in Haihe River Basin, China. J Geophys Res Atmos 114:D24105. https://doi.org/10.1029/2009JD012203

Zhou LM, Dickinson RE, Tian YH, Fang JY, Li QX, Kaufmann RK, Tucker CJ, Myneni RB (2004) Evidence for a significant urbanization effect on climate in China. Proc Natl Acad Sci 101(26):9540-9544 
Zhu J, Liang XZ (2013) Impacts of the Bermuda high on regional climate and ozone over the United States. J Clim 26:1018-1032. https://doi.org/10.1175/JCLI-D-12-00168.1

Zhu J, Liao H, Li J (2012) Increases in aerosol concentrations over eastern China due to the decadal-scale weakening of the East Asian summer monsoon. Geophys Res Lett 39(9):L09809. https://doi. org/10.1029/2012GL051428 